\title{
ASSOCIAÇÃO ENTRE BRUXISMO DO SONO E DISFUNÇÃO TEMPOROMANDIBULAR
}

\section{LEYLHA MARIA OLIVEIRA NUNES}

Tese apresentada à Faculdade de Odontologia de Bauru, da Universidade de São Paulo, como parte dos requisitos para obtenção do título de Mestre em Odontologia, na Área de Reabilitação Oral.

(Edição Revisada) 


\section{ASSOCIAÇÃO ENTRE BRUXISMO DO SONO E DISFUNÇÃO TEMPOROMANDIBULAR}

\section{LEYLHA MARIA OLIVEIRA NUNES}

Tese apresentada à Faculdade de Odontologia de Bauru, da Universidade de São Paulo, como parte dos requisitos para obtenção do título de Mestre em Odontologia, na Área de Reabilitação Oral.

(Edição Revisada)

Orientador: Prof. Dr. Carlos dos Reis Pereira de Araujo 


\begin{tabular}{|c|c|}
\hline \multirow{7}{*}{ N922a } & NUNES, LEYLHA MARIA OLIVEIRA \\
\hline & $\begin{array}{l}\text { Associação entre bruxismo do sono e disfunção } \\
\text { temporomandibuar / Leylha Maria Oliveira Nunes. - Bauru, } \\
\text { 2003. }\end{array}$ \\
\hline & 192p. : il. ; 30cm \\
\hline & Dissertação (Mestrado) - Faculdade de Odontologia de \\
\hline & Bauru. USP \\
\hline & Orientador: Prof. Dr. Carlos dos Reis Pereira de Araujo \\
\hline & Co-orientador: Prof. Dr. Paulo César Rodrigues Conti \\
\hline
\end{tabular}

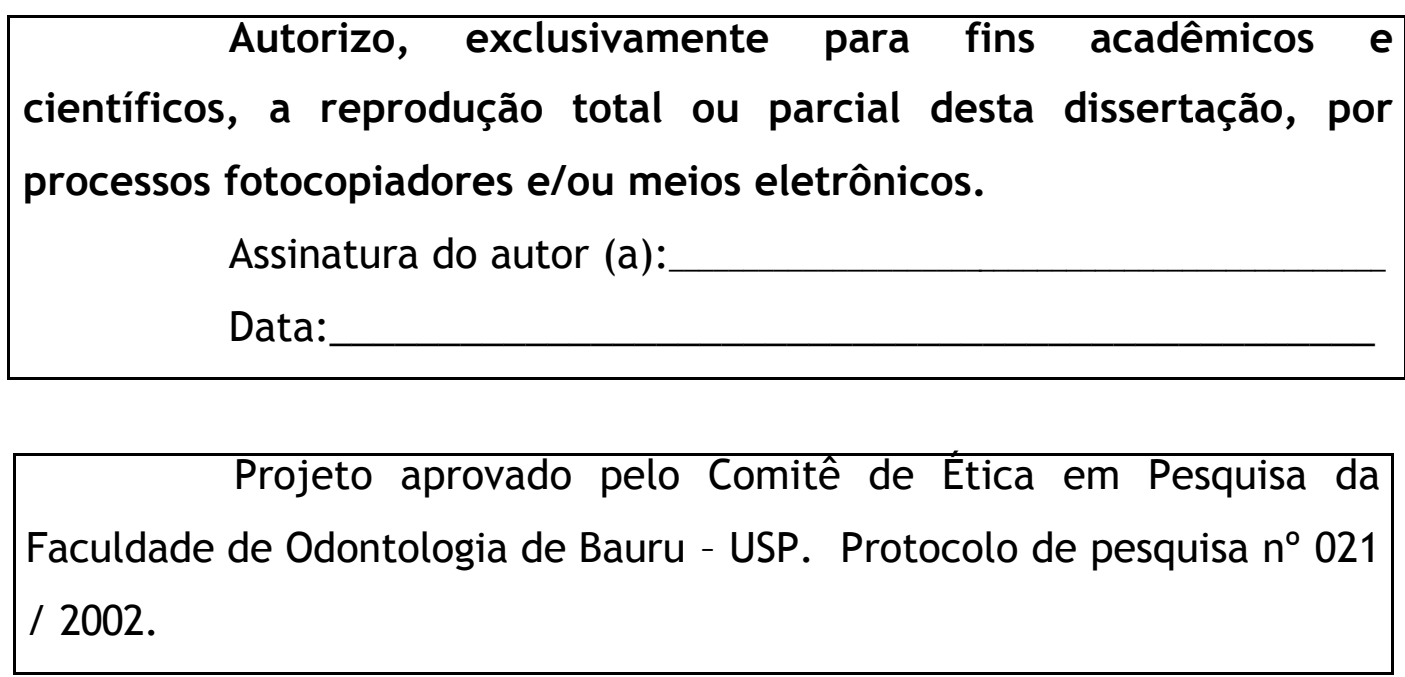




\section{LEYLHA MARIA OLIVEIRA NUNES}

05 DE MAIO DE 1974 - Nascimento - TIANGUÁ - CE

Filiação: $\quad$ FRANCISCA LÚCIA DE OLIVEIRA

LUIZ NUNES NETO

1992-1995

Curso de Graduação em Odontologia na Universidade Federal do Ceará - UFC.

$1996-1998$

Professora Substituta de Prótese Parcial II do curso de Odontologia da Universidade Federal do Ceará - UFC

$1996-1996$

Curso de Atualização em Diagnóstico e Tratamento de Problemas Oclusais da Universidade Federal do Ceará UFC.

1996-1996

Curso de Aperfeiçoamento em Endodontia da Universidade Federal do Ceará - UFC.

1998-1998

Curso de Atualização em Odontologia Cosmética da Escola de Aperfeiçoamento Profissional - (EAP- ABO-CE) Associação Brasileira de Odontologia - ABO-CE.

$1999-2000$

Curso de Especialização em Prótese Dental da Escola de Aperfeiçoamento Profissional (EAP - ABO-CE).

2000-2000 Curso de Aperfeiçoamento em Implantes Osseointegrados da Escola de Aperfeiçoamento Profissional (EAP - ABO-CE)

\section{ASSOCIAÇÕES DE CLASSE E SOCIEDADES CIENTÍFICAS}

Associação Brasileira de Odontologia - ABO - Secção Ceará 
A Deus,

Por guiar meus passos, por jamais ter me deixado só, por iluminar meu caminho e por provar, a cada dia, das mais variadas formas, que Seu amor é infinito, e que, portanto, vale a pena sonhar... ...Vale a pena acreditar.

"O Senhor é minha força e meu escudo; Nele o meu coração confia, Dele recebo auxílio."

S1 28:7"

\begin{abstract}
A minha mais que amada Mãe, Lúcia
Cujo exemplo de garra e fortaleza deram-me, em momentos de extrema dificuldade, razão e forças para continuar. Mesmo tão distante, Mãe, teu amor me acalma e acalenta, teu bravo coração ensina-me também a ter coragem.
\end{abstract}

A meus amados irmãos Carlos e Leydiane Por estarem ao meu lado, em alma e coração, alegrandome, cooperando e acompanhando meus passos. Por manterem firme a certeza de que algo mais forte do que laços de sangue nos une.

A meu pai, Luiz Por sua torcida.

A meu amor, Paulo

Por estar guardado junto ao teu, meu coração se aquieta e se fortalece. Em tua doce e indispensável presença, encontro a felicidade.

"You are my tomorrow, There's safety in your arms, Where you go, I'll follow, Cause you're the world where I belong."

Steve Morales, Kara DioGuardi, David Siegel, Shep Soloman. 


\section{AGRADECIMENTOS ESPECIAIS}

Ao Prof. Dr. Antônio Materson da Silva,

a você, devo muito mais do que conhecimentos...

Seu profissionalismo, competência e carisma o tornam um professor

marcante e inovador.

Mais que professor, você tornou-se amigo e, como poucos, o sabe ser. Esteja certo de que guardarei, sempre comigo, meu respeito, admiração e, principalmente, minha mais profunda e sincera amizade. Pelo apoio, pela confiança, pela preocupação... serei eternamente grata.

Ao Prof. Dr. Marco Aurélio Rabelo Lima Verde, a você devo a descoberta do amor a esta profissão.

Alicerçado em seu exemplo de determinação e competência, cresceu meu desejo de desenvolvimento e a certeza de que, com trabalho, persistência e fé, realizamos os nossos sonhos. 
Ao Prof. Dr. Talapala Gowindaswamy Naidu, meu querido e eterno professor... meu primeiro orientador... Desde a primeira aula, como sempre o fez, demonstrou o significado da palavra ensinar. Exemplo de sabedoria aliada à simplicidade; de grandeza humana aliada ao desejo de que seus alunos aprendam. Sempre de portas abertas a nossa curiosidade, sua influência em muito transcendeu a disciplina, pois é exemplo de profissionalismo, ética e companheirismo. Para mim, é e sempre será uma grande honra ser sua aluna e amiga.

\section{Meus três mestres e grandes amigos, vocês são, em grande parte responsáveis pelo meu caminho, direcionamento e amor à ciência, ao ensino e à Odontologia.}


Professor Dr. Carlos dos Reis Pereira de Araujo que, por sua singular habilidade em inspirar a busca pelo desafio, por sua paciência, estímulo e principalmente, confiança, permitiu que eu caminhasse sem medo na elaboração e execução deste projeto. Agradeço por estar ao meu lado, por apoiar-me e encorajar-me em momentos precisos e fundamentais Levarei sempre comigo, meu respeito, minha admiração e minha gratidão.

Ao Professor Dr. Paulo César Rodrigues Conti, por cujo apoio, incentivo, orientação próxima e segura, serei eternamente grata. Seu profissionalismo e seriedade associados à sensibilidade e percepção o tornam um verdadeiro exemplo de Mestre e Professor.

"O mestre que caminha à sombra do templo entre seus discípulos, não dá de sua sabedoria, mas de sua fé e de seu amor. Ele na verdade não vos convida a entrar na mansão de seu saber, mas vos conduz aos limites de sua própria mente." Gibran Kalil Gibran 


\title{
AGRADECIMENTOS
}

Ao CNPq, pela bolsa consedida, por meio da qual foi possível minha permanência e a conclusão deste tão almejado curso.

\begin{abstract}
À Professora Dra. Fidela de Lima Navarro, diretora da FOB-USP, por nos ter fornecido os meios de execução deste projeto. Sua contribuição foi, simplesmente, indispensável.
\end{abstract}

Ao Pró-Reitor de Pesquisa Dr. Luíz de Oliveira Nunes, por haver confiado neste projeto e nos proporcionado o financiamento para realizá-lo

Ao Dr. Alberto Luiz Moura dos Santos, em primeiro lugar por haver nos aberto as portas, alavancando nossa idéia inicial. Em segundo, por sua fundamental participação e espírito de cooperação em momentos críticos. 
Ao Professor Dr. Luiz Fernando Pegoraro, por sua experiência, apoio e preocupação em ajudar-me, por meio de suas sensatas sugestões, a concluir, em tempo hábil este projeto.

Ao Professor Dr. Francisco Guedes Pereira Alencar Junior, por ter aceito o convite para participar da banca examinadora durante a defesa desta dissertação e por sua agradabilíssima presença. Por sua maneira plácida e tranquilizadora de questionar, ao mesmo tempo em que enriqueceu este trabalho.

Ao Professor Lauris, pela orientação durante a análise estatística deste trabalho.

Ao Professor Dr. José Carlos Pereira, por haver disponibilizado a Clínica de Pós Graduação em horários extras, possibilitando o cumprimento do prazo da execução deste trabalho 
À Professora Dra. Lucimar Falavinha Vieira, a quem tanto tenho a agradecer. Por seu doce e plácido apoio, dentro e fora da Universidade. Por seu exemplo de compreensão e carinho, os quais refletem o quão humana é.

Ao Prof. Dr. Alceu Trindade, do Departamento de Fisiologia da FOBUSP, que tão bem me recebeu e abdicou de seu escasso tempo para contribuir com este trabalho. Nos poucos instantes de conversa, logo percebi seu entusiasmo e amor ao ensino e à ciência. Ao senhor, o meu muitíssimo obrigada.

A todos os outros professores do Departamento de Prótese: Prof. Dr. Accácio Lins do Valle, Prof. Dr. Gerson Bonfante, Prof. Dr. José Henrique Rubo, Prof. Dr. José Valdes Conti; Prof. Dr. Paulo Martins Ferreira, Prof. Dr. Renato de Freitas, Prof. Dr. Milton Carlos Gonçalves Salvador; Prof. Dr. Vinícius Carvalho Porto; Prof. Dr. Wellington Cardoso Bonachela. 
Ao corpo de funcionários do Instituto do Sono Dr. Alberto Luiz Moura dos Santos - Adriana, Andréa, Ana Paula, Camila, Meire e Rosângela por seu eficiente trabalho, paciência, gentileza e disponibilidade em contribuir da melhor maneira possível. Sem o seu empenho e zelo, não teria sido possível a execução deste estudo.

\begin{abstract}
À Daniela, Edson, Mariluce e Nice, cuja gentileza e colaboração no Instituto de Ensino Odontológico - IEO, em muito facilitaram a difícil fase da seleção dos pacientes da pesquisa.
\end{abstract}

À Leuci e à Célia, do setor de triagem da FOB-USP, por nos ter auxiliado durante a fase de seleção dos pacientes.

Ao corpo de funcionários da biblioteca.

Vocês são o exemplo vivo de que é possível unir eficiência, organização e, ao mesmo tempo, deixar, em cada canto, em cada membro, o calor humano, a simpatia, a amistosidade, o carinho e a dedicação. É essa riqueza de qualidades que tornam a biblioteca um dos lugares mais agradáveis desta Universidade. A cada um de vocês, meus parabéns e meu muito obrigada. 
À Cláudia, Débora, Edna e Valquíria, por seu bom humor, acolhedora simpatia e prestatividade.

À Dona Ana, Dona Cleusa e Débora, cuja disponibilidade e cooperação, na Clínica de Pós Graduação, possibilitaram, em diversos momentos, o bom andamento dos trabalhos.

À Ivânia e Edilane, por sua companhia, ajuda e, principalmente, alegria, nas tardes de quarta-feita da Clínica Integrada. 
A cada voluntário, Aparecida Donizete, Cíntia Magali, Edna Zaupa, Érika Kanagusuko, Érika Renata, Felipe Lucareli, Fernanda Lourenção, Isaac Góes, José Gustavo, Leila Haruco, Mauro Aparecido, Regina Célia, Renato Veridiani, Regina Condi, Robert, Rodrigo Andreis, Rogério Padula e Tatiana Camargo, sem cuja disponibilidade seria impossível a realização deste trabalho.

Ao Sr. Paulo Roberto Longui, paciente do Instituto do Sono que gentilmente permitiu a realização de algumas fotografias, no decorrer da elaboração deste trabalho.

A cada colega e amigo que, voluntariamente participou da pesquisa, Ana Paula, Anuar Xible, Carlos Neanes. Celso Tinoco, Dioracy Vicioso, Evelyn Mikaela Kogawa, Helena Menezes, Linda Wang, Jéferson Ricardo, Lívia, Lucas Cavalcante, Luiz Gustavo, Paulo Rossetti, Renato Oliveira, Renata Freitas, Stefânia Kano, Thania Rodriguez e Yamile. 
A todos os colegas do mestrado, Jefferson Ricardo, Luciana Grês, Luiz Gustavo, Mariana Carvalho, Mauro Batista, Oswaldo Kaiser, Paulo Rossetti, Rafael Santos, Renato Oliveira, Stella Noronha e Tatiany Mendonça, os quais ajudaram de tantas formas, pela cooperação na execução do trabalho, pelo apoio e pela amizade.

Aos amigos do doutorado, Anuar Xible, Carlos Neanes, Juliano Scolaro, Nelsinho, Rudys de Jesus e Stefânia Kano, William Barnabé, que ajudaram com amizade, acolhida, cooperação e disponibilidade durante todo o curso.

Aos amigos, Álica Carolina, Natália Henostroza, Laurence, Celiane, pela disponibilidade em ajudar e pela amizade. 
Aos amigos de Fortaleza, Cid, Ricardo Lira e Roberta Dalcico, que a tanto tempo não vejo, mas que, nem por isso, deixaram de emprestar o ombro, de segurar a barra...Vocês provam a força e a verdade de nossa amizade A minha amiga incondicional Thania, que dividiu e viu de perto todos os momentos. Que me ajudou, de forma decisiva, em diversos deles, tanto incentivando-me quanto encontrando soluções. Sua presença e amizade serão eternamente de inestimável valor.

A minha amiga de todas as horas, Renatinha, que me "salvou" de tantos apuros... Meu muitíssimo obrigada.

A minha primeira amiga em Bauru, Mariana Mandim, por ter sido sempre... amiga. Por sua autenticidade, por sua verdade...

Ao amigo Mauro Batista, por ter se mostrado surpreendentemente e verdadeiramente amigo. Com você divido minha alegria e minha paz de espírito.

O amigo ama em todos os momentos; é um irmão na adversidade." 


\section{AGRADECIMENTO ESPECIAL}

Ao Sr. Rossetti, Dona Alice e Fernando, por enriquecerem minha vida com carinho e atenção. Por se preocuparem com meu bem-estar...

...por amenizarem em mim a saudade, proporcionando-me, tantas vezes, a sensação de que não estou tão longe de casa assim. 


\section{SUMÁRIO}

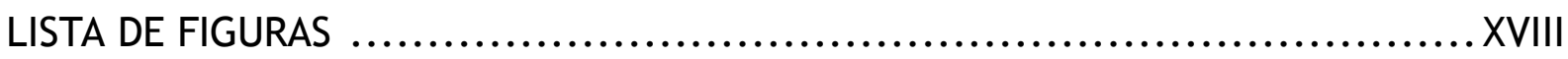

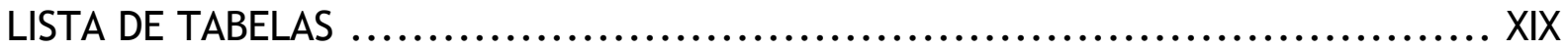

LISTA DE ABREVIATURAS E SÍMBOLOS ..................................... XXI

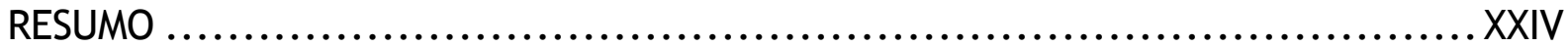

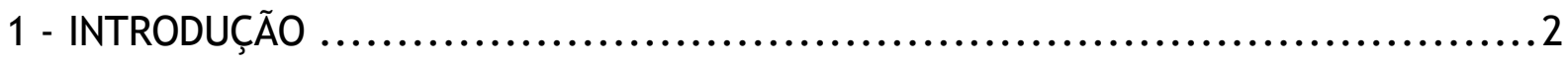

2 - REVISTA DA LITERATURA......................................................

2.1. Bruxismo do Sono ...............................................

2.2. Disfunção Temporomandibular ..................................... 27

2.3. Integração Sensorial-Motora na Dor Muscular e Articular ................ 35

2.3.1. Teorias sobre atividade muscular como fator etiológico da DTM.... 35

2.3.2. Atividade Muscular e Alteração Somato-Motora .................... 37

2.3.3. Dor e Alterações Motoras ........................................ 51

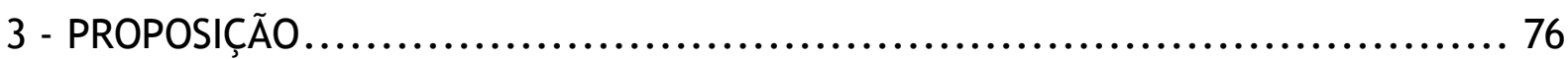

4 - MATERIAL E MÉTODOS................................................... 78

4.1. Estabelecimento dos grupos..................................... 78

4.2. Critérios de inclusão e exclusão ................................... 79

4.3. Aplicação dos questionários e realização dos exames clínico e radiográfico

4.4. Polissonografia .................................................... 87

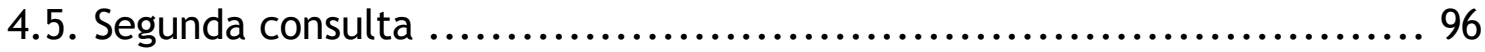

4.6. Análise dos dados............................................... 96

4.7. Análise estatística ................................................. 99

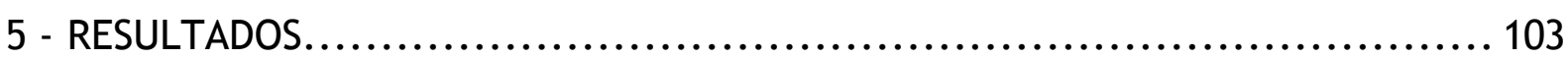

5.1.Do quadro clínico de DTM ...................................... 103

5.2.Do diagnóstico de bruxismo ....................................... 104

5.2.1 Diagnóstico polissonográfico de bruxismo ...................... 107

5.3.Variáveis oro-motoras e DTM ..................................... 116

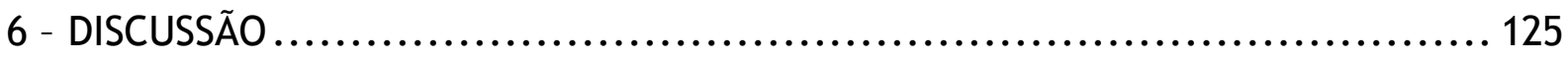


6.1. Diagnóstico de Bruxismo ....................................... 125

6.2. Prevalência de bruxismo nos grupos e sua associação com $\mathrm{dtm}$......... 132

6.3. Sobre a inter-relação atividade muscular e dor ....................... 140

6.4. Relação de causa e efeito bruxismo e DTM ........................... 153

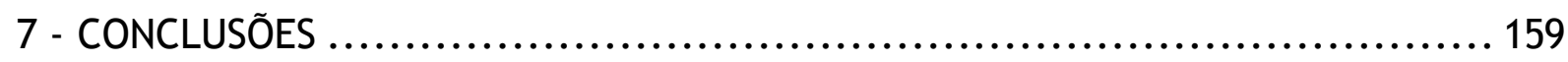

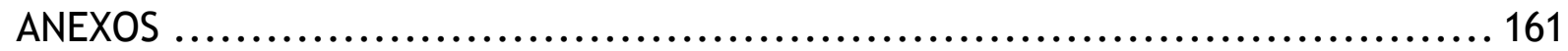

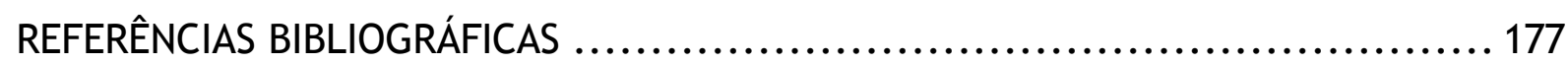

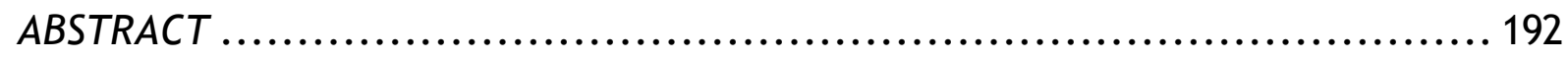




\section{LISTA DE FIGURAS}

FIGURA 1 Representação de como o registro é realizado durante o sono.............. 87

FIGURA 2 Pletismografia de esforço respiratório torácico e abdominal.

FIGURA 3 Microfone próximo à cavidade oral para captar sons de ranger de dentes (A); eletrodo do EOG (B); eletrodo da EMG do músculo mentoniano (C). 89

FIGURA 4 Fotografia representando o posicionamento dos eletrodos para o EEG. 90

FIGURA 5 Posicionamento do fio terra (A); EOG (B e C); microfone (D); EMG do músculo mentoniano $(E)$; registro de fluxo aéreo oral nasal $(F)$ e eletromiografia do músculo masseter $(\mathrm{G})$. 91

FIGURA 6 Posicionamento dos eletrodos para EMG dos músculos tibiais anteriores. 92

FIGURA 7 Exemplo da visualização dos canais de entrada no monitor. Na entrada queixo, a CVM com o indivíduo em vigília.

FIGURA 8 Câmera de vídeo para registro visual do sono e aparelho de TV para distração do paciente. 94

FIGURA 9 Computador e conversos analógico/digital por onde é realizado parte do monitoramento e a leitura dos dados polissonográficos 95

FIGURA 10 Exemplos de episódios de bruxismo fásico $(A)$, tônico $(B)$ e misto $(C)$, registrado de um músculo masseter direito. Modificado de LAVIGNE; ROMPRÉ; MONTPLAISIR[LAVIGNE, 1996 \#24] 1996).

FIGURA 11 Distribuição dos indivíduos com bruxismo clínico e PSG nas populações com DTM e com dor à palpação. 109

FIGURA 12 Distribuição dos indivíduos com bruxismo clínico e polissonográfico nas populações sem DTM e sem dor à palpação. 


\section{LISTA DE TABELAS}

TABELA 1 Tabela de associação 2x2 entre bruxismo clínico e DTM, com valores percentuais sobre a linha (DTM e controle). 105

TABELA 2 Tabela de associação 2x2 entre bruxismo clínico e dor à palpação, com valores percentuais sobre a linha (COM e SEM dor à palpação) 106

TABELA 3 Tabela de associação $2 \times 2$ entre bruxismo-PSG e DTM, com valores percentuais sobre a linha (DTM e controle) 108

TABELA 4 Tabela de associação 2x2 entre bruxismo-PSG e dor à palpação, com valores percentuais sobre a linha (COM e SEM dor à palpação) 108

TABELA 5 Médias e desvio padrão das variáveis oromotoras de corte para o diagnóstico de bruxismo dos grupos com e sem bruxismo, segundo o critério polissonográfico.

TABELA 6 Médias e desvio padrão das variáveis oromotoras e sua distribuição com relação aos estágios do sono dos grupos com e sem bruxismo definido pelo critério polissonográfico.

TABELA 7 Variáveis convencionais do sono de indivíduos diagnosticados com e sem bruxismo, segundo o critério polissonográfico.

TABELA 8 Médias e desvio padrão das variáveis motoras de corte para o diagnóstico de bruxismo dos grupos com e sem bruxismo diagnosticado clinicamente.

TABELA 9 Diagnóstico clínico de bruxismo positivo (reforçado pelo acompanhamento de bruxismo) discrepante do diagnóstico polissonográfico. 115

TABELA 10 Médias com desvio padrão das variáveis de sono, seguidas dos valores de p, após realização do teste Mann-Whitney para comparação dos grupos. 116 
TABELA 11 Médias com desvio padrão das variáveis oromotoras, seguidas dos valores de $p$, após realização do teste Mann-Whitney para comparação dos grupos com e sem DTM

TABELA 12 Médias com desvio padrão das variáveis oromotoras, seguidas dos valores de $\mathrm{P}$, após realização do teste Mann-Whitney para comparação dos grupos com e sem dor na EAV, na manhã seguinte ao exame polissonográfico.

TABELA 13 Médias com desvio padrão das variáveis oromotoras, seguidas dos valores de $P$, após realização do teste Mann-Whitney para comparação dos grupos com e sem dor à palpação, na manhã seguinte ao exame polissonográfico.

TABELA 14 Valores das médias e desvio padrão das variáveis oromotoras de corte de 7 indivíduos com dor matinal à palpação e de 4 indivíduos sem dor matinal à palpação.

TABELA 15 Índice de correlação de Spearman entre as variáveis oromotoras de corte e o índice de DTM na amostra total.

TABELA 16 Índice de correlação de Spearman entre as variáveis oromotoras de corte e o índice de DTM dos indivíduos com DTM 122

TABELA 17 Correlação de Spearman entre as variáveis oromotoras de corte e o índice de DTM dos indivíduos com DTM e bruxismo-PSG. 123

TABELA 18 Índice de correlação de Spearman entre as variáveis oromotoras de corte e a intensidade da dor medida por meio da EAV da amostra total. 


\section{LISTA DE ABREVIATURAS E SÍMBOLOS}

\begin{tabular}{|c|c|}
\hline$\%$ & Porcentagem \\
\hline$\alpha:$ & Alfa \\
\hline$\gamma:$ & Gama \\
\hline$\mu \mathrm{g}:$ & Micrograma \\
\hline$\mu \mathrm{V}:$ & Microvolt \\
\hline$\mu \mathrm{V} / \mathrm{cm}:$ & Microvolt por centímetro \\
\hline$\Omega:$ & Ohm \\
\hline AADO: & Academia americana de dor orofacial \\
\hline AADS: & Associação americana de desordens do sono \\
\hline A/D: & Analógico/digital \\
\hline ARMM: & Atividade rítmica dos músculos mastigatórios. \\
\hline B/hora: & Burst de bruxismo por hora de sono \\
\hline Bruxismo-PSG: & $\begin{array}{l}\text { Bruxismo diagnosticado pelo critério } \\
\text { polissonográfico }\end{array}$ \\
\hline BS: & Bruxismo do sono \\
\hline Burst /segundo: & Burst por segundo \\
\hline $\mathrm{Cm} / \mathrm{s}:$ & Centímetro por segundo \\
\hline CVM: & Contração voluntária máxima \\
\hline $\mathrm{dB}:$ & Decibel \\
\hline DTM: & $\begin{array}{l}\text { Disfunção temporomandibular ou disfunções } \\
\text { temporomandibulares }\end{array}$ \\
\hline Epi/hora: & Episódios de bruxismo por hora de sono \\
\hline Epi/noite: & Episódios de bruxismo por noite \\
\hline GC: & Grupo controle \\
\hline GE: & Grupo experimental \\
\hline $\mathrm{Hz}:$ & Hertz \\
\hline EAV: & Escala de análise visual \\
\hline ECG: & Eletrocardiograma \\
\hline
\end{tabular}




$\begin{array}{ll}\text { EEG: } & \text { Eletroencefalograma } \\ \text { EMG: } & \text { Eletromiograma } \\ \text { FOVM: } & \text { Força oclusal voluntária máxima } \\ \text { h } & \text { Hora } \\ \text { Kgf: } & \text { Quilogramaforça } \\ \text { LDP: } & \text { Limiar de dor por estímulos de pressão } \\ \text { ml: } & \text { Mililitro } \\ \text { min: } & \text { Minuto } \\ \text { mm: } & \text { Milímetro } \\ \text { ms: } & \text { Milisegundo } \\ \text { MPE: } & \text { Mialgia pós-exercício } \\ \text { Nm: } & \text { Newton metro } \\ \text { NREM: } & \text { Não REM } \\ \text { PMB: } & \text { Placas de medição de bruxismo } \\ \text { PSG: } & \text { Polissonografia } \\ \text { QDM: } & \text { Questionário de dor de McGill } \\ \text { RMS: } & \text { Síndrome da apnéia obstrutiva do sono } \\ \text { Sothean square: (retificação e integração do } & \text { Sinal eletromiográfico) } \\ \text { SAOS: } & \text { Segundo } \\ \text { SNC: } & \text { Segundos por hora }\end{array}$


RESUMO 


\section{RESUMO}

A fim de ampliar o entendimento sobre a relação estabelecida - entre bruxismo do sono (BS) e Disfunção Temporomandibular (DTM) e de verificar a confiabilidade do diagnóstico clínico de BS, 14 pacientes com DTM e 12 indivíduos sem DTM (correspondentes em sexo e idade) foram avaliados quanto à presença de BS, por meio de diagnóstico clínico (executado por três examinadores) e de avaliação polissonográfica (PSG) de uma noite. Foi realizada avaliação clínica de DTM (anamnese e exame físico, o qual constou de avaliação da dor por EAV, avaliação objetiva de DTM - índice de DTM, palpação articular e dos músculos mastigatórios e cervicais) antes e na manhã seguinte ao exame PSG. O objetivo do estudo foi verificar a presença de associação entre BS e DTM, discutindo alguns aspectos quanto ao estabelecimento de relação de causa-e-efeito, e também a confiabilidade do exame clínico, com relação à PSG. Não foi verificada associação entre BS e DTM, nem entre BS e dor à palpação articular ou muscular e o exame clínico apresentou sensibilidade de $75 \%$ e especificidade de $57 \%$. Todos os pacientes, independente da presença de atividade de bruxismo na noite anterior, apresentaram sintomatologia dolorosa na manhã seguinte à PSG. Alguns indivíduos do grupo controle, diagnosticados clinicamente como bruxômanos, apresentaram leve sintomatologia à palpação dos músculos mastigatórios e/ou cervicais, apesar de, na noite do exame PSG não terem apresentado atividade de bruxismo. Concluise que o fato de alguns indivíduos com bruxismo não apresentarem qualquer 
sintomatologia e o de outros com sintomatologia de DTM, e até piora no quadro clínico, não apresentarem BS reforça a ausência de associação entre essas entidades. 
INTRODUÇÃO 


\section{1 - INTRODUÇÃO}

O bruxismo foi definido em 1996, pela Academia Americana de Dor Orofacial ${ }^{1}$ como uma atividade parafuncional diurna ou noturna, incluindo apertamento ou ranger dos dentes. Já a Associação Americana de Desordens do Sono $(A A D S)^{82}$, em 1997, diferenciou a categoria bruxismo do sono, como uma entidade independente e o definiu como uma parassônia (desordem do sono que não se trata de uma anormalidade nos processos de sono e vigília per se, mas sim, um fenômeno físico indesejável que ocorre paralelo ao sono) caracterizada por movimentos estereotipados e periódicos do sistema mastigatório que envolve apertamento ou ranger de dentes durante o sono, excluindo, portanto, atividades parafuncionais diurnas (em vigília).

Em geral, acredita-se que o bruxismo do sono esteja envolvido na etiologia da dor nos músculos mastigatórios. Durante o diagnóstico e tratamento de diversos distúrbios funcionais do sistema mastigatório ${ }^{5}$, o bruxismo tem sido apontado como um fator contribuinte e até mesmo etiológico; levando, muitas vezes, ao direcionamento das diversas medidas terapêuticas desses distúrbios no sentido da "eliminação" do hábito em si ou de suas conseqüências"57. Entretanto, ainda persiste a controvérsia sobre a relação existente entre bruxismo e outros distúrbios do sistema mastigatório. 
Disfunção temporomandibular (DTM) é um termo genérico empregado a um conjunto de problemas músculo-esqueletais do sistema mastigatório ${ }^{1}$. Muito embora a etiologia precisa da DTM ainda não seja conhecida, LOBBEZZO e LAVIGNE45, 1997 sustentam a hipótese de uma etiologia multifatorial, substanciada pela ação conjunta de fatores estruturais (oclusão, anatomia das articulações temporomandibulares e esqueleto); psicológicos e funcionais (neuromuscular). LASKIN ${ }^{39}$, em 1969, propôs uma teoria psicofisiológica para a etiologia das DTM, baseada no trabalho de SCHWARTZ70, 1959, onde este sugere que espasmos musculares são o principal fator para a ocorrência dos sinais e sintomas de DTM. Como se acreditava que a fadiga muscular, devido ao apertamento e ranger de dentes, fosse a principal causa de mioespasmos, LASKIN 39 hipotetizou então uma condição auto-perpetuante onde um padrão anormal de atividade muscular reforçaria o mioespasmo original e a dor, gerando um ciclo vicioso entre um problema funcional (bruxismo) e uma doença orgânica (DTM). Entretanto, de acordo com MENSE52, em 1991, não há nenhuma prova experimental de que esse ciclo vicioso de eventos realmente exista.

Vários estudos foram desenvolvidos nas últimas décadas com a finalidade de esclarecer a relação existente entre bruxismo do sono (BS) e DTM. Esses estudos encontram-se divididos em duas correntes principais, a primeira, que acredita no papel etiológico da hiperatividade muscular no desencadeamento de dor e disfunção temporomandibular e na geração do ciclo vicioso entre esta e aquela $13,39,57,58,68,70,83,86,89$ e a segunda, que, na busca por evidências 
científicas, não encontra suporte para o pensamento da primeira corrente $3-5,18,19$, $30,36,48,51,53,76-81$.

Um fator limitante ao esclarecimento dessa questão refere-se à subjetividade inerente ao diagnóstico clínico do bruxismo do sono ${ }^{45}$. Por serem conhecidas as limitações referentes ao diagnóstico por meio do auto-relato 44 ou da avaliação do desgaste dentário ${ }^{71}$, a partir da década de 70 passaram-se a utilizar unidades de registro eletromiográfico para a medição da atividade do músculo masséter durante o sono69. Em 1988, RUGH; HARLAN68 desenvolveram um sistema de escore para a contagem dos eventos eletromiográficos dos músculos mastigatórios no intuito de diferenciar a atividade muscular noturna, como, sonilóquio, deglutição e outras contrações musculares, da atividade de bruxismo. Esse passou a ser o critério mais comumente utilizado nesse tipo de estudo e baseia-se na contagem de bursts eletromiográficos, ou seja, elevações ou surtos de atividade muscular que, se ocorrem próximos, em seqüência rápida e em número igual ou maior que três, compõem um episódio fásico de bruxismo e, se ocorrem isolados e com duração de 2,0 segundos ou mais, caracterizam um episódio tônico de bruxismo.

A utilização do registro eletromiográfico para o diagnóstico de bruxismo tornou-se um método ainda mais objetivo quando aliado ao registro polissonográfico 42 , onde se dispõe da possibilidade de caracterizar a atividade de bruxismo segundo as fases do sono e outras funções motoras e autonômicas, além do recurso audio-visual, por meio do qual se eliminam, de forma precisa, quaisquer 
atividades eletromiográficas decorrentes de outras atividades orofaciais que não o bruxismo $^{84}$

Em face da ausência de evidência científica acerca da relação estabelecida entre bruxismo do sono e os sinais e sintomas de disfunção temporomandibular, o presente estudo avaliou a associação entre estes e aquele, incluindo em seu modelo o estudo da prevalência de bruxismo do sono em uma amostra de indivíduos com e sem DTM, ou seja, o bruxismo do sono apareceria em ambos os grupos da amostra de maneira aleatória e, a fim de minimizar a subjetividade ou a tendência do diagnóstico de bruxismo, utilizou-se o registro polissonográfico com essa finalidade e a leitura dos eventos eletromiográficos realizada de maneira cega. 
REVISTA DA LITERATURA 


\section{2 - REVISTA DA LITERATURA}

\subsection{Bruxismo do Sono}

Até o início da década de 50 do século $X X$, quando surgiram os laboratórios de estudo do sono, a atividade de bruxismo ainda não havia sido medida. Nos anos 70 do mesmo século, utilizaram-se as unidades portáteis de registro eletromiográfico desenvolvidas por RUGH; SOLBERG69, em 1975, para registrar a atividade do músculo masséter na própria residência do paciente. Esse dispositivo fornecia o registro elétrico acumulado durante a noite na faixa de $20 \mu \mathrm{V}$ e trouxe novos e importantes dados sobre os níveis de atividade do músculo masséter. A maioria dos estudos que utilizou a unidade eletromiográfica portátil considerou a faixa de $20 \mu \mathrm{V}$ como aquela a partir da qual o paciente apresentaria bruxismo, não registrando índices de contração inferiores, presumindo-se que as mesmas não comporiam um quadro de bruxismo. A maior desvantagem desse método é que níveis de bruxismo segundo a segundo não eram mensurados e não havia a possibilidade de traçar a correlação entre a atividade motora e os estágios do sono.

GLAROS25 realizou, em 1981, um estudo da prevalência de bruxismo noturno e diurno em uma população de 1052 estudantes (544 homens e 508 mulheres) com 19 anos de idade, em média. Por meio de questionário, o autor registrou os relatos de apertamento ou ranger de dentes e sua ocorrência diurna 
e/ou noturna. Verificou-se a prevalência de bruxismo exclusivamente diurno, como atividade presente $(13,4 \%)$ ou passada $(12,0 \%)$; bruxismo exclusivamente noturno, como atividade presente $(3,3 \%)$ ou passada $(6,6 \%)$ e atividade de bruxismo noturno e diurno presente $(4,5 \%)$ ou passada $(4,8 \%)$.

WAGNER ${ }^{85}$, em 1981, desenvolveu um sistema de registro eletromiográfico portátil, que incluía um amplificador eletromiográfico, um filtro e um integrador. Diferente da unidade portátil de medição cumulativa de RUGH; SOLBERG69, o bruxismo foi definido como uma atividade superior a $5 \mathrm{~V}$ (média integral). 0 autor também determinou que deveria haver no mínimo 3 segundos de silêncio no registro eletromiográfico para separar os episódios de bruxismo.

Em 1982, PICCIONE et al.61 definiram os eventos de bruxismo usando critérios de amplitude, ritmo e duração da atividade eletromiográfica, no músculo masseter, a partir de registros poligráficos. Eles propuseram que os eventos de bruxismo estariam presentes apenas se a amplitude eletromiográfica excedesse $20 \mu \mathrm{V}$ e se a atividade eletromiográfica permanecesse nesse nível por, no mínimo, 0,5 segundo e, no máximo, 1,5 segundo. Era também requerido que os eventos de bruxismo ocorressem em uma série de duas ou mais contrações separadas por, no máximo, 2,5 segundos. Os autores não registraram nenhuma elevação eletromiográfica prolongada, ou seja, com duração igual ou superior a 1,5 segundo.

Em 1983, STOCK; CLARKE75, descreveram um sistema de detecção de bruxismo, que consistia em um dispositivo de registro eletromiográfico, um 
conversor analógico/digital, um microprocessador e um gravador de fita cassete. Os eventos de bruxismo eram selecionados automaticamente se os mesmos satisfizessem os seguintes critérios: 1) as elevações eletromiográficos deveriam ser maiores do que o quarto menor bit significativo de um amplificador de 8 bits, cujo ganho foi ajustado para não disparar com movimentos orofaciais ordinários; 2) as elevações eletromiográficas deveriam durar 2 segundos ou mais e 3 ) intervalos de duração iguais ou inferiores a 1 segundo entre as elevações eletromiográficas eram unidos e isso caracterizava um evento.

RUGH; HARLAN68, em 1988, esclareceram que o bruxismo noturno e o diurno são duas entidades diferentes, ocorrendo em diferentes estágios de consciência, com diferentes etiologias e que requerem diferentes modalidades de tratamento. Os autores afirmam que o bruxismo do sono aparentemente não apresenta finalidade funcional, podendo levar a condições patológicas, incluindo desordens temporomandibulares, desgaste dental, dor periodontal, hipertrofia dos músculos mastigatórios e dores de cabeça. Afirmaram ainda que, embora os episódios de bruxismo do sono pareçam ocorrer no estágio 2 do sono NREM e durante atividades de microdespertar, os episódios que ocorrem durante o sono REM podem ser mais danosos às estruturas orais.

Em 1988, WARE; RUGH86 desenvolveram um sistema de escore de bruxismo com a finalidade de analisá-los e relacioná-los aos episódios de microdespertar. Caracterizou-se como um episódio de bruxismo fásico aquele onde pelo menos três bursts eletromiográficos encontravam-se separados por dois 
intervalos (2 intervalos eram necessários para caracterizar um ritmo). Cada burst fásico deveria durar de 0,25 a 2 segundos. Se um episódio apresentasse um burst com duração superior a 2 segundos, o mesmo era caracterizado como tônico. Os episódios deveriam ser separados por um intervalo maior que 3 segundos. Se um conjunto de bursts fásicos (caracterizando um episódio fásico) estivesse a uma distância igual ou menor que 3s de 1 ou mais bursts tônicos (episódio tônico), ele seria considerado um único episódio misto. O sinal eletromiográfico (EMG) deveria ser visto como um artefato no traçado eletroencefalográfico (EEG) ou o sinal eletromiográfico (EMG) deveria ser maior que $75 \mu \mathrm{V}$ ou o dobro da atividade de base. Os autores hipotetizaram ainda, que não bastaria a presença de bruxismo durante o sono para causar sintomatologia dolorosa no sistema mastigatório, mas que seu padrão e relacionamento com os estágios do sono eram os fatores que afetariam os sintomas clínicos. Os resultados indicaram que os pacientes com severa sintomatologia atribuída à atividade de bruxismo do sono apresentaram mais atividade de bruxismo na fase REM do que os outros grupos.

PIERCE e GALE62, em 1989, realizaram o monitoramento do sono, na residência de 100 pacientes com atividade de bruxismo, por meio de uma unidade modificada de medição eletromiográfica. Utilizaram-se placas interoclusais para a medição do bruxismo. Essas placas, feitas de polivinil, continham quatro camadas coloridas e a espessura total de $0,51 \mathrm{~mm}$. Impressos em sua superfície, havia micropontos, de $0,14 \mathrm{~mm}$ de diâmetro, totalizando 2228 pontos por centímetro quadrado. À medida que a placa era usada, os pontos iam sendo desgastados e, em seguida, as camadas coloridas subseqüentes da placa. Os indivíduos foram então 
subdivididos em 5 grupos de tratamento em que dez indivíduos de cada grupo foram selecionados aleatoriamente para terem seu sono monitorado por meio das placas e da unidade eletromiográfica. Os outros 10 pacientes de cada grupo foram monitorados apenas pela unidade eletromiográfica, sem as placas. Ou seja, todos os pacientes tiveram sua atividade eletromiográfica monitorada durante todo o período do experimento e as placas de medição de bruxismo só foram utilizadas no período inicial, no período pós-tratamento e na avaliação seis meses após o tratamento. Inicialmente, os pacientes foram divididos em dois grupos principais, com e sem placas. Os pacientes do grupo com placas receberam duas placas para serem utilizadas a cada 7 dias do período inicial (duas semanas). Concomitantemente, foi monitorada a atividade eletromiográfica durante o sono de todos os pacientes (de ambos os grupos, com e sem placas). Após os primeiros 14 dias (período inicial), realizaram-se duas semanas de tratamento, no qual foi interrompido o uso da placas, mas continuado o monitoramento eletromiográfico. Após a fase de tratamento (duas semanas) os pacientes do grupo com placas receberam mais duas placas novas, para utilizarem por mais duas semanas, da mesma maneira do período inicial. Após seis meses, 69 dos 100 pacientes retornaram. Os pacientes do grupo com placas receberam duas novas placas e todos os pacientes receberam a unidade de medição eletromiográfica, a fim de monitorarem a atividade de bruxismo por mais duas semanas. Os resultados demonstraram que as placas podem influenciar a atividade de bruxismo, uma vez que, no grupo que a utilizou - durante a fase inicial e pós tratamento - houve uma redução da atividade eletromiográfica dos pacientes, em comparação ao grupo sem placas, sugerindo que a mesma atua de maneira similar a placas interoclusais, as 
quais induzem mio-relaxamento. Verificou-se também baixa correlação entre a quantidade de desgaste das placas e a atividade eletromiográfica (EMG) dos grupos. Os autores atribuem essa discordância ao fato de as placas registrarem apenas atividade de ranger de dentes mas não a de apertamento, enquanto a unidade de medição eletromiográfica registra a atividade dos músculos situada acima da faixa de $20 \mu \mathrm{V}$. Os autores concluíram portanto, que as placas não medem a atividade de bruxismo da mesma maneira que o aceito método de medição eletromiográfica (EMG), e que ainda afetam a atividade medida, provocando confusão na interpretação de possíveis efeitos terapêuticos.

OKESON et al.60, em 1990, definiram um evento de bruxismo como a atividade do músculo masséter que excedesse $40 \%$ da força de apertamento máximo, com duração maior ou igual a 2 segundos.

Segundo a AADS22, em 1992, a ocorrência de episódios de microdespertar durante o sono é um fenômeno normal, com uma freqüência de 14,7 vezes por hora de sono em um indivíduo adulto jovem normal.

O diagnóstico clínico do bruxismo do sono é complicado pelo fato de que o aparecimento dos sinais e sintomas varia ao longo do tempo e da não confiabilidade dos relatos de ranger de dentes. 0 bruxismo pode ainda ser confundido com muitos outros movimentos orofaciais realizados durante o sono, tais como os relacionados à movimentação do corpo, deglutição, abertura e fechamento da boca, contraturas faciais, contrações mioclônicas, movimentos de mastigação e sonilóquio. No intuito de precisar o diagnóstico de atividade de 
bruxismo, VELLY-MIGUEL et al. ${ }^{84}$, realizaram em 1992, um estudo de identificação e diferenciação de diferentes padrões comportamentais durante o sono que pudessem ser confundidos com bruxismo e caracterizá-los no exame poligráfico. Para tanto, os autores realizaram o exame polisonográfico de 5 pacientes com bruxismo. Os registros de vídeo e de áudio foram realizados, durante toda a noite, por meio de uma câmera com captação infra-vermelha, focalizada na área da cabeça e pescoço do paciente e por meio de um microfone posicionado sobre a cabeça do mesmo. Marcou-se o tempo da câmera de vídeo paralelamente ao do papel da polissonografia. Cada paciente realizou uma série de movimentos mandibulares, antes dos registros do sono, a fim de fornecer valores conscientes de alguns movimentos. apertamento voluntário nas posições cêntrica (em três níveis de intensidade - leve, moderada e forte) e excêntricas, movimentos mandibulares de abertura, fechamento e lateralidade, contrações rítmicas, deglutição e tosse. A atividade de bruxismo foi diferenciada das demais atividades orais motoras por meio dos registros de vídeo, áudio e sinais poligráficos. Os autores concluíram que os pacientes com bruxismo do sono apresentaram bursts fásicos e tônicos de atividade dos músculos mastigatórios. Esses episódios ocorreram principalmente durante os estágios 1 e 2 do sono NREM. Numerosos outros tipos de movimentos orofaciais, os quais poderiam facilmente ser confundidos com bruxismo, se se utilizasse apenas os critérios eletromiográficos como método de pontuação, foram observados nesses indivíduos. Isso ressalta a importância dos estudos poligráficos do sono, acompanhados de monitoramento audiovisual, nos estudos da atividade de bruxismo em que se deseje diferenciá-lo das demais atividades motoras oro-faciais 
HARTMANN 33 , em 1994, lembra que as estimativas de incidência de bruxismo dependem de como a questão é feita e de quem a responde. Muitas pessoas com bruxismo desconhecem sua própria condição; assim, baixas estimativas são obtidas quando os indivíduos simplesmente respondem $\Re$ têm ou não bruxismo. 0 autor relata que parece haver uma distribuição eqüitativa entre os sexos e uma maior incidência em crianças e adultos jovens, sendo bem menos comum a partir dos 40 anos. 0 autor descreve um curso de evolução típico que envolve o início na adolescência, assumindo um curso que flutua de acordo com períodos de maior ou menor estresse emocional e diminui gradualmente após os 40 anos. O bruxismo na infância parece tratar-se de uma entidade separada.

LAVIGNE; MONTPLAISIR40, em 1994, estimaram a prevalência do bruxismo por meio de entrevista realizada com 2019 pessoas. A prevalência diminuiu de 13\%, na faixa etária de 18 a 29 anos, para 3\%, na população com idade igual ou superior a 60 anos. Não se notou diferença na prevalência entre os sexos. 0 relato de ranger de dentes ocorreu em $8 \%$ da população geral. Os autores comentam que a prevalência de outras atividades oro-motoras (atividade rítmica ou movimentos de mastigação durante o sono) também é reduzida de forma significativa com a idade.

MARCEL et al.50, em 1995, examinaram, por meio de espectroscopia de ressonância magnética $\left({ }^{31} \mathrm{P}-\mathrm{NMR}\right)$, os músculos masséteres de 6 indivíduos sem bruxismo (5 homens, 1 mulher) e 6 indivíduos com bruxismo (4 homens e 2 mulheres) durante a mastigação. Foram realizados 3 eventos completos de 
repouso/mastigação/repouso durante cada sessão de 2 minutos. Em cada sessão, coletou-se a média espectral de fosfato inorgânico, fosfocreatina e 3 picos de adesonisa 5-trifosfato. Em repouso, os indivíduos com bruxismo apresentaram menor concentração de fosfato total e de fosfocreatina do que os indivíduos do grupo controle (indivíduos sem bruxismo). Durante a mastigação, os indivíduos com bruxismo apresentaram um aumento significativamente inferior do fosfato inorgânico em relação aos não bruxômanos. Os níveis de $\mathrm{pH}$ durante o repouso e durante a mastigação foram similares para ambos os grupos. Esses resultados preliminares sugerem que os indivíduos com bruxismo possuem o metabolismo do fosfato alterado durante o repouso e mastigação, quando comparados aos indivíduos sem bruxismo.

Em 1995, SELIGMAN; PULLINGER71 concluíram, em seu estudo sobre atrição dental na sociedade moderna que, além de atividade parafuncional, uma parte significativa do desgaste dentário observado é atribuída à fatores tais como idade e geometria das relações de contatos oclusais.

WILDMALM et al.87 relataram, em 1995, a prevalência de $20 \%$ de bruxismo em crianças brancas e negras de 4 a 6 anos de idade e reconheceram que uma associação significativa não prova a existência da relação causa-e-efeito, mas pode atuar como possível fator de risco.

IKEDA et al. ${ }^{35}$, em 1996, realizaram um estudo, em que nove indivíduos (cinco homens e quatro mulheres) realizaram exame polissonográfico por 4 noites consecutivas em ambiente domiciliar. Os autores relataram que a natureza variável 
do bruxismo muitas vezes resultou em registros improdutivos durante as duas primeiras noites e que houve um pequeno, mas consistente aumento no nível de bruxismo ao longo das 4 noites estudadas. Registraram-se os níveis de contração de todos os pacientes e escolheu-se o valor mais freqüente na população estudada. Uma vez que $20 \%$, e mais seguramente, $40 \%$ tratam-se de valores elevados para serem utilizados como limites mínimos de detecção de eventos de bruxismo - em particular se se utiliza o método de média eletromiográfica integral suavizada elegeu-se o valor de $10 \%$ da contração voluntária máxima para essa finalidade. Os autores sugeriram uma associação de critérios para a detecção de eventos de bruxismo, dentre eles: 1) o intervalo mínimo entre episódios de 5 segundos; 2) a eliminação de quaisquer elevações eletromiográficas de duração inferior a 3 segundos, com o objetivo de excluir artefatos ou mioclonia e 3) uma alteração na freqüência cardíaca maior do que $5 \%$ durante o evento eletromiográfico.

LAVIGNE; ROMPRÉ; MONTPLAISIR ${ }^{42}$, em 1996, enfatizaram a necessidade de diferenciação entre as atividades oromotoras distintas de bruxismo, por meio do registro áudio-visual concomitante ao registro polissonográfico de uma noite inteira de sono. Tantos requisitos necessários a uma análise desse porte inviabilizam sua realização em ambiente ambulatorial (em casa). Com o objetivo de validar a PSG com relação aos critérios da AADS, os autores propuseram-se a: 1) caracterizar as variáveis motoras orofaciais durante o sono de pacientes com bruxismo definido clinicamente e compará-las àquelas apresentadas por uma população assintomática; 2) estabelecer valores limítrofes de atividade EMG indicadora de bruxismo durante o sono e 3) testar a sensibilidade e a especificidade desses 
valores limítrofes no diagnóstico do BS. Para isso, foram selecionados 18 indivíduos com bruxismo e 18 indivíduos sem bruxismo, distribuídos eqüitativamente em idade (20 a 45 anos) e sexo. Para o grupo experimental, os autores utilizaram os seguintes critérios de inclusão: idade entre 20 e 45 anos, ter apresentado, nos últimos 6 meses, em pelo menos 5 noites por semana, sons de ranger de dentes durante o sono; e um ou mais dos seguintes critérios subjetivos: desgaste dentário ou pontos brilhantes nas restaurações metálicas; relato de fadiga ou dor nos músculos mastigatórios ao acordar ou hipertrofia do músculo masseter. Os critérios de exclusão eram: ausência de dois ou mais dentes (excluindo-se os terceiros molares); utilização de prótese dental; presença de má-oclusão grosseira; uso de medicação com possíveis efeitos sobre a atividade motora durante o sono, estar sob tratamento dentário ou físico, apresentar grandes desordens neurológicas ou psiquiátricas e outras desordens do sono. Para o grupo controle, os autores utilizaram como critérios de inclusão: indivíduos de ambos os sexos, distribuídos de maneira o mais similar possível ao grupo experimental e, como critérios de exclusão, os mesmos utilizados para o grupo experimental, adicionando-se a apresentação de qualquer sinal ou sintoma sugestivo da presença de bruxismo. A polissonografia foi realizada por duas noites seguidas em laboratório. A primeira noite tinha por finalidade permitir a adaptação do paciente ao ambiente e captar o padrão de outras desordens do sono. Somente na segunda noite era realizada a coleta dos dados experimentais. Como resultados, os autores verificaram que a polissonografia e o registro áudio-visual confirmaram uma atividade motora orofacial durante o sono significativamente maior nos pacientes com bruxismo do que nos indivíduos do grupo controle. Os dados demonstraram que os indivíduos do 
grupo experimental exibiram três vezes mais episódios de bruxismo por noite e seis vezes mais bursts de bruxismo por hora. Como divergências entre as manifestações laboratoriais durante a PSG e os dados fornecidos pelo exame clínico, verificou-se que, ao exame clínico, todos os pacientes do GE manifestavam ruídos típicos de ranger de dentes enquanto nenhum dos indivíduos do GC o fazia. Já durante o sono no laboratório, quatro indivíduos do GE não manifestaram tais sons e 1 indivíduo do grupo controle o fez em 5 episódios. Apesar da divergência, houve diferença estatisticamente significativa para a manifestação de episódios de bruxismo acompanhados de sons de ranger de dentes entre os GE e GC. Os autores elaboraram os seguintes critérios para se utilizar uma PSG como exame de diagnóstico de BS: pelo menos 2 episódios de ARMM com sons de ranger de dentes, por noite, seguido de 1 ou mais dos seguintes critérios: mais de 4 episódios de ARMM por hora de sono; mais de 5 bursts eletromiográficos por episódio de ARMM ou mais de 25 bursts eletromiográficos por hora de sono. A maioria dos episódios de BS ocorreu durante os estágios 1 e 2 do sono não REM (NREM).Verificou-se também que há, durante o sono tanto de indivíduos normais quanto de indivíduos portadores de bruxismo do sono (BS), episódios de ARMM; sendo, a freqüência dos eventos o fator de diferenciação dos grupos.

Na população em geral, MIGRAINE et al. ${ }^{54}$, em 1996, observaram, por meio de questionário enviado às mães de 2000 crianças de 11 anos de idade de Quebec, que a prevalência de bruxismo foi de aproximadamente $14,1 \%$. 
Apesar da obscuridade que permeia os conhecimentos sobre a etiopatogenia do BS, REIMÃO66, em 1996, considerou as seguintes hipóteses: 1) hipótese da alteração primária do sono, como consequiência de distúrbio inespecífico, frente a estímulos de ativação. Essa hipótese apoia-se na observação da deflagração imediata do bruxismo em resposta a estímulos externos, auditivos, visuais e tácteis, a qual é acompanhada do aparecimento de características de microdespertar no registro polissonográfico; 2) hipótese relacionada a fatores emocionais e/ou de estresse como desencadeadores e 3) hipótese relacionada a fatores oclusais. O autor relata ainda que a maioria dos episódios de BS ocorre durante os estágios 1 e 2 do sono não REM (NREM), primariamente no estágio 2 e, em menor grau, no estágio 1 e transição entre estágios do sono NREM.

BADER et al. ${ }^{6}$, em 1997 relatam que em cerca de 1/4 dos eventos de BS há movimento corpóreo brusco acompanhado de episódios de ranger de dentes e aumento da freqüência cardíaca, embora de curta duração, ou seja, restrito ao período do bruxismo.

Em 1997, DAL FABRO17, em estudo de avaliação polissonográfica de um indivíduo portador de BS durante 30 noites consecutivas, mostrou a variabilidade da ocorrência do bruxismo. A leitura eletromiográfica foi realizada com uma amplificação de $50 \mu \mathrm{V} / \mathrm{cm}$.

Os achados polissonográficos e estudos clínicos de LOBBEZOO; LAVIGNE45, em 1997, têm relacionado o BS ao campo das desordens do sono e a 
fatores que indicam sua superficialização, tais como a presença dos complexos $\mathrm{K}$ no traçado eletroencefalográfico, atividade rápida e transitória das pernas e do corpo, pequenos aumentos na freqüência cardíaca e elevação do estágio do sono para estágios mais superficiais ( 1 e 2 ).

De acordo com THORPY82, 1997, o que se denomina por mecanismos de ativação do sono ou microdespertares são mudanças bruscas na freqüência da atividade eletro-encefalográfica cortical, comumente associada à atividade motora, com duração entre 3 e 15s, sem completo despertar.

MACALUSO et al.49, em 1998 estudaram, por meio de registro polissonográfico, a ocorrência e as características do bruxismo do sono e sua relação com fenômenos de microdespertar, bem como as características do sono de indivíduos com e sem bruxismo. Seis indivíduos (2 mulheres e 4 homens) portadores de bruxismo do sono e um grupo controle de 6 indivíduos, correspondente em sexo e idade, sem queixas de BS participaram do estudo. Os pacientes e o grupo controle não apresentaram diferenças significativas entre as variáveis convencionais do sono, mas os indivíduos com bruxismo mostraram um número significativamente maior de microdespertares, caracterizados por dessincronização ao EEG. Os episódios de bruxismo foram igualmente distribuídos entre as fases REM e não REM do sono, embora fossem mais freqüentes nos estágios 1 e 2 ( $p<0,0001$ ) do que nos estágios profundos ( 3 e 4) do sono NREM. A grande maioria dos episódios de bruxismo detectada durante o sono não REM (88\%) estava associada ao padrão de mudança de estágio cíclica do sono e sempre ocorria durante um 
microdespertar. A freqüência cardíaca durante os episódios de bruxismo (69,3 \pm 18,2) foi significativamente maior $(p<0,0001)$ do que durante o período pré episódio $(58,1 \pm 15,9)$. Quase $80 \%$ de todos os episódios de bruxismo estavam associados com espasmos dos músculos tibiares anteriores.

Embora muitas vezes tenha-se creditado ao bruxismo um importante papel na etiologia da DTM, ainda não foi evidenciada, por meio de registros eletromiográficos (EMG), a atividade dos músculos mastigatórios relativa à posição mandibular durante a atividade de ranger os dentes durante o sono. Com essa finalidade, em 1998, MINAGI et al. 55 realizaram EMG bilateral de superfície dos músculos masseter, onde se registrou a posição mandibular durante o sono por meio de sensores magnéticos nos lados esquerdo e direito da mandíbula. Uma das posições mandibulares foi a de topo-a-topo do canino, e a outra foi o ponto médio entre a posição de intercuspidação e de topo-a-topo do canino. A proporção de atividade trabalho/não-trabalho atingiu a faixa de $1 / 10$ a $2 / 10$, mostrando a marcada predominância de atividade do músculo masseter do lado de não-trabalho durante o ranger de dentes noturno. Durante o bruxismo do sono, os bursts eletromiográficos do músculo masseter foram observados principalmente com o movimento mandibular mediotrusivo, a partir da posição de topo-a-topo do canino. Os resultados sugeriram que a dinâmica muscular durante o sono é única, quando comparada aos movimentos de apertamento diurno e exerce uma maior carga mecânica na ATM do lado de não-trabalho. 
Muito embora o bruxismo seja reconhecido como um problema de relevância clínica, o tema ainda carece de uma maior compreensão no âmbito de sua patofisiologia (KATO et al. $\left.{ }^{38}, 2001\right)$. E, embora a muito enquadrada como uma desordem do sono, os conhecimentos referentes a sua natureza encontram-se aquém daqueles referentes a outras desordens como, por exemplo, a síndrome da apnéia obstrutiva do sono (SAOS). Os autores fizeram referência a uma recente classificação que separa o bruxismo em duas formas, primária (idiopática) e secundária (iatrogênica). Na ausência de história médica iniciadora do bruxismo, tem-se a forma primária, a qual inclui o bruxismo diurno e o bruxismo noturno. A forma secundária do bruxismo encontra-se associada a outras desordens neurológicas, psiquiátricas ou do sono, podendo, ainda, ocorrer em decorrência da administração de algumas drogas.

KATO et al.37, em 2001 buscaram caracterizar uma relação temporal entre atividade cardíaca, cortical e muscular em pacientes com e sem bruxismo, a fim de determinar se se pode associar uma seqüência de eventos à ocorrência de ARMM e BS. Para tanto, os autores utilizaram 10 pacientes com bruxismo e 10 pacientes sem bruxismo. Os pacientes com bruxismo foram selecionados de acordo com os seguintes critérios de inclusão: relato de ocorrência de ranger de dentes mais de 3 vezes por semana nos últimos 6 meses, relato de fadiga ou desconforto muscular (sem dor) ao acordar e a presença de desgaste dentário e hipertrofia do músculo masseter durante a contração voluntária. Os indivíduos do grupo normal não deveriam apresentar nenhuma história de ranger de dentes durante a noite ou qualquer evidência clínica de BS. Nenhum dos pacientes, de ambos os grupos 
poderia apresentar história ou sinais de apéia obstrutiva do sono, movimento periódico das pernas, insônia ou alguma desordem médica, tais como, problemas psiquiátricos, neurológicos ou de movimento e também não poderiam estar utilizando qualquer medicação. Os autores utilizaram os critérios da AADS2, 1992 para definir a ativação do sono: um aumento abrupto da atividade cortical, com duração maior do que 3 segundos, sem completo despertar. Episódios de bruxismo noturno dos tipos fásico e misto, independentemente do ranger de dentes, foram selecionados como ARMM. Utilizou-se detecção semi-automática do episódio de ARMM, marcando-se o seu início (tempo 0) a partir do início da atividade dos músculos supra-hioídeos. O final do episódio era marcado pelo final do último burst do músculo masséter. Os autores também selecionaram os seguintes registros para análise: 1) episódios em que a atividade dos músculos supra-hioídeos precedia a atividade dos músculos masséteres; 2) episódios de ARMM precedidos por pelo menos 60 segundos livres de artefatos durante o estágio 2 do sono NREM e 3) episódios de ARMM em que o traçado do ECG não foi obscurecido por artefato durante o tempo mínimo de 5 ciclos cardíacos após o início a ARMM. No exame do EEG, os autores registraram 7 séries de 4 segundos, livres de artefatos, (60 a 56, 50 a 46, 40 a 36, 30 a 26, 20 a 16, 10 a 6 e 4 segundos imediatamente antes do início da atividade rítmica dos músculos supra-hioídeos - tempo 0). Calculourse também a amplitude das ondas delta $(0,75$ a $4,5 \mathrm{~Hz})$ e alfa $(8 \mathrm{a} 12 \mathrm{~Hz})$ como parâmetro de atividade de ativação ao EEG. Também se registrou a presença de complexos-K, bem como realizou-se a análise dos episódios não precedidos por complexos-K, a fim de determinar se a presença destes influencia na amplitude das ondas delta. Quanto a este aspecto os autores encontraram que a presença dos complexos K não 
influencia os dados apresentados pelo EEG. Os autores também registraram as mudanças de estágio do sono após os episódios de ARMM. Para a análise do ECG, os autores marcaram uma média de 10 batimentos cardíacos a 60, 40 e 20 segundos imediatamente anteriores ao início do episódio de ARMM, a fim de verificar alguma alteração transitória na frequiência cardíaca relacionada à ARMM. Também foram registrados 5 ciclos cardíacos após o final do episódio de ARMM. Registrou-se também a presença de atividade motora (maior do que 0,5 segundo) nos músculos esternocleidomastóideo e/ou músculo tibial anterior em associação com a ARMM. Como resultados, os autores observaram que: 1) os pacientes com bruxismo apresentaram um número de episódios de ARMM 8 vezes maior do que o grupo sem bruxismo por hora de sono (duzentos e noventa e nove episódios de ARMM e 44 respectivamente, durante a fase 2 do sono); 2) a incidência de eventos de microdespertar não diferiu entre os grupos; 3) não se observou nenhuma diferença entre os grupos quanto à duração dos episódios ou à percentagem de episódios relacionados à mudança de estágio do sono ou à atividade motora dos músculos esternocleidomastóideo e/ou tibial anterior; 4) as diferenças apresentadas no EEG só se mostraram evidentes entre os grupos nos 4 segundos imediatamente anteriores ao início do episódio de ARMM, onde foi observado um aumento significativo na amplitude tanto das ondas alfa quanto delta no grupo com bruxismo, em relação ao grupo sem bruxismo. Ao ECG verificou-se um pequeno, mas significativo aumento na freqüência cardíaca dos pacientes com bruxismo durante os 10 batimentos cardíacos anteriores ao início do episódio e 1 ciclo cardíaco antes ocorreu um significativo aumento na freqüência cardíaca, embora durante e após a ARMM, nos indivíduos normais, também aconteça um significativo 
aumento na freqüência cardíaca. Assim, neste estudo verificou-se que os episódios de ARMM nos pacientes com BS foram claramente precedidos primeiramente por mudanças corticais ao EEG e depois por um aumento da frequiência cardíaca. Nos pacientes de ambos os grupos os episódios de ARMM também se associavam a atividade motora do pescoço e das pernas. Assim, os autores constataram: 1) um aumento da atividade alfa, ao EEG, em 50\% dos episódios de ranger de dentes e 2) um aumento da frequiência cardíaca entre 10 e 27\% dos episódios de bruxismo iniciando-se antes ou concomitante ao início do mesmo. Também foi demonstrado que 70 a $80 \%$ dos episódios de ARMM foram precedidos por atividade dos músculos supra-hioídeos, o que confirma a informação de que a ativação desses músculos é um sinal eletromiográfico clássico de ativação do sono, confirmando-se que a ativação eletroencefalográfica (por exemplo, a intrusão de ondas alfa) precede a ARMM. Entretanto, a eficiência do sono e o número de microdespertares e despertares por hora de sono dos pacientes com BS foram similares aos dos pacientes normais. Os autores concluíram que a ARMM durante o sono dos pacientes com BS é uma resposta oro-motora potencializada, associada a fenômenos espontâneos de microdespertar. Os autores encontraram que 60\% dos indivíduos normais exibiram ARMM sem ranger de dentes durante a noite.

LAVIGNE et al. ${ }^{43}$, no mesmo ano, com o objetivo de avaliar a freqüência da ARMM em indivíduos com e sem BS, realizaram uma avaliação por meio de PSG, em apenas uma noite, de 82 indivíduos sem BS (grupo controle) e em 33 indivíduos bruxômanos (grupo experimental). 0 grupo controle era composto por 44 mulheres e 38 homens, com idade média de 40,0 $\pm 1,5$ anos - 15 a 69 anos, sem nenhuma 
história, sinais clínicos ou evidência de desordens do sono, DTM ou qualquer outra desordem médica ou psiquiátrica. O grupo experimental era composto por 15 mulheres e 18 homens, com idade média de 26,8 $\pm 1,0$ anos, com história de ranger os dentes mais de 3 vezes por semana, a pelo menos 6 meses, segundo relato de seu companheiro de quarto. Além disso, todos apresentavam desgaste dentário, fadiga nos músculos mandibulares, desconforto, dor ou hipertrofia do músculo masseter. Foram verificadas a prevalência e as características eletrofisiológicas da ARMM e variáveis do sono em ambos os grupos. Como resultados, observou-se que os episódios de ARMM também ocorreram em aproximadamente $60 \%$ dos indivíduos do grupo controle, embora com menor freqüência do que nos indivíduos bruxômanos. Os grupos não diferiram quanto à organização do sono. Os indivíduos com bruxismo apresentaram duas vezes mais bursts por episódio e episódios com maior amplitude em comparação ao grupo controle com ARMM. O número de epi/hora e de MD/hora dos bruxômanos foi significativamente maior do que dos indivíduos do grupo controle com ARMM. Os indivíduos bruxômanos também apresentaram mais bursts/s dentro dos episódios, mas os indivíduos do grupo controle apresentaram bursts mais longos $(p=0,009)$. Em ambos os grupos, a ARMM do músculo masseter estava sempre associada à ativação dos músculos suprahióideos, sendo que esta ocorria em média $804 \mathrm{~ms}$ antes da ativação dos músculos masséteres. Essa alta prevalência de ARMM observada em indivíduos normais sugere que essa atividade relaciona-se a certas funções fisiológicas, incluindo ativação autonômica. 
NISHIGAWA; BANDO; NAKANO59, em 2001, mediram a força de mordida associada a bruxismo do sono de 10 indivíduos. Foram fabricados dispositivos intraorais de acrílico para as arcadas superior e inferior de cada indivíduo. Foram montados transdutores aferidores de tensão em miniatura ao dispositivo superior nas regiões de primeiros molares esquerdo e direito. Em seguida, foram conectadas finas placas de metal ao dispositivo inferior, as quais entravam em contato com os transdutores. Após 1 semana de familiarização com os dispositivos, a força de mordida durante o sono foi medida por três noites, na própria cada de cada participante. Nos 30 registros, 499 eventos de bruxismo que preencheram o critério de definição foram selecionados. O sistema acima descrito também foi usado para medir as forças de mordida voluntária máxima durante a vigília. A amplitude média detectada de eventos de bruxismo foi de $22,5 \mathrm{Kgf} \pm 13,0$ e a duração média foi de $7,1 \mathrm{~s} \pm 5,3$. A amplitude média de força de mordida máxima, durante o sono, foi 42,3Kgf (15,6 - 81,2Kgf). A força de mordida voluntária máxima durante a vigília foi 79,0Kgf (51,8 a 99,7Kgf) e a proporção média de força máxima de mordida noturna/diurna foi de 53,1\%. Esses dados indicam que a força de mordida durante o bruxismo do sono pode exceder a amplitude da força de mordida voluntária máxima durante a vigília.

\subsection{Disfunção Temporomandibular}

GREENE; MARBACH ${ }^{32}$, em 1982, em uma revisão sobre estudos epidemiológicos, sugerem que o fato de alguns indivíduos procurarem ajuda 
profissional para a resolução de seus problemas os distingue dos demais, ou seja, quando se realiza um estudo epidemiológico baseado apenas nas características da doença obtidas por meio de anamnese, exame clínico e/ou exames adicionais sem se considerar a queixa principal do paciente como fator de motivação a procurar tratamento, pode-se obter como resultado não a prevalência de pessoas realmente doentes e sim, a prevalência de pessoas com características fora do padrão tido como normal.

DROUKAS; LINDEE; CARLSSON22, em 1985, encontraram, em um estudo prévio, a falta de um relacionamento significativo entre condições oclusais e o grau de disfunção mandibular em um grupo de indivíduos jovens não pacientes. Utilizando o mesmo modelo metodológico, os autores investigaram o mesmo relacionamento em uma população de pacientes indicados para tratamento de distúrbios funcionais do sistema mastigatório. A avaliação clínica consistiu em um questionário de sintomas subjetivos para o registro de um índice de disfunção; consciência de bruxismo; tipo, localização e severidade dos sintomas e características oclusais. 0 índice de bruxismo relatado foi positivamente correlacionado com cefaléia e atrição e negativamente correlacionado com sinais de disfunção articular e sobremordida vertical.

LOCKER; SLADE47, em 1988, realizaram um estudo de prevalência e distribuição dos sintomas comumente associados à DTM em uma amostra de adultos em Toronto, Canadá. De 1002 indivíduos com idades acima de 18 anos, 67,7\% preencheram um questionário sobre sua sintomatologia. Do total, 48,8\% 
responderam positivamente a uma ou mais das nove questões sobre os sintomas. Sons articulares, cansaço ou rigidez dos músculos mandibulares e mordida desconfortável foram os sintomas mais freqüentemente relatados. Dor funcional ou em repouso foi relatada por $12,9 \%$. As diferenças em sexo e idade foram pequenas mas significativas, sendo que, o grupo de mulheres mais jovens relatou um ou mais sintomas mais freqüentemente do que o grupo de homens mais velhos. Os autores encontraram uma correlação positiva entre "fatores de risco hipotéticos", tais como relato de ranger os dentes à noite; apertamento diurno e estresse freqüente com sinais e sintomas de DTM. Entretanto, os próprios autores advertem que esses achados precisam ser interpretados com cuidado. Pois em um estudo transversal como esse não é possível estabelecer uma seqüência temporal de causa e efeito. Além do mais, esse modelo de estudo não permitiu estimar o poder da relação entre os fatores de risco e os sintomas por meio de medidas tais como relação das probabilidades (odds ratio). Consequentemente, o estudo fornece fraca evidência da implicação desses fatores na causa das DTMs, havendo a necessidade de estudos de avaliação longitudinal para estabelecer seu exato papel etiológico.

DWORKIN et al. 23 , em 1990, realizaram um estudo epidemiológico e compararam sinais e sintomas clínicos de pacientes com DTM selecionados de forma aleatória na mesma comunidade. Os autores relataram que a média de abertura mandibular máxima não-assistida (sem dor) e assistida (com dor) nos pacientes com sintomatologia de DTM foi significativamente menor do que nos indivíduos sem qualquer sinal ou sintoma de DTM. 
Em 1991, CLARK; ADLER; LEE12 sugeriram que a preexistência de uma condição patológica nos músculos mastigatórios pode ser necessária para o desenvolvimento da dor muscular persistente.

GOULET; LAVIGNE; LUND28, em 1995 obtiveram uma taxa de aproximadamente $5 \%$ para dor mandibular freqüente de intensidade moderada a severa; $4 \%$ de ruídos articulares e $9 \%$ de dificuldade durante a abertura da boca entre a população adulta de Quebec, Canadá. Os autores verificaram ainda que a prevalência dos sintomas de DTM era duas vezes maior nas mulheres do que nos homens.

Embora os mecanismos da dor muscular crônica fossem pobremente compreendidos, em 1996, DELCANHO; KIM; CLARK21, investigaram uma das teorias predominantes sobre essa questão: a hipóxia localizada. Realizou-se o monitoramento das mudanças relativas na concentração de hemoglobina $(\mathrm{Hb})$ intramuscular e nos níveis de saturação de oxigênio. Os dados foram coletados do masseter humano durante e após três sessões de 30s de contração isométrica com 50\% da FOVM. Participaram do estudo 10 mulheres com história de dor muscular crônica na região mandibular e 8 mulheres saudáveis sem dor muscular. Ao início da contração do músculo masseter, ocorreu uma rápida redução na concentração intramuscular de $\mathrm{Hb}$, concomitantemente à redução dos níveis de saturação de oxigênio. Após o término da contração, a concentração de $\mathrm{Hb}$ aumentou rapidamente até voltar ao nível inicial. Houve diferenças significativas no perfil de recuperação da saturação de oxigênio entre a primeira e as duas sessões seguintes 
no grupo com dor crônica, com relação ao grupo controle. Olhando apenas para a primeira sessão, ajustando-se as co-variadas altura, peso e força de mordida na análise, verificou-se uma significativa diferença pós-contração entre os dois grupos - com um menor nível de saturação de oxigênio durante a recuperação no grupo com dor muscular crônica. Houve diferenças significativas nas concentrações de Hb entres os grupos, sem nenhum efeito da sessão. As bem conhecidas alterações no fluxo sangüíneo intramuscular durante e após a contração em músculos humanos refletiram-se nessas concentrações de $\mathrm{Hb}$ relativamente alteradas. $\mathrm{O}$ grupo com dor muscular crônica apresentou uma clara redução na recuperação da concentração de $\mathrm{Hb}$ durante o período pós-contração. Os resultados suportam o conceito de que os pacientes com dor muscular crônica possuem uma reperfusão mais lenta durante a fase de recuperação pós contrações isométricas sustentadas.

FRICTON; OLSEN24, em 1996, visando ampliar o entendimento sobre os fatores preditores da resposta ao tratamento de pacientes com DTM crônica (desordens articulares e dor-disfunção mio-fascial), investigaram o risco envolvido com alguns fatores psicosociais (cognitivos, demográficos, emocionais, comportamentais e sociais), nessa questão. Noventa e quatro indivíduos com DTM crônica foram submetidos a um teste de identificação de fatores psicosociais e demográficos associados à dor temporomandibular crônica. Em seguida, passaram por um programa de tratamento interdisciplinar, cujo resultado baseou-se na redução significativa do Índice Craniomandibular e do Índice de Severidade de Sintomas. Em metade dos indivíduos (47) realizou-se o teste de regressão múltipla para identificar os itens psicosociais e demográficos com maior capacidade de 
predizer a resposta ao tratamento. Em seguida, aplicou-se uma análise discriminativa para testar a utilidade preditora dos itens identificados para esses indivíduos (grupo 1). Nos demais indivíduos, realizou-se um teste de validação cruzada (grupo 2) A regressão múltipla identificou os seguintes itens como preditores do resultado do tratamento para o grupo 1: (1) sucesso de tratamentos prévios; (2) baixa auto-estima; (3) baixa energia; (4) sentimentos de preocupação; (5) nível de atividade sexual; (6) hábitos de alimentação; (7) nível de sono; (8) sentimento de confusão; (9) quanto tempo o indivíduo pensa que seu tratamento irá demorar e (10) quão freqüentemente o seu problema é uma desculpa para não fazer algo. Quando foi realizada uma segunda regressão múltipla sobre esses 10 fatores, os seguintes 4 fatores emergiram (listados em ordem de valor preditor): baixa auto-estima, sentimentos de preocupação, de falta de energia e atividades durante o sono. Cada um desses fatores estava correlacionado à depressão. A análise discrimitativa empregando esses 4 itens considerando-os para $49 \%$ da variação no resultado do tratamento, foi estatisticamente significativa $(p<0,0001)$ e predisse corretamente a resposta ao tratamento para 41 dos 47 indivíduos (87\%) do grupo 1. A utilidade preditora dos itens identificados permaneceu significativa quando aplicados ao grupo 2 ( $p<0,01)$. A função discrimitativa empregando os itens, predisse corretamente o resultado do tratamento de 37 dos 47 indivíduos (79\%) e explicou $28 \%$ da variação do resultado do tratamento. Os achados desse estudo sugerem que é importante tomar informações psicossociais do paciente na fase prétratamento a fim de melhor prever o resultado do tratamento das desordens temporomandibulares crônicas e que os sintomas de depressão mediam a resposta ao tratamento dos pacientes com dor crônica. 
Em 1997, MINAGI et al.56. avaliaram o efeito do padrão de contatos oclusais do lado de não-trabalho durante os movimentos excursivos da ATM. Mediuse o deslocamento vertical do segundo molar inferior no lado de não-trabalho, durante o apertamento na posição de topo-a-topo do canino, com uma distância de 0 e $1 \mathrm{~mm}$ inter-caninos, em 42 indivíduos normais com relação ao contato oclusal no lado de não-trabalho. Os contatos oclusais no lado de não-trabalho foram classificados em 4 padrões: 1) contatos simultâneos no lado de trabalho e de nãotrabalho (sem apertamento); 2) contatos no lado de não-trabalho (apenas com apertamento); 3) sem contatos no lado de não-trabalho (com ou sem apertamento) e 4) contato exclusivamente no lado de não-trabalho (sem contato no lado de trabalho). O deslocamento vertical do côndilo do lado de não trabalho, calculado pelo deslocamento do segundo molar do mesmo lado, apresentou três diferentes padrões de deslocamento. Esses três tipos apresentaram incidência distinta em relação ao padrão de contato oclusal no lado de não trabalho. Verificou-se que o contato oclusal do lado de não trabalho pode afetar a dinâmica da ATM ipisilateral, onde, na ausência de contato de não trabalho, houve uma maior movimentação do segundo molar do mesmo lado.

Perscrutando o campo dos fatores envolvidos na etiologia da DTM, CARLSSON; EGERMARK; MAGNUSSON, publicaram um estudo em 2002, que tinha o objetivo de encontrar possíveis fatores de previsibilidade de sinais e sintomas de desordens temporomandibulares em uma perspectiva de longo prazo. Aplicou-se um questionário e um exame clínico sobre função e disfunção do sistema mastigatório a uma amostra de 402 indivíduos com 7, 11 e 15 anos de idade. Depois 
de 20 anos, 320 indivíduos (80\% da amostra original) preencheram um questionário similar ao primeiro. Escolheram-se três variáveis dependentes do acompanhamento de 20 anos, para uma análise de regressão logística, com as variáveis independentes selecionadas do exame inicial. Três variáveis do exame inicial foram significativamente preditoras para o relato de estalido na ATM, o índice de desgaste dentário foi o fator de risco mais forte (odds ratio $=4,3$ ). 0 relato de estalido articular no início foi o único fator de previsibilidade para sintomas de DTM sem estalido 20 anos depois (odds ratio $=2,3$ ). Um terceiro modelo de regressão logística, usando o Escore de Disfunção Clínica de Helkimo como variável dependente, resultou em 4 fatores de previsibilidade do exame inicial: bruxismo, parafunção oral, estalido da ATM e sobremordida. Os resultados indicaram que alguns sinais e sintomas podem predizer sinais e sintomas de DTM em uma perspectiva de longo prazo. Entretanto, não se pode concluir que esses sinais registrados na infância (parafunção oral, desgaste dentário, estalido na ATM e mordida profunda) podem ser usados para predizer DTM manifesta na idade adulta. 


\subsection{Integração Sensorial-Motora na Dor Muscular e Articular}

\subsubsection{Teorias sobre atividade muscular como fator etiológico da DTM}

TRAVELL et al. ${ }^{83}$, em 1942, hipotetizaram a existência de um ciclo vicioso relacionando dor e tônus muscular. Nesse modelo, acredita-se que os aferentes musculares do grupo III e IV têm ações excitatórias sobre os neurônios fusomotores e, portanto, aumentam a atividade subjacente dos fusos musculares e/ou a sensibilidade dos mesmos ao estiramento. Via excitação autogenética, isso poderia levar a um nível de ativação aumentado nos motoneurônios alfa e ao acúmulo de metabólitos. Se a produção de metabólitos fosse alta o suficiente ou se os impulsos das articulações e ligamentos fossem combinados a impulsos musculares nociceptivos, isso poderia iniciar o "ciclo vicioso" e levar a uma rigidez muscular aumentada.

Em 1969, LASKIN39 elaborou uma discussão acerca das teorias existentes sobre a etiologia do que se chamava na época síndrome dor-disfunção da articulação temporomandibular (originalmente descrita por COSTEN ${ }^{16}$, em 1934). Em sua revisão, o autor explica que a base da maioria dessas teorias era formada por conceitos sobre discrepâncias oclusais, relacionamento maxilo-mandibular ou ambos. As teorias "oclusionistas" propunham que, quando os dentes entram em contato durante a mastigação ou a deglutição, as discrepâncias oclusais produzem um deslocamento da mandíbula, usualmente em uma direção posterior, resultando na compressão dos tecidos retrodiscais densamente inervados e vascularizados. Sua contínua compressão resultaria não apenas em dor, mas impedimento do 
suprimento sangüíneo às estruturas articulares, levando a alterações degenerativas. 0 autor descreve a evolução das teorias exclusivamente oclusionistas para as que incorporavam a influência muscular. Essas últimas não propunham um deslocamento mandibular diretamente causado por discrepâncias oclusais, mas sim, que as interferências oclusais levariam a um inadequado feedback proprioceptivo, causando espasmos e incoordenação de alguns músculos da mastigação. Em seguida, o autor cita SCHWARTZ70, 1959, que reconheceu em sua teoria, o papel dos distúrbios funcionais da musculatura mastigatória na etiologia da disfunção da ATM. Baseando-se nessa teoria, o autor desenvolveu a teoria psicofisiológica, a qual atribui aos espasmos musculares o posto de fator primariamente responsável pelos sinais e sintomas da síndrome dor-disfunção da ATM. E, uma vez que o envolvimento patológico das estruturas articulares ocorreriam apenas em estágios mais avançados, o autor sugere a mudança do termo para "síndrome dor-disfunção mio-fascial". O autor explica que restaurações inadequadas levariam à sobrextensão ou sobrecontração muscular, bem como hábitos parafuncionais como apertamento e ranger de dentes (em geral decorrentes de estresse emocional) levariam à fadiga muscular. Tanto a fadiga, quanto a sobreextensão ou a sobrecontração levariam aos espasmos musculares. Esses últimos, levariam não apenas à dor e à limitação, mas ainda produziriam uma alteração na posição mandibular de maneira que os dentes não ocluiriam de forma apropriada. Se esse relacionamento mandibular anormal persistisse por vários dias, os dentes gradualmente se alterariam para acomodarem-se a essa nova posição. A persistência do mio-espasmo também poderia levar a alterações degenerativas (devido à função da articulação em posição inadequada) e à contratura muscular 
(alteração degenerativa no músculo decorrente de espasmo persistente). Assim, a condição se tornaria auto-perpetuante, visto que todas essas alterações levariam a um padrão de mastigação alterado, reforçando o espasmo original e a dor.

Em uma análise dos conhecimentos acerca da etiologia da DTM, GREENE ${ }^{31}$, em 2001 após revisar a história do pensamento nessa área, concluiu que não apenas estavam os velhos conceitos mecanicistas incorretos, como 2 dos mais populares conceitos atuais (biopsicosocial e multifatorial) apresentam sérias falhas. Assim, o autor considera que, o que realmente existe em nível de indivíduo com DTM é, quase sempre, uma condição idiopática - sobre a qual não se sabe o suficiente, nem se pode medir de forma satisfatória, não se podendo determinar por que um paciente desenvolve aquela condição. Acrescenta ainda a falta de entendimento dos fatores de resistência individual, os quais, em última instância, realmente determinam por que uma pessoa fica doente e outra não.

\subsubsection{Atividade Muscular e Alteração Somato-Motora}

\section{a) Atividade Muscular Experimental e Atividade Somato-Motora}

Em 1979, CHRISTENSEN 8 realizou, com 10 adultos e 10 crianças, um estudo sobre limiar e tolerância à dor provocada pelo apertamento dental experimental. Os participantes eram instruídos a apertar seus dentes até que a dor intolerável e a exaustão dos músculos elevadores da mandíbula os forçassem a 
parar. Durante essas sessões determinava-se o limiar de dor (momento de início da dor) e a tolerância à dor (período do início da dor até a cessação do apertamento devido à mesma ter se tornado insuportável). Verificou-se correlação entre limiar e tolerância à dor, ou seja, aparentemente, quanto mais baixo foi o limiar, menor a tolerância. Os indivíduos com alguma história de dor apresentaram níveis de limiar e tolerância à dor menores do que a média. 0 autor considerou que o metabolismo muscular anaeróbio estaria entre os maiores determinantes do nível de tolerância individual à dor muscular decorrente de apertamento dental.

Em 1981, CHRISTENSEN realizou uma revisão de literatura sobre dor e fadiga muscular e concluiu que, após aproximadamente $0,5 \mathrm{~min}$ de apertamento dos dentes, ocorre a sensação de fadiga muscular. 0 autor sugeriu que o início da fadiga seria determinada, em grande parte, pela quantidade de contração isométrica e, talvez pela resistência original do músculo, admitindo a possibilidade de alguma influência dos fatores psicológicos individuais. Ou seja, que a ocorrência precoce da sensação de fadiga muscular deve estar associada a baixos níveis de contração voluntária ou a músculos relativamente fracos - com relação à produção de força. Do mesmo modo, uma percepção tardia do início da fadiga deve estar associada à altos níveis de atividade muscular voluntária ou a músculos relativamente fortes na geração de altos níveis de tensão. Nem o limiar de fadiga ao apertamento dental, nem a atividade elétrica muscular decorrente apresentaram variações intra-individuais significativas estatisticamente; o contrário ocorreu nas análises inter-individuais. Definiu-se como tolerância muscular à dor por apertamento dental como o momento após o início do apertamento em que 
ocorreu desconforto muscular severo e intolerável, com aumento gradual da sensação subjetiva de exaustão de um ou mais músculos mandibulares, que forçasse o indivíduo a cessar a atividade. A tolerância à dor foi medida em segundos. Definiu-se limiar de dor como o momento em que surgiu a sensação inicial de desconforto intenso em um ou mais músculos mandibulares após o início do apertamento. 0 autor relatou uma relação linear positiva entre os limiares de fadiga e dor muscular ao apertamento dental, sugerindo que o limiar de fadiga pode ser um dos determinantes do limiar de dor, ou que esses dois parâmetros subjetivos podem ser influenciados pelos mesmos determinantes. A atividade elétrica muscular no limiar de dor (70\% da FOVM) é significativamente menor do que no limiar de fadiga muscular (90\% da FOVM). O autor explica a redução na atividade contrátil como provavelmente uma expressão da fadiga muscular fisiológica progressiva. A dor nos músculos elevadores surgiu após $1 \mathrm{~min}$ de apertamento. No mesmo artigo o autor afirma que o teste de atividade mioelétrica no limiar de dor varia significativamente tanto intra como interindividualmente e que não houve nenhum relacionamento linear entre limiar de dor muscular e sua atividade elétrica. O autor menciona ainda a possível influência da isquemia decorrente da contração muscular isométrica no início da dor. Entretanto, não forneceu nenhuma explicação conclusiva sobre os mecanismos pelos quais a supressão total ou parcial do fluxo sangüíneo possa ser relacionada à dor dos músculos mastigatórios. A tolerância à dor muscular decorrente do apertamento dental foi de aproximadamente $2 \mathrm{~min}$. Esse resultado não apresentou variações intra-individuais, mas inter-individuais. Os valores de tolerância à dor diferiram significativamente dos valores de limiar de fadiga e dor. Entretanto, 
houve uma correlação positiva entre o primeiro e os dois últimos, sugerindo que os limiares de dor e fadiga podem estar entre os determinantes da tolerância à dor ou que esses três parâmetros são afetados pelos mesmos determinantes. 0 autor sugeriu que a tolerância muscular à dor estaria relacionada aos parâmetros fisiológicos da contração isométrica (isquemia e metabolismo muscular) e também seria influenciada por fatores psicológicos individuais.

Em 1982, CHRISTENSEN; MOHAMED; HARRISON10 verificaram os efeitos de diferentes níveis de contração isométrica voluntária dos músculos masséteres sobre o limiar e a tolerância à dor em indivíduos saudáveis. Seis voluntários do sexo masculino, com idade média de 35 anos foram primeiro instruídos a exercitarem apertamento dental (100\% FOVM) durante 10s. Após um intervalo de $5 \mathrm{~min}$, o exercício muscular isométrico era repetido (100\% FOVM) até que a dor se iniciasse no músculo masseter direito ou esquerdo (definindo assim o limiar de dor, em segundos). Após outro intervalo de $5 \mathrm{~min}$, realizava-se novamente apertamento dental (50\% FOVM). Nas três fases do teste foi realizado o monitoramento eletromiográfico dos músculos masséteres. Houve uma correlação positiva linear significativa entre a atividade elétrica média da sessão de apertamento a $100 \%$ FOVM $(195,3 \mu \mathrm{V})$ e a atividade elétrica média da sessão de apertamento a 50\% FOVM $(47,4 \mu \mathrm{V})$. Houve também uma correlação positiva linear significativa entre o nível de atividade elétrica no teste de limiar de dor a $100 \%$ FOVM $(209,5 \mu \mathrm{V})$ e a $50 \%$ FOVM $(47,4 \mu \mathrm{V})$. Segundo os autores, o início e o atraso no início da dor após apertamento dental não podem ser totalmente explicados por uma isquemia mais ou menos pronunciada do tecido muscular. Os autores consideram que o início da 
dor deve relacionar-se ao aparecimento de alguns metabólitos químicos, cujo acúmulo depende da quantidade de tensão isométrica.

SVENSSON; ARENDT-NIELSEN78, em 1996 estudaram o limiar de percepção à dor (LPD) e o limiar de tolerância à dor (LTD) provocada por estímulo de pressão percutânea (palpação), durante 5 dias em que 10 mulheres sem dor, com idade média de 24,2 anos, realizaram sessões de apertamento dental de baixa intensidade (25\% FOVM) durante 45min. Os dez resultados apresentaram níveis moderados de dor $(53,0 \mathrm{~mm} \pm 1,0-$ em EAV $100 \mathrm{~mm})$, sensibilidade $(52,0 \mathrm{~mm} \pm 1,0)$ e desconforto $(56,0 \mathrm{~mm} \pm 0,8)$ e níveis moderados de escore no questionário de dor de McGill - QDM $(16,4 \pm 4,9)$ imediatamente após a sessão de apertamento de baixo nível no primeiro dia. Nos dias seguintes, as sessões de apertamento não aumentaram esses escores. Pelo contrário, ocorreu uma redução significativa no quinto dia de apertamento para intensidade de dor $(-48,9 \% \pm 14,6 \%)$, sensibilidade $(-46,1 \% \pm 14,2 \%)$, desconforto $(-50,4 \% \pm 8,5 \%)$ e escores do QDM $(-45,8 \% \pm 13,3 \%)(P$ $<0,05)$, em comparação ao primeiro dia. O procedimento de apertamento falhou em induzir um aumento progressivo da dor e da sensibilidade nos músculos mastigatórios durante 5 dias. Concluiu-se que nenhum dos parâmetros avaliados sugeriu o início de um ciclo vicioso.

Apesar da fraca evidência de que hábitos parafuncionais ou de apertar de dentes não induzidos experimentalmente possam causar sintomas, em 1998, GLAROS; GLASS27, examinaram o papel do apertamento parafuncional experimental sobre várias medidas de dor e DTM. Cinco indivíduos (3 homens e 2 mulheres, com 
idades entre 23 e 29 anos) participaram de sessões de treinamento de biofeedback (com 17 minutos de duração cada). As sessões foram organizadas em três fases. $\mathrm{Na}$ primeira fase, denominada fase de relaxamento, os indivíduos eram instruídos a manter a atividade dos músculos temporal e masseter abaixo de $2 \mu \mathrm{V}$ durante 10 sessões. Na segunda e terceira fases, os indivíduos eram instruídos a manter a atividade do músculo masseter acima de $10 \mu \mathrm{V}$ (fase de contração, composta por $1 \mathrm{a}$ 8 sessões) e abaixo de $4 \mu \mathrm{V}$ (fase de relaxamento, composta por 10 a 15 sessões) respectivamente. Verificou-se previamente que nenhum dos indivíduos apresentava sintomatologia de DTM, entretanto duas mulheres relataram dor intolerável durante a segunda fase (de contração), e ambas foram diagnosticadas com sintomatologia de DTM durante esta fase, entretanto, a dor tendia a se resolver nas 24 horas seguintes. Era dada aos participantes a opção de parar o treinamento de contração, e passar para a terceira fase (de relaxamento) se a dor fosse intolerável. A decisão de terminar a fase de contração prematuramente não esteve em função dos níveis de atividade eletromiográfica apenas, visto que uma das participantes que o fizeram apresentou a menor atividade EMG média, enquanto a outra apresentou um nível mediano de atividade. Nenhum indivíduo apresentou sintomatologia de DTM durante as fases de relaxamento. Os autores demonstraram que atividade parafuncional crônica, de baixo nível, pode causar dor semelhante à de DTM.

Devido à crescente sugestão de que a dor em alguns bruxômanos representaria um estado de mialgia pós-exercício (MPE), ARIMA; SVENSSON; ARENDT-NIELSEN4, em 1999, examinaram o efeito de movimentos voluntários e 
controlados de ranger de dentes sobre o desenvolvimento da dor e da sensibilidade no sistema mastigatório. Doze homens saudáveis, com idades entre 21 e 42 anos, sem qualquer sinal ou sintoma de DTM participaram do estudo. No primeiro dia, foram realizadas 9 sessões, com 5 minutos de duração cada, de movimentos repetidos de ranger de dentes, da posição de intercuspidação até a posição de topo-a-topo no canino direito, a uma freqüência de meio ciclo por segundo. A atividade eletromiográfica (EMG) do músculo masseter direito foi mantida em aproximadamente $50 \%$ de sua FOVM, por meio do biofeedback. A intensidade de dor, o desconforto e a sensibilidade foram registrados por meio de EAV de $100 \mathrm{~mm}$ e outras medidas de dor foram registradas pelo QDM. Antes e após cada sessão, era determinada a FOVM e o limiar de dor ao estímulo por pressão (LDP) em 9 diferentes sítios dos músculos masséteres. Os indivíduos retornaram ao laboratório por 3 dias consecutivos, onde novamente eram registrados o LDP, a EAV e a FOVM. Os resultados mostraram que, imediatamente após a última sessão de ranger de dentes, havia um aumento significativo nos escores da EAV e do QDM para intensidade de dor, desconforto e sensibilidade, quando comparados aos valores iniciais (ANOVA, $p<0,001$ ). Houve ainda um efeito significativo do ranger de dentes nos escores de EAV e sensibilidade muscular nos dias seguintes, com o pico no primeiro dia depois do exercício (teste Tukey, $\mathrm{p}<0,023$ ). A dor foi freqüentemente relatada (em 7 de 12 indivíduos) na ATM ou em sua proximidade. Houve um efeito significativo do ranger de dentes sobre o LDP em ambos os músculos masséteres (ANOVA, $\mathrm{p}<0,043$ ) com LDP significativamente inferior (redução de 15 a 20\%) no primeiro dia após o exercício (teste de Tukey, $\mathrm{p}<0,046$ ). Não houve efeito do ranger de dentes sobre a FOVM. Os autores concluíram que 45 
minutos de forte atividade experimental de ranger de dentes padronizada pode evocar mialgia pós-exercício; sintomatoloiga marginal e auto-limitante, de valores significativos, porém baixos na ATM e músculos mastigatórios de indivíduos saudáveis, nos dias que se seguem ao exercício.

A fim de tentar elucidar se a atividade de ranger de dentes do bruxismo do sono estaria associada à maior sensibilidade a um estímulo intramuscular, ARIMA; SVENSSON; ARENDT-NIELSEN 5 realizaram um estudo em 2000 , em que foram comparados os efeitos hiperalgésicos de uma injeção intramuscular de capsaicina no músculo masseter direito com e sem atividade prévia de ranger de dentes. Dez homens saudáveis participaram de duas sessões aleatórias (exercício, nãoexercício) separadas pelo intervalo de 1 semana. Imediatamente após a sessão de exercício (quarenta e cinco minutos de atividade de ranger de dentes - similar ao estudo anterior, com $50 \%$ da FOVM), injetou-se $0,1 \mathrm{ml}$ de capsaicina $(100 \mu \mathrm{g} / \mathrm{ml})$ no interior do músculo masseter direito. Na sessão de não exercício, a capsaicina foi injetada, só que o indivíduo não realizou atividade de ranger de dentes. Registrouse a intensidade de dor provocada pela injeção de capsaicina por meio de uma EAV de 100mm. As medidas foram tomadas 8 vezes: inicialmente, antes da injeção, cinco, 15 e 45 minutos depois da injeção e uma vez por dia durante os próximos 3 dias. Foram registrados o limiar de dor por estímulo de pressão (LDP), a contração voluntária máxima $(C V M)$ e a dor na EAV. Os resultados demonstraram que a injeção de capsaicina no interior do músculo masseter, exercitado ou não, não causa picos de intensidade de dor significativamente diferentes (valores de EAV: $57,0 \pm 6,0 \mathrm{~mm}$, no masseter exercitado e $53,0 \pm 6,0 \mathrm{~mm}$ e no masseter não 
exercitado; $p=0,464)$. O limiar de dor à pressão (LDP) no masseter exercitado reduziu-se significativamente por até 1 dia após a injeção de capsaicina $(\mathrm{p} \leq$ 0,038), enquanto para o músculo masseter não exercitado, o LDP reduziu-se por apenas $5 \min (p=0,017)$. A CVM do lado direito estava reduzida 5 minutos após a injeção de capsaicina após a sessão de exercício $(p<0,010)$ e até 15 min após a injeção, na sessão sem exercício. A CVM no lado esquerdo foi significativamente reduzida por 15 minutos após a injeção de capsaicina, apenas na sessão de exercício $(p<0,019)$. Os autores concluíram que o aumento da sensibilidade à pressão provavelmente reflete uma mialgia pós-exercício conseqüente do ranger de dentes, enquanto a sensibilidade intramuscular a estímulos químicos nocivos imediatamente após o exercício não parece ser alterada, visto que não houve diferenças na intensidade da dor evocada por capsaicina entre os musculares mandibulares exercitados ou não.

CHUNG; KIM; MCCALL11, em 2002, investigando as seqüelas do apertamento sustentado, realizaram um experimento que registrou e comparou a duração, a amplitude, o número de fases e a área do potencial de ação de uma unidade motora antes e após o apertamento sustentado e a freqüência média do espectro de força eletromiográfica em 41 indivíduos (29 homens com média de 26,6 anos de idade e 12 mulheres com média de 23,6 anos de idade). Após o apertamento a freqüência média do espectro de força foi menor; a duração e a área do potencial de ação foram maiores. Entretanto a amplitude não diferiu entre os grupos. Também não houve diferença entre o grupo do sexo masculino e feminino. Os autores concluíram que os resultados desse estudo eram consistentes 
com uma redução na velocidade de condução do potencial de ação dos músculos, provavelmente decorrente de fadiga, como uma explicação para a alteração espectral observada.

\section{b) Atividade Muscular Clínica e Alterações Somato-Motoras}

No intuito de evidenciar o papel da atividade parafuncional dos músculos mastigatórios na etiologia dos sintomas de disfunção mastigatória, CLARK; BEEMSTERBOERT; RUGH13, em 1981, selecionaram 85 pacientes e estudantes da Faculdade de Odontologia da Universidade Católica de Los Angeles e os alocaram de acordo com o quadro clínico: 25 indivíduos sem dor ou disfunção nos músculos mastigatórios e que não relatassem apertamento dental noturno e 60 pacientes com sinais e sintomas (dor, limitação de abertura e estalido ou salto na ATM) de moderados a severos relacionados à atividade de apertamento ou ranger de dentes. Após a classificação clínica, os indivíduos realizaram registros eletromiográficos dos músculos mastigatórios durante um período de 10 a 14 dias. Os indivíduos que apresentavam pouca ou nenhuma sintomatologia também demonstraram os menores índices de atividade eletromiográfica. Essa relação seguiu de forma linear para a sintomatologia moderada e severa com relação à atividade eletromiográfica moderada e intensa. Os autores concluíram que hiperatividade prolongada dos músculos mastigatórios correlacionam-se com sintomas de disfunção mandibular. Mais especificamente, quanto maior o nível de atividade eletromiográfica noturna, mais provavelmente o indivíduo apresentará sinais e sintomas de disfunção mandibular. 
Em 1993, GOULET et al. 29 avaliaram, por meio de entrevista, a influência de fatores psicofisiológicos (auto-relato de níveis de estresse) e comportamentais (auto-relato de apertamento diurno ou bruxismo noturno) na etiologia da DTM. Estimou-se a prevalência do apertamento dental diurno (20\%), ranger de dentes noturno (6\%) e altos níveis de estresse emocional (38\%) na população geral $(n=897)$. Aproximadamente um quinto dos indivíduos que relataram hábitos parafuncionais experimentavam dor mandibular e a mesma proporção relatou barulhos articulares. Observou-se uma forte associação entre apertamento diurno e sintomas de DTM. Essa tendência foi moderada para o ranger de dentes noturno e baixa para os altos níveis de estresse. Ocorreu substancial associação dos sintomas de DTM com ambos os hábitos parafuncionais, e essa associação aumentou quando combinava-se aos hábitos parafuncionais, altos níveis de estresse. As medidas de risco relativo, relação das probabilidades "odds ratio" e fração etiológica foram bem mais elevadas entre os sintomas de DTM e o apertamento diurno. Os autores concluíram que comportamentos parafuncionais devem exercer um importante papel na ocorrência dos sintomas da DTM.

JUNGE; CLARK ${ }^{36}$, em 1993 relatam que apertar os dentes não causa fadiga muscular, pois os músculos compensam a manutenção da atividade muscular por meio do não recrutamento dos neurônios motores ou através de "frequiências de disparo" mais lentas.

Não obstante tenha-se sugerido que o bruxismo é uma causa ou é um fator de risco para a dor mio-fascial dos músculos mastigatórios, DAO; LUND; 
LAVIGNE ${ }^{18}$, em 1994, argumentam que a prevalência de dor e suas características em bruxômanos ainda não haviam sido verificadas ou comparadas àquelas dos pacientes de dor mio-fascial em geral. Os autores registraram auto-relatos de dor (em escala de análise visual de $100 \mathrm{~mm}$ ) e qualidade de vida (em escala com categorias em cinco pontos) em duas populações: 1)19 indivíduos bruxômanos que participaram de um estudo polissonográfico e 2)61 pacientes com dor mio-fascial nos músculos mastigatórios sem evidência de bruxismo, que participaram de um estudo clínico controlado da eficácia de placas intra-orais. Os resultados mostraram que a dor era mais intensa nos bruxômanos que relatavam dor do que nos pacientes com dor mio-fascial, apesar da dor não ser a queixa principal dos bruxômanos. É interessante notar que a análise geral dos níveis de dor de todos os bruxômanos mascararam o fato de alguns indivíduos terem apresentado níveis mais altos de dor (58mm - média dentre os bruxômanos com dor) do que os indivíduos com dor miofascial (20 a 48,6mm). Sendo que a maioria dos indivíduos com bruxismo era livre de dor. Ambas as condições (bruxismo e dor) reduziam a qualidade de vida dos pacientes, embora os pacientes com dor (em ambos os grupos) parecessem muito mais afetados do que os indivíduos bruxômanos livres de dor. 0 fato de a dor do bruxismo ter sido pior pela manhã sugere uma possível forma de mialgia pós exercício. A dor dos pacientes com dor mio-fascial era pior ao anoitecer, sugerindo uma etiologia diferente.

DAO; LUND; LAVIGNE19, em 1994, testaram a dor antes e depois da mastigação em 20 indivíduos assintomáticos (6 homens e 14 mulheres, com idade média de 28,6 \pm 7,8 anos) e em 61 pacientes (10 homens e 51 mulheres, com idade 
média de 30,7 \pm 7,5 anos) com dor muscular. Primeiro, foram obtidos auto-relatos de dor por meio de um questionário e de uma escala dividida em cinco categorias (CAT), na sessão de triagem. Nenhum dos indivíduos assintomáticos relatou que a mastigação ou qualquer outro movimento causou dor. Antes do exercício, 80,3\% dos pacientes reportaram ao questionário, dor durante os movimentos mastigatórios. Mais especificamente $67,2 \%$ associaram dor com mastigação, enquanto alguns reportaram dor durante outros movimentos, tais como abertura e fechamento mandibular e bocejo. De forma similar, 78,7\% dos pacientes reportaram que sua dor dificultava a mastigação. Depois de tudo, registrou-se a intensidade da dor em repouso e após a mastigação de cera por $3 \mathrm{~min}$, em uma EAV de 100mm. Nenhum indivíduo assintomático sentiu dor antes ou depois do teste de mastigação, enquanto cerca de $50 \%$ dos pacientes reportaram um aumento na dor após a mastigação. Após o exercício, os escores de dor aumentaram em 48,3\%, mas diminuíram em $31,7 \%$ dos pacientes. Nenhuma alteração foi encontrada em $20 \%$ dos pacientes. No primeiro subgrupo de pacientes, a intensidade média de dor aumentou até $28,3 \mathrm{~mm}$ (um aumento de $102,9 \%$ ), enquanto diminuiu no segundo subgrupo até $26,8 \mathrm{~mm}$ (uma redução de $56,5 \%$ ). Quando foram comparados os níveis de dor desses dois subgrupos antes do exercício (em repouso), verificou-se que os níveis de dor eram significativamente maiores no subgrupo que apresentou redução da dor com o exercício $(47,4 \pm 5,1 \mathrm{~mm})$, do que no que apresentou aumento da dor com o exercício $(27,5 \mathrm{~mm} \pm 3,1)$. Esses dados mostram que um teste de curto tempo de mastigação pode exacerbar a dor na maioria dos pacientes com dor mio-fascial, mas não afeta os indivíduos assintomáticos. Surpreendentemente, o exercício reduziu a dor em um importante subgrupos de pacientes. Esses resultados sugerem 
que pode haver dois subgrupos de pacientes com dor mio-fascial com reações opostas ao exercício. Resta saber se essas reações se devem a diferentes patologias ou à diferença nos níveis de dor pré-exercício foram significativamente diferentes nos dois grupos.

DE LEEUW et al.20, em 1994 verificaram que a hiperatividade muscular não parece estar associada com desordens artrógenas da ATM.

MOLINA et al.58, em 1999, avaliaram 276 pacientes encaminhados ao Centro de Estudo de DTM e Dor Facial para diagnóstico e tratamento e, utilizandose de questionário, análise da história de sinais e sintomas e exame físico que incluiu palpação dos músculos e das articulações, avaliação dos movimentos mandibulares, busca de trigger points e padrão de dor referida, associados a modelos de estudo, radiografias panorâmica e transcraniana e tomografias quando necessário. Os autores definiam se os pacientes eram ou não portadores de DTM e, em seguida, parte do questionário era utilizado para diagnosticar se o paciente apresentava ou não bruxismo (noturno ou diurno). Em seguida, aqueles pacientes onde era constatada a presença do bruxismo, preenchiam um segundo questionário acerca do mesmo a fim de alocá-lo em uma das três categorias de severidade. Os critérios utilizados pelos autores para alocar os pacientes com DTM e bruxismo em uma categoria específica incluíam a análise das seguintes características: 1) presença de facetas de desgaste nos dentes; 2) história recente (nos últimos seis meses) de ruídos associados a ranger de dentes noturno, segundo relato de amigo, parente ou cônjuge; 3) relato anamnésico de apertamento diurno; 4) informação 
anamnésica de tensão ou cansaço durante o dia ou ao acordar; 5) informação anamnésica de despertar a noite apertando ou rangendo os dentes; 6) hipertrofia do músculo masseter e/ou temporal; 7) informação anamnésica de cansaço, dor ou tensão no músculo masseter e/ou temporal ao acordar e/ou durante o dia; 8) relato de travamento das ATM ao acordar; 9) relato de dor cervical ao acordar; 10) relato de fadiga ao acordar ou de sono de baixa qualidade; 11) relato de sensação de desconforto nos dentes ao acordar e 12) história recente de deslocamento crônico de restaurações provisórias ou definitivas. De acordo com o número de itens positivos os pacientes eram então alocados a uma das três categorias específicas de severidade de bruxismo. Ao analisarem os resultados, os autores sugerem que os pacientes portadores de bruxismo severo apresentam também mais desordens musculares e articulares, levando-os a indicarem uma modificação na terapia para DTM no sentido de proteger, por períodos de tempo mais longos, as articulações e os músculos de pacientes portadores de bruxismo severo.

\subsubsection{Dor e Alterações Motoras}

\section{a) Dor Muscular ou Articular Experimental e Atividade EMG Postural e de Força Oclusal Voluntária Máxima}

STOHLER; ZHANG; LUND77, em 1996, examinaram, por meio de EMG, a atividade postural dos músculos temporal, masséter, de ambos os lados, em quatro situações experimentais, realizadas de maneira aleatória: 1) ausência de dor; 2) dor tônica: provocada pela infiltração de solução salina hipertônica no corpo do músculo masseter - dor tônica; 3) dor simulada: lembrar e reviver experiência 
passada de dor e 4) ausência de dor. Quando da situação 2, à medida que era infiltrada a solução salina, o nível de dor do paciente era monitorado por meio de EAV eletrônica e coletavam-se os dados eletromiográficos quando o nível de dor estivesse relativamente estável entre 40 a $60 \mathrm{~mm}$. Após esse procedimento, cessava-se a infusão e a dor diminuía para 0 , dentro de 5 min. Para a situação 3 , do mesmo modo, a coleta dos dados eletromiográficos era realizada quando o nível de dor situava-se entre 40 a 60mm. Para as situações 1 e 4 , era requerido o nível de dor entre 0 e $2 \mathrm{~mm}$. Como resultados, as situações 1, 2, 3 e 4 exerceram um efeito significativo sobre a atividade eletromiográfica nos 4 sítios de registro (músculos temporal e masseter, de ambos os lados). A atividade postural nos quatro sítios de registro foi maior durante a dor tônica e simulada em comparação à situação 1. Ou seja, o aumento significativo da atividade eletromiográfica integrada (RMS) durante a dor tônica foi quase o mesmo daquele durante a dor simulada. Tanto que essas duas situações não podiam ser distinguidas uma da outra, quando comparadas às situações de atividade EMG de repouso. Os autores atribuíram o aumento da atividade EMG durante as situações de dor tônica e simulada à atividade modificada por programas motores e acompanhada de expressões faciais e gestos relacionados àdor, não exercendo o papel de fator patogênico responsável pela dor. Concluiu-se que os dados não deram suporte ao modelo de ciclo vicioso entre dor e hiperatividade muscular.

GRAVEN-NIELSEN et al.30, em 2002, investigando se a fraqueza muscular, que freqüentemente acompanha as condições de dor músculo-esqueletal devem-se a processos periféricos ou centrais, verificaram o efeito da dor muscular 
experimental induzida por injeção de salina hipertônica, sobre o torque de contração voluntária máxima e as propriedades contráteis periféricas do mesmo. A dor muscular experimental reduziu o torque produzido pela extensão isométrica do joelho durante a injeção de salina hipertônica, mas as propriedades contráteis verificadas por interpolação twich não foram afetadas. Isso indica que a inibição da força muscular pela dor é mediada centralmente. Esse achado tem implicação clínica na reabilitação e treinamento de pacientes com dor músculo-esqueletal, em que não é evidente o dano muscular.

RO; SVENSSON; CAPRA67, em 2002, realizaram um estudo cujo objetivo era investigar os efeitos do estímulo químico nocivo dos músculos mandibulares sobre a atividade eletromiográfica (EMG) postural. Foram estudados os músculos masséter, temporal e digástrico de ratos levemente anestesiados. Realizou-se injeção unilateral de uma substância que, sabidamente, induz à dor muscular aguda $(\mathrm{NaCl} 5 \%)$ ou à dor de maior duração com inflamação (óleo mostarda) no interior do músculo masseter. Registrou-se a atividade EMG após a injeção nos músculos masséteres (ipsi e contralateral) e digástrico ipsilateral. Todas as substâncias químicas algogênicas produziram um aumento significativo da atividade EMG, embora de curta duração. Os dados do presente estudo e observações similares de estudos clínicos e experimentais em humanos sugerem que o aumento da atividade EMG dos nociceptores musculares não foi suficiente para produzir um aumento prolongado da atividade EMG postural. Portanto, o desenvolvimento e manutenção de dor crônica dos músculos mandibulares não parece resultar de um mecanismo cíclico de feedback. 


\section{b) Dor Muscular ou Articular Clínica e Atividade Eletromiográfica Postural e de}

\section{Força Oclusal Voluntária Máxima}

Em 1982, SHEIKHOLESLAM; MÖLLER; LOUS72 realizaram um estudo longitudinal em que foram comparados os dados clínicos de dor e desconforto com registros eletromiográficos durante a atividade máxima e postural dos músculos temporal (porções anterior e posterior) e masseter de 37 pacientes antes e depois do tratamento de desordens funcionais do sistema mastigatório (placas oclusais, ajuste oclusal e combinação de ambos). Quarenta e três estudantes serviram como controle. O tratamento seguiu-se de concomitante redução da dor, do desconforto e da atividade postural relativa. Atribuiu-se o termo atividade postural relativa à atividade dos músculos elevadores, em termos de percentual do esforço total. Em valores absolutos, houve uma redução de 1,5 a 2, $4 \mathrm{VV}(\mathrm{p}<0,01)$ na atividade do músculo temporal anterior; de cerca de $\varkappa_{\imath} \mathrm{V}(\mathrm{p}<0,01)$ na atividade do músculo temporal posterior e de 0,5 a $1 \mu \mathrm{V}(\mathrm{p}<0,001)$ na atividade do músculo masseter. Após o tratamento, a atividade postural relativa nos pacientes diminuiu de forma significativa e tornou-se mais simétrica nos músculos temporais anteriores, enquanto houve uma tendência de redução nos músculos temporal posterior e masseter - embora ainda excedesse, de forma significativa, a atividade postural relativa do grupo controle. A atividade durante a CVM na posição de intercuspidação, não foi alterada pelo tratamento e foi significativamente inferior à do grupo controle. Entretanto, em contraste com a atividade postural relativa, não foi alterada com a redução da dor e do desconforto. Ocorreram alterações quanto à simetria da ação entre os lados direito e esquerdo, principalmente para a 
porção anterior do músculo temporal e músculo masseter. Uma vez que o tratamento envolveu a correção da oclusão, os autores concluíram que as condições intermaxilares dos contatos dentários durante a função exercem um papel na etiologia das desordens funcionais e que a redução do carregamento postural relativo dos músculos elevadores dos pacientes pelo tratamento contribui para o alívio das desordens funcionais. O valor relativamente alto de atividade postural relativa mostrado pelos pacientes, mesmo após o tratamento, pode explicar, segundo os autores, a flutuação dos sinais e sintomas das desordens funcionais do sistema mastigatório, o que enfatiza a necessidade de melhores métodos de tratamento para reduzir a probabilidade de recorrência.

SHERMAN73, em 1985, não encontrou diferenças na atividade EMG de repouso entre pacientes com bruxismo, com e sem DTM, e pacientes sem bruxismo, com e sem DTM, mas verificou que os pacientes com bruxismo, com e sem DTM, apresentavam níveis eletromiográficos de repouso maiores do que os pacientes sem bruxismo (com ou sem DTM). Ou seja, os bruxômanos exercitam seus músculos mais do que o normal e apresentam níveis eletromiográficos de repouso mais elevados do que os indivíduos controle. E esse fato se verifica, independentemente do paciente apresentar ou não dor.

HIGH; MACGREGOR; TOMLINSON34, em 1988, mediram níveis subjetivos de dor e níveis de contração voluntária máxima antes e após a exodontia de terceiros molares, e verificaram que, no período pós-operatório, a contração voluntária máxima de quase todos os indivíduos estava muito reduzida. 
Em 1997, GLAROS; GLASS26 testaram a hipótese de que a atividade eletromiográfica de repouso deveria ser significativamente maior nos pacientes de DTM com dor mio-fascial do que em indivíduos controle e que poder-se-ia estabelecer um escore limítrofe, baseado nos valores EMG, para separar precisamente esses dois grupos. Foram examinados 54 pacientes de DTM diagnosticados com dor mio-fascial e 54 indivíduos controle sem dor, compatíveis em idade e sexo. Ambos os grupos participaram de um procedimento de leitura EMG em que os músculos frontais, temporais e masséteres foram examinados. 0 grupo com DTM apresentou atividade EMG de repouso significativamente maior, para 3 dos 6 sítios examinados. Entretanto a aplicação de um valor de corte que produziu o menor erro de classificação resultou em classificação inadequada de aproximadamente um terço dos pacientes com DTM e dos indivíduos sem dor.

PINHO et al.63, em 2000 realizaram eletromiografia de superfície nos músculos mastigatórios de 40 pacientes com DTM. Esses pacientes apresentavam queixas de dor temporomandibular e estalidos articulares. Na maioria dos casos (75\%) os sintomas afetavam o lado esquerdo da face. A média geral da atividade eletromiográfica de repouso foi de $2,52 \pm 1,25 \mu \mathrm{V}$, o que foi levemente superior à média dos indivíduos do grupo controle $(1,92 \pm 1,20 \mu \mathrm{V})$. A atividade média de repouso mais alta ocorreu no músculo digástrico $(3,49 \mu \mathrm{V})$ do lado esquerdo. A média geral de atividade durante o apertamento foi de $66,77 \pm 35,22 \mu \mathrm{V}$, o que foi aproximadamente metade daquela observada nos indivíduos do grupo controle $(110,30 \mu \mathrm{V} \pm 82,97)$. Durante o movimento da mandíbula em direção ao lado esquerdo, a maior média de atividade ocorreu no músculo digástrico do lado 
esquerdo, enquanto que, durante o movimento para a direita, a maior média de atividade ocorreu na porção anterior do músculo temporal direito. Os resultados indicaram que os pacientes com desordens na ATM apresentam: 1) um leve aumento no tônus basal; 2) uma significativa redução da capacidade de apertamento e 3) uma inibição aparentemente paradoxal do músculo temporal anterior no lado mais afetado durante os movimentos em direção a este lado.

\section{c) Dor Muscular ou Articular Experimental e Atividade EMG durante o}

\section{Movimento}

Em 1996, SVENSSON; ARENDT-NIELSEN; HOUE79 realizaram dois experimentos. No primeiro, estudaram-se os efeitos sensoriais da dor. Provocou-se dor experimental por meio da injeção de $0,15 \mathrm{ml}$ de solução salina hipertônica (5\%) no interior do músculo masseter de 10 indivíduos do sexo masculino sem dor. A experiência sensorial foi descrita por meio de uma EAV de $100 \mathrm{~mm}$ e pelo questionário de dor de McGill (QDM). No segundo experimento, estudaram-se as interações entre dor nos músculos mandibulares e mastigação, em 13 indivíduos sem dor, do sexo masculino, distintos do primeiro grupo. Todos os indivíduos eram livres de sintomas de DTM. Verificaram-se quantitativamente os efeitos da dor sobre a mastigação deliberada unilateral, por meio de registros cinemáticos da mandíbula e de eletromiografia dos músculos mandibulares. A injeção de salina $5 \%$ levou a perfis de EAV e características do QDM similares. O deslocamento da mandíbula durante a mastigação dolorosa foi significativamente menor no eixo 
vertical $(10,0 \pm 11,5 \%, p<0,05 \%)$ e no eixo lateral $(22,6 \pm 20,9 \%, p<0,05)$ quando comparada aos valores da mastigação não dolorosa. A abertura média e as velocidades de fechamento da mandíbula foram significativamente reduzidas $(10,5$ $\pm 16,3 \%$ e $15,3 \pm 21,2, p<0,05) ;$ as distâncias acumuladas do movimento mandibular também foram significativamente menores durante a dor $(10,4 \pm 11,8 \%, p<0,05)$. A atividade eletromiográfica dos músculos agonistas durante a dor foi significativamente inferior no músculo masseter ipsilateral $(20,3 \pm 25,4 \%, p<0,05)$ quando comparada aos valores pré-dor. Os autores concluíram que as interações sensoriais-motoras podem ser explicadas por um efeito de facilitatório da atividade dos aferentes nociceptivos musculares sobre os interneurônios inibitórios do tronco encefálico durante a ação agonista. Assim, são gerados movimentos menos amplos e mais lentos, o que mais provavelmente representa uma adaptação funcional à dor muscular mandibular experimental.

O estudo de MATRE et al.51, em 1998, investigou o efeito da dor muscular experimental em humanos sobre o reflexo-H (Hoffman) e de estiramento como indicadores de alterações na sensibilidade dos fusos musculares. Participaram do estudos 14 voluntários do sexo masculino, sem dor. A dor muscular foi produzida por meio de infusão de salina hipertônica durante o período de 10-15 minutos no músculo sóleo e no músculo tibial anterior. Os reflexos foram elicitados no músculo sóleo relaxado e ativo (torque no tornozelo de 10 a $15 \mathrm{Nm}$ ) antes, durante e depois da dor muscular. As mensurações controle, foram feitas com infusões de salina fisiológica $(0,9 \%)$. Mediu-se a atividade eletromiográfica de superfície do músculo sóleo e o torque da articulação do tornozelo, para averiguar o reflexo de 
estiramento. Na presença de dor no músculo sóleo, a resposta reflexa de estiramento (torque no tornozelo) aumentou significativamente ( $p=0,0007)$, em comparação ao período antes da dor. Com dor no músculo tibial anterior, tanto a resposta mecânica quanto a resposta EMG aumentaram significativamente no músculo sóleo $(p=0,001 ; p=0,0003)$ em comparação ao período antes da dor. 0 reflexo-H não apresentou quaisquer alterações significativas durante as infusões em ambos os músculos. Esse estudo demonstrou um aumento relacionado à dor na amplitude dos reflexos de estiramento sem um aumento correspondente na amplitude do reflexo-H. Uma explicação pode ser um aumento na sensibilidade dinâmica dos fusos musculares durante a dor muscular causada por um aumento na taxa de disparo dos motoneurônios- $\gamma$ dinâmicos, evidenciado pelo aumento na resposta do reflexo de estiramento. Entretanto os dados podem não suportar o modelo do ciclo vicioso porque a excitabilidade dos motoneurônios alfa não foi alterada, evidenciado pela não alteração do reflexo-H.

Visando ampliar a compreensão acerca da influência da dor muscular sobre a atividade motora, SVENSSON; ARENDT-NIELSEN; HOUE 80 em 1998, realizaram um estudo com os seguintes objetivos: determinar o efeito da dor muscular experimental constante sobre a função motora mandibular, especificamente a mastigação ipsi e contralateral à infusão de solução salina hipertônica (5\%); estender a análise ao padrão mastigatório a um nível ciclo-a-ciclo e estudar a influência da dor muscular sobre a função motora isométrica dos músculos mastigatórios. Nesse estudo, a dor foi induzida no músculo masseter por meio da infusão tônica da solução salina em 12 homens sem dor. Antes, durante e 
após os períodos de dor muscular constante, analisou-se quantitativamente a mastigação por meio de traçado do movimento mandibular e de registros eletromiográficos dos músculos elevadores da mandíbula. Também foi monitorada a força oclusal voluntária máxima (FOVM). Os movimentos mandibulares e os dados eletromiográficos foram divididos em ciclos mastigatórios isolados e analisados ciclo-a-ciclo a fim de detectar e quantificar a variabilidade interciclo. Em todos os indivíduos, a infusão tônica causou uma dor profunda localizada de intensidade clínica relevante (EAV média \pm DP, 46,00 $\pm 3 \mathrm{~mm})$. A FOVM foi afetada de forma significativa pela dor muscular ( $p<0,0005)$, com valores significativamente inferiores durante a dor em comparação aos períodos pré e pós dor $(p<0,05)$. Em um número significativo de ciclos mastigatórios, a atividade eletromiográfica média de todos os músculos elevadores da mandíbula diminuiu durante sua função agonista ipsi e contralateral à dor $(p<0,05)$. Essas mudanças eletromiográficas são provavelmente um reflexo do padrão natural de recrutamento bilateral dos músculos elevadores da mandíbula durante a mastigação. Não foram detectadas alterações significativas nos movimentos mandibulares durante a mastigação dolorosa por meio do dispositivo de traçado mandibular. Os autores concluíram que a dor experimental nos músculos mandibulares levou à redução de sua capacidade de trabalho contra carga, o que está de acordo com uma adaptação funcional à dor muscular. Provavelmente, a finalidade biológica dessa adaptação é permitir o reparo da área traumatizada. 


\section{d) Dor Muscular ou Articular Clínica e Atividade EMG Durante o Movimento}

Sobre a etiopatogenia da disfunção temporomandibular, YEMM ${ }^{89}$, em 1985, em sua discussão, relata que a hipótese de que alguns músculos do sistema mastigatório estariam continuamente ativos, devido a espasmos, gerando dor isquêmica, não encontrou suporte científico em estudos eletromiográficos. 0 autor cita estudos que demonstraram aumento da atividade muscular dos músculos elevadores da mandíbula durante a abertura em pacientes com DTM, e que essa atividade é máxima quando o paciente alcança o grau de abertura em que a dor se inicia, sugerindo que essa seria uma forma de reação protetora. Acrescenta que isso ocorre bilateralmente nos músculos masseter e temporal, mesmo quando apenas um músculo (geralmente o masseter) de um dos lados está clinicamente afetado. O autor discute ainda o papel do bruxismo noturno e diurno, do estresse emocional, do macrotrauma, das alterações oclusais e da alteração da atividade muscular sobre a etiologia da disfunção temporomandibular, e conclui que os componentes do sistema mastigatório, em particular os músculos, e aqueles associados com a ATM são susceptíveis à cargas excessivas provenientes de um padrão mastigatório alterado pela oclusão e/ou de hábitos parafuncionais (devido ao estresse emocional).

Em 1986, CLARK; LYNN14 registraram e compararam três parâmetros do movimento mandibular (magnitude, reprodutibilidade e velocidade) no plano horizontal de 20 indivíduos controle (não-pacientes) e de 20 pacientes que procuraram tratamento para DTM. Na primeira parte do estudo observou-se a 
extensão do movimento mandibular no plano horizontal por meio de um dispositivo de traçado do movimento mandibular. Executaram-se os movimentos lateral direito completo, lateral esquerdo completo e protrusivo completo, três vezes cada. Foi realizada, previamente ao registro, uma sessão de treino de reprodutibilidade dos movimentos com feedback visual da trajetória do movimento. A sessão de registro foi então realizada sem o feedback visual. A reprodutibilidade do movimento foi expressa como a razão entre o comprimento e largura máximos dos movimentos superpostos para cada excursão. Os dados eram derivados da medida tanto das distâncias máximas de excursão mandibular quanto da reprodutibilidade do movimento. O grupo controle e o grupo com DTM não diferiram de maneira significativa com relação à magnitude dos movimentos, tanto em lateralidade quanto em protrusão. Mas os indivíduos normais apresentaram uma velocidade retrusiva maior do que os indivíduos com DTM. A habilidade dos pacientes com DTM realizar com precisão os movimentos laterais direito e esquerdo foi marcadamente reduzida.

STOHLER; ASHTOWN-MILLER; CARLSON76, em 1988, estudaram o padrão de mastigação habitual de 12 indivíduos dentados com sintomatologia de dor e disfunção articular e muscular e 12 indivíduos saudáveis controle. Executou-se o registro eletromiográfico bilateral dos músculos elevadores e dos movimentos mandibulares durante três seqüências mastigatórias completas. Utilizou-se análise computadorizada para classificar os movimentos mastigatórios como contínuos ou descontínuos. Embora ciclos mastigatórios descontínuos tenham sido significativamente mais freqüentes durante a função dolorosa $(p=0,001)$, eles 
também ocorreram durante a função livre de dor, o que reduz seu valor de diagnóstico. Quando usados como antagonistas, como durante a abertura mandibular, os músculos elevadores apresentaram atividade com maior pico médio durante a função dolorosa do que não dolorosa $(p=0,0001)$.

WARE; RUGH86, em 1988, procuraram correlacionar a severidade do quadro clínico de pacientes com queixas de dor de disfunção temporomandibular à peculiaridades do bruxismo noturno, tais como o estagiamento. Os autores selecionaram três grupos de pacientes: Grupo 1) chamado de grupo destrutivo, consistia de cinco pacientes do sexo feminino, com idade entre 24 e 33 anos. Os pacientes apresentavam queixas de severa dor na ATM e músculos mastigatórios, provavelmente causadas por bruxismo crônico relacionado ao sono. Todas as pacientes exibiam excessivo desgaste dentário e dor. A presença do bruxismo nesse grupo foi confirmada por meio de monitoramento eletromiográfico do músculo masseter por meio de unidade eletromiográfica portátil. Todas as pacientes também apresentavam sinais de depressão. Duas pacientes estavam livres de medicação e as demais tomaram alguma medicação apenas na manhã antes da avaliação. Grupo 2) constituído de pacientes portadores de bruxismo (diagnosticado por meio da unidade eletromiográfica portátil), porém sem sinais ou sintomas de DTM. Os pacientes apresentavam queixa de insônia e excessiva sonolência diurna e seis estavam livres de medicação. A maioria apresentava diagnóstico de insônia psicosocial ou apnéia. Com idades entre 21 e 55 anos. Grupo 3) Grupo controle, constituído de 35 pacientes do sexo feminino com depressão, porém livres de medicação e sem queixas de bruxismo. A idade das pacientes variava de 25 a 38 
anos. Apenas a primeira noite de exame foi analisada e a atividade de bruxismo foi medida por um técnico experiente como parte dos registros de rotina da polissonografia. Como resultados, os autores verificaram a baixa ocorrência de bruxismo no grupo 3 (com depressão) em comparação aos demais grupos. 0 grupo 1 (bruxismo destrutivo) e o grupo 2 (bruxismo não destrutivo) não diferiram, exceto quanto à quantidade de eventos de bruxismo na fase REM do sono. 0 grupo 1 apresentou o número e a duração dos episódios de bruxismo significativamente maior durante o estágio REM do sono do que o grupo 2. Os grupos 2 (bruxismo não destrutivo) e 3 (com depressão) não diferiram quanto aos episódios de bruxismo na fase REM do sono. O número de bursts fásicos por episódio não variou significativamente entre os grupos em qualquer estágio do sono, nem o padrão de bruxismo (fásico, tônico-fásico e fásico-tônico) variou entre os grupos. 0 padrão fásico foi o predominante entre os grupos.

LUND et al. ${ }^{48}$, em 1991, questionaram a hipótese de que a disfunção (hiperatividade ou espasmos musculares) característica nos vários quadros de dores musculares crônicas (por exemplo, a disfunção temporomandibular) seja a causa da dor; propondo tratar-se a disfunção de um mecanismo adaptativo normal de proteção. Os autores discutem a relação dor-hiperatividade muscular em 5 condições: fibromialgia, dor mio-fascial, dor crônica na região lombar e cefaléia tensional. Atribui-se essa hiperatividade a várias causas, sendo as mais comuns, a fadiga ou a sobrecarga funcional, anormalidades estruturais e estresse emocional. Os autores expõem a teoria de Travell83, sobre a conversão de uma condição aguda em crônica, a qual hipotetiza que a dor e a hiperatividade estão reciprocamente 
ligadas: os espasmos musculares causando dor, que por sua vez, reforça a disfunção, compondo um "ciclo vicioso" auto perpetuante. Os autores apresentam evidências de que, embora a dor provoque pequenas mudanças na atividade postural dos músculos, ela modifica a performance muscular reduzindo a ação dos músculos agonistas e aumentando o nível de contrações dos antagonistas. Os autores criticam a parcela de estudos que vinculam a dor à hiperatividade muscular após análises de grupos de pacientes sem correspondência quanto ao sexo e à idade, lembrando que esses dois aspectos exercem efeito significativo sobre os níveis da atividade eletromiográfica de repouso. Acrescentou-se que, embora eventualmente tenha sido provado que pacientes com cefaléia apresentam pequenos aumentos nos níveis eletromiográficos dos músculos da cabeça e do pescoço, isso não é evidência suficiente de que a "hiperatividade" seja a causa da dor. Os autores atribuem, mais provavelmente, a uma resposta geral do paciente à dor, parte da responsabilidade pela hiperatividade muscular, o que inclui mudanças na expressão facial e na postura da cabeça. Há evidências de que se pode distinguir um paciente com dor crônica pela postura de seu corpo, gestos e expressões faciais. E ainda, indivíduos com dor lombar crônica, apresentaram maiores níveis de "comportamentos de dor" durante o caminhar do que o grupo controle, incluindo contrações dos músculos faciais. Também se encontrou evidência de que esses pacientes apresentam níveis eletromiográficos dos músculos anteriores significativamente maiores, tanto no repouso quanto durante o movimento, do que o grupo controle com correspondência de idade. No mesmo artigo, os autores explicam que a dor associada a condições como bruxismo e síndrome das pernas inquietas possa ser tipos de fadiga pós-exercício. A natureza crônica dessas dores 
pode ser devido à repetição periódica do trauma, visto que a dor e o cansaço que ocorrem, um ou dois dias após uma única sessão de novos exercícios, raramente permanecem por mais do que poucos dias. Os autores concluem que há evidências de que a dor não causa hiperatividade muscular e de que sua capacidade de contração máxima é reduzida, e não aumentada pela dor. A única situação em que a atividade EMG parece estar mais alta do que o normal, na presença de dor crônica, é quando um músculo age como antagonista. Os autores propõem a hipótese de que isso trate-se de um reflexo adaptativo útil na limitação da amplitude e velocidade do movimento, o que, provavelmente, reduz dano e dor adicionais.

MENSE52, no mesmo ano, explica os mecanismos envolvidos na neurobiologia da dor muscular crônica. Dentre esses mecanismos o autor cita alguns ciclos viciosos, os quais exercem um importante papel na perpetuação da transmissão de mensagens nociceptivas. Ressalta, entretanto, que os mecanismos exatos pelos quais esses ciclos operam não são totalmente conhecidos, podendo ocorrer tanto nos tecidos periféricos quanto no sistema nervoso central. Sabe-se que um importante aspecto desse conceito é que o SNC é capaz de influenciar o comportamento de resposta dos nociceptores periféricos, por meio da alteração das condições sob as quais estes operam. 0 autor explica como se dá um dos ciclos viciosos mais debatidos na literatura: o que se origina nos nociceptores da musculatura (ou nos nociceptores das articulações e mecanoceptores) e que, supostamente, levaria a espasmos musculares crônicos. O ciclo funcionaria da seguinte maneira: uma lesão dolorosa excita as fibras aferentes nociceptivas (fibras 
III e IV) do músculo, essas fibras ativam os motoneurônios- $\gamma$, os quais aumentam a taxa de descarga elétrica nos fusos musculares. Isso leva ao estímulo das fibras aferentes primárias dos fusos musculares (fibras la), as quais estabelecem conexão monosináptica com os motoneurônios- $\alpha$, estimulando-os, o que leva à contração muscular. Portanto, uma lesão dolorosa do músculo, supostamente induziria a um mioespasmo no músculo afetado, o que por sua vez, levaria à isquemia devido à compressão dos vasos sangüíneos. Sabe-se que contrações isquêmicas são dolorosas e ativam nociceptores musculares, fechando, dessa forma, o mecanismo de ciclo vicioso. Nessa revisão de literatura, em seguida a essa explicação, o autor cita um experimento em que se testou esse conceito em animais experimentais. Utilizaramse gatos anestesiados e, por meio da infiltração de carragina no músculo gastrocnemius-soleus (GS) dos mesmos, provocou-se inflamação. Registrou-se a atividade dos motoneurônios- $\gamma$ que inervavam o músculo inflamado. Em contraste com o conceito acima descrito, observou-se menor atividade $\gamma$ nos músculos inflamados do que nos músculos que não sofreram a inflamação experimental. Concluiu-se que a miosite inibiu a atividade $\gamma$ nos músculos inflamados e que, se os motoneurônios- $\gamma$ comportarem-se de maneira similar nos pacientes com dor, esses resultados podem oferecer uma explicação para a fraqueza sentida em músculos inflamados e, possivelmente, para os fracos reflexos e a atrofia dos músculos que agem sobre uma articulação com artrite. Logo, os espasmos musculares presentes nos pacientes que sofrem de dor profunda não puderam ser explicados de forma inequívoca pelos mecanismos neurofisiológicos. 
SPILKER74, em 1991, explica que muitos tipos de relação podem ser observados entre duas condições. Por exemplo, quando se trata de um relacionamento de causa-e-efeito direto ou indireto, na verdade, devido à presença de subjetividade, tal relação pode não existir efetivamente, até o ponto em que pode ser possível a não existência de nenhum tipo de relação entre ambas, sendo estas, portanto, completamente independentes. Logo, a fim de perscrutar o tipo de relacionamento existente entre bruxismo do sono e DTM, dever-se-ia eliminar toda subjetividade, erro e influências que possam confundir a análise.

Devido às recentes evidências experimentais sugerindo que dor muscular nem sempre causa hiperatividade no ser humano, LAVIGNE et al.41, em 1997, resolveram investigar a influência da dor sobre a atividade de bruxismo do sono. As medidas das variáveis oromotoras (burst/episódio; episódio/hora) foram comparadas entre dois subgrupos de bruxômanos: 1) 6 pacientes ( 3 homens e 3 mulheres, com idade média de 25,3 anos $\pm 3,6$ ), cuja queixa principal era bruxismo do sono e relatos de dor (não mio-fascial) nos músculos mastigatórios; 2) 7 indivíduos (5 homens e 2 mulheres, com idade média de 27,3 \pm 4,8) com bruxismo sem nenhuma dor. Todos os participantes passaram por duas noites consecutivas de exame polissonográfico, sendo a primeira para o condicionamento do paciente ao ambiente e para a coleta de dados que pudessem excluí-lo. Antes e após da segunda noite, na qual seria realizada a coleta de dados para análise, os pacientes registravam seus índices de dor em uma EAV de 100mm. Enquanto os indivíduos sem dor registraram valores de EAV iguais a zero, os indivíduos com dor marcaram índices médios de 36,7 $\pm 28,2 \mathrm{~mm}$, antes de dormirem e 44,0 $\pm 28,3 \mathrm{~mm}$ ao 
amanhecer. A fim de evitar que fatores como dor crônica pudessem afetar os resultados, foram excluídos pacientes com dor mio-fascial, fibromialgia ou qualquer desordem temporomandibular artrogênica. Os resultados mostraram que, na presença de dor (não-mio-fascial) encontrou-se um número de episódios/hora 40\% menor, do que nos indivíduos sem queixa de dor. Os autores, entretanto, recomendaram cautela na interpretação desses resultados devido ao reduzido tamanho da amostra e sugeriram ainda investigações sobre a natureza do relacionamento entre bruxismo (e suas características, episódios fásicos ou tônicos) e a dor muscular, incluindo estudos com dor experimental ou experiências de multicentros colaboradores.

Não obstante a literatura científica apresente sérias críticas e contestações ao relacionamento direto entre bruxismo e DTM. LOBBEZZO; LAVIGNE45, em 1997, enfatizam que, quando da avaliação da existência de relação de causa-e-efeito entre duas entidades biológicas, os fatores de subjetividade deveriam ser diminuídos até o ponto de não serem percebidas, embora admitam a impossibilidade de sua completa eliminação (ou seja, 100\% de certeza), sugerindo que se busque a maior probabilidade de segurança possível. Os autores indicam portanto, a adoção de um modelo de estudo duplo-cego, a fim de minimizar o erro e a tendência. Indicam também que, deve-se buscar estabelecer uma associação consistente, ou seja, o maior grau de reprodutibilidade possível entre os experimentos, bem como uma relação temporal onde a causa preceda o efeito. Sugerem ainda, a observação de um gradiente dose-resposta positivo, no qual, quanto mais intensa ou presente for a causa, mais forte será o efeito. E, por fim, 
acrescentam que a associação deve apresentar concordância com os achados epidemiológicos e especificidade, ou seja, o efeito não poderá ocorrer sem que a causa tenha acontecido previamente. Os autores resumiram os critérios de estabelecimento de relação causa-e-efeito (modificados de SPILKER ${ }^{74}$, 1991) em: 1) ausência de subjetividade, erro ou influências que possam confundir a análise; 2) estabelecimento de uma associação consistente; 3) relação temporal onde a causa preceda o efeito; 4) presença de gradiente dose-resposta; 5) concordância com achados epidemiológicos e 6) especificidade da associação.

Em 2001, ARIMA; ARENDT-NIELSEN; SVENSSON³ realizaram um estudo com o objetivo específico de avaliar o efeito da dor e do desconforto (clínicos e experimentais) dos músculos mandibulares sobre a atividade motora orofacial do sono. Vinte indivíduos saudáveis com idades entre 21 e 31 anos participaram desse estudo. Todos tinham ciência de seus sinais e sintomas de atividade motora orofacial durante o sono e foram subdivididos em um grupo com queixas de dor clínica $(n=5)$ e um grupo sem dor $(n=7)$. Todos os indivíduos dormiram em um laboratório por 3 noites consecutivas, incluindo uma noite de adaptação, uma noite de registro inicial e uma noite experimental. Foram realizados durante o sono, 0 EEG e a EMG dos músculos masséteres. Na noite experimental, antes de dormir, todos os indivíduos receberam uma injeção de capsaicina $(0,1 \mathrm{ml}, 100 \mu \mathrm{g} / \mathrm{ml})$ no músculo masseter que apresentou maior atividade EMG durante os registros prévios. Os eventos de atividade motora orofacial e os episódios foram quantificados e comparados entre as noites de registro inicial e experimental. A cada noite e manhã durante o período de estudo, os indivíduos atribuíram valores 
de intensidade de dor, desconforto e sensibilidade em escalas de análise visual e também foram medidos o limiar de dor nos músculos masséteres e a força de CVM. Os resultados demonstraram que a injeção de capsaicina antes do sono não causou diferenças significativas entre os grupos na intensidade do pico de dor na EAV. Nem o limiar de dor nem a CVM apresentaram quaisquer diferenças significativas entre os grupos, entre o lado que recebeu e o que não recebeu a injeção ou entre as noites e as manhãs das noites de registro inicial e experimental. 0 número de episódios EMG por hora de sono, o número de bursts por hora de sono e a área total de todos os bursts e episódios durante a noite de registro inicial foram significativamente maiores nos indivíduos sem dor do que nos indivíduos com dor. Entretanto, a injeção de capsaicina não causou qualquer alteração significativa nesses parâmetros. Os autores concluíram que um estímulo doloroso agudo antes de dormir não exerce qualquer efeito sobre a atividade motora orofacial do sono, mas esse estudo confirmou achados prévios de que a dor e o desconforto estão associados a uma menor atividade EMG dos músculos mastigatórios.

SVENSSON; GRAVEN-NIELSEN81, em 2001, revisaram a literatura em que a dor muscular craniofacial era induzida por técnicas experimentais em animais e em voluntários humanos, e os efeitos somatosensoriais e motores da dor eram verificados sob condições padronizadas. Os autores comparavam essas situações às situações de dor clínica, descritas e avaliadas em vários estudos transversais de pacientes com dor muscular craniofacial. Os estímulos de dor foram classificados em endógenos (tais como atividade parafuncional ou exercício) e exógenos (por exemplo, infusão de salina hipertônica) e foram descritos, além dos efeitos 
somatosensoriais, os efeitos motores em diferentes modalidades: a atividade motora postural ou de repouso, a contração muscular estática (CVM) e a atividade muscular dinâmica (mastigação) Verifica-se, claramente, que a dor muscular induz a significativos efeitos tanto na função motora craniofacial quanto na função somatosensorial. Primeiro, com relação ao estímulo endógeno, verificou-se que condições de carregamento mecânico pesado com insuficientes períodos de relaxamento, produzem dor muscular, provavelmente por isquemia; que sessões de apertamento dental sustentado ou estático repetido em diferentes posições mandibulares podem levar à intensa dor nos músculos mandibulares com um rápido início, mas, cessado o apertamento, a dor logo desaparece. Depois, avaliando-se as interações somato-motoras de pacientes com dor experimental e clínica, os autores concluíram que a dor dos músculos mandibulares de um nível clinicamente relevante tem pouco ou nenhum efeito sobre a atividade EMG postural dos músculos elevadores da mandíbula; que a atividade EMG máxima e a força oclusal voluntária máxima (FOVM) em pacientes com dor muscular craniofacial são reduzidas em comparação a indivíduos controle; que a função motora dinâmica é alterada pela presença de dor e ainda, que o principal efeito da dor muscular seria a redução dos bursts EMG agonistas e a facilitação dos bursts EMG antagonistas, o que poderia levar a movimentos mais lentos e menos amplos. Isso pode levar a um reparo mais rápido e à minimização do dano ao sistema. Finalmente, a literatura revisada demonstrou que a função motora craniofacial é principalmente inibida durante a dor muscular experimental, mas com excitação fase-dependente durante a mastigação, redução da amplitude e dos movimentos mandibulares. Os mecanismos neurobiológicos subjacentes provavelmente envolvem combinações 
variadas de sensitização dos aferentes periféricos, hiperexcitabilidade dos neurônios centrais e desequilíbrio dos sistemas de modulação de dor. Acrescentando-se que os circuitos reflexos no mesencéfalo parecem importantes para o ajuste das funções sensoriais-motoras na presença da dor craniofaicial, devendo, portanto a função motora e somato-sensorial serem vistas como conseqüências da dor e não como fatores que levam à dor.

Em 2002, baseando-se na premissa de que o espasmo dos elevadores da mandíbula é uma das causas da limitação de abertura mandibular, YAMAGUCHI et al.88 examinaram se havia diferenças entre a atividade EMG dos músculos de fechamento da mandíbula durante a abertura mandibular em pessoas saudáveis e em pacientes com espasmos do músculo masseter, sem história de trauma ou infecção. 0 grupo de pacientes consistiu de 11 mulheres (18-62 anos de idade) sem nenhuma história de trauma ou infecção, com limitação de abertura de boca devido a espasmo no músculo masseter. O grupo controle incluiu 11 mulheres saudáveis (23-50 anos de idade). A atividade EMG foi registrada bilateralmente na porção central do músculo masseter, na porção anterior do músculo temporal e no ventre anterior do músculo digástrico. Nove das 11 pacientes apresentaram atividade EMG óbvia no músculo masseter durante a abertura da boca, o que foi tipicamente diferentes dos padrões EMG exibidos durante a abertura da boca de até $40 \mathrm{~mm}$ do grupo controle. Dentre as 9 pacientes, 8 apresentaram contrações dos músculos temporal e masseter, quando atuando como antagonistas. 0 valor da média integral da atividade dos músculos masseter e temporal durante a abertura da boca dos pacientes foi significativamente superior ao do grupo controle 
$(p<0,01)$. Esses resultados sugerem que a atividade EMG dos músculos elevadores da mandíbula, durante a abertura, em pacientes com espasmos musculares sem história de trauma ou infecção é diferente da atividade de pacientes saudáveis. 
PROPOSIÇÃO 


\section{3 - PROPOSIÇÃo}

O presente estudo visa a:

1) Verificar a presença de associação entre a ocorrência de bruxismo do sono e a presença de sinais e sintomas de Disfunção Temporomandibular.

2) Verificar a presença de correlação entre a atividade parafuncional realizada durante uma noite de exame polissonográfico e a intensidade da dor na manhã seguinte, por meio de Escala de Análise Visual.

3) Verificar as diferenças entre a atividade rítmica dos músculos mastigatórios (ARMM) de indivíduos com e sem Disfunção Temporomandibular.

4) Verificar a presença dos seguintes requisitos para o estabelecimento de uma relação de causa e efeito entre bruxismo do sono e sinais e sintomas de DTM: a) associação consistente; b) relação temporal e c) gradiente dose-resposta.

5) Verificar a confiabilidade do exame físico associado a um questionário específico em se diagnosticar a presença de bruxismo ativo nos pacientes. 
MATERIAL E MÉTODOS 


\section{4 - MATERIAL E MÉTOdOS}

\subsection{ESTABELECIMENTO DOS GRUPOS}

Todos os participantes assinaram o termo de consentimento livre e esclarecido (Anexo 3), após a leitura da carta de informação ao paciente sobre todos os procedimentos a serem realizados (Anexo 2). Este estudo recebeu a aprovação do Comitê de Ética em Pesquisa da Faculdade de Odontologia de Bauru, Universidade de São Paulo, e encontra-se protocolado pelo número 021/2002 (Anexo 1)

O grupo experimental (GE) foi composto por 20 pacientes com DTM, acompanhados na Clínica de Tratamento de Disfunção Temporomandibular da Faculdade de Odontologia de Bauru, Universidade de São Paulo e no Instituto de Ensino Odontológico - IEO, Bauru, SP. Os pacientes foram selecionados por meio de um questionário sobre seus sintomas e histórico associado a uma extensa entrevista e a um exame físico.

Os pacientes do GE realizaram exames de radiografia para complementação do diagnóstico e observação dos critérios de exclusão. (LOBBEZOO-SCHOLTE et al. $\left.{ }^{46}, 1995\right)$.

O grupo controle (GC) foi composto por 19 indivíduos saudáveis, sem DTM. Contou-se com a participação voluntária de estudantes de odontologia da Faculdade de Odontologia de Bauru - Universidade de São Paulo. A seleção foi 
realizada por meio de um questionário sobre seus sintomas, histórico associado a uma extensa entrevista e a um exame físico.

\subsection{CRITÉRIOS DE INCLUSÃO E EXCLUSÃO}

\subsubsection{Critérios de exclusão iniciais}

Utilizaram-se os seguintes critérios de exclusão para todos os participantes da pesquisa (baseados nos critérios sugeridos pela AADS (LAVIGNE; ROMPRÉ; MONTPLAISIR42, 1996): apresentação de dois ou mais dentes perdidos (excluindo-se os terceiros molares); utilização de prótese dental removível; presença de má-oclusão grosseira, especificamente, mordida aberta anterior, mordida cruzada unilateral, sobrepasse horizontal (overjet) maior que $6 \mathrm{~mm}$ e interferência no arco de fechamento que provocasse um deslize de RC para MIH maior do que 5mm (características oclusais de risco, de acordo com PULLINGER et al. 64,1993$)$. Esses critérios visaram à exclusão de fatores que pudessem predispor o paciente a DTM, para uma maior objetividade do estudo. Eram critérios de exclusão: a utilização de medicação e/ou dispositivos com possíveis efeitos sobre a atividade motora durante o sono, tais como benzodiazepínicos, L-dopa, neurolépticos e antidepressivos-tricíclicos); abuso de álcool ou drogas; ou utilização de placa intermaxilar, (KATO et al. ${ }^{38,2001) ; ~ a p r e s e n t a c ̧ a ̃ o ~ d e ~ g r a n d e s ~}$ desordens neurológicas, psiquiátricas ou de movimento (KATO et al. ${ }^{38,} 2001$ e KATO et al. $\left.{ }^{37}, 2001\right)$, por ex.: atividade indicadora de epilepsia (epileptiforme) no EEG ou mal de Parkinson; relato de mioclonia cervical, narcolepsia, insônia, movimentos periódicos das pernas ou apnéia do sono. 
Com relação às desordens de sono ou motoras menos evidentes, procurou-se selecionar os participantes inicialmente por meio do questionário e entrevista iniciais. Entretanto, se qualquer dos eventos acima ocorressem durante o exame polissonográfico, o indivíduo seria excluído da pesquisa. Utilizaram-se os seguintes critérios: para movimento periódico das pernas, um índice superior a 20 eventos por hora de sono e para apneia do sono, mais de 5 eventos por hora de sono (KATO et al37, 2001) (Anexo 4).

Após o questionário e entrevista iniciais, se os indivíduos não apresentassem qualquer das desordens acima, era realizado o exame clínico específico de DTM:

\subsubsection{Critérios de inclusão e exclusão para Grupo Experimental}

Como critério de inclusão inicial, os pacientes deveriam apresentar como queixa principal, a dor e/ou a disfunção temporomandibular. Seguindo a recomendação de GREENE; MARBACH ${ }^{32}$, indivíduos com sinais e sintomas de DTM, mas sem motivação para a busca de tratamento não foram considerados doentes e, portanto não foram incluídos na pesquisa.

De acordo com os critérios de inclusão e de exclusão descritos (e recentemente publicados) pela Academia Americana de Dor Orofacial - AADO1 ${ }^{1}$ ), os pacientes foram selecionados para o grupo experimental (com DTM) se apresentassem um quadro de dor e disfunção característico de um dos subtipos de DTM: 


\subsubsection{DTM predominantemente articular:}

Critérios de inclusão: 1) quadro clínico de deslocamento de disco com redução: estalido recíproco na ATM (que ocorra a uma distância interincisal maior que pelo menos $5 \mathrm{~mm}$ na abertura do que no fechamento), reproduzível em duas de três tentativas consecutivas e que seja eliminado durante a abertura em protrusão, podendo estar acompanhado de desvio da trajetória mandibular durante a abertura; 2) quadro clínico de deslocamento de disco sem redução com limitação de abertura: abertura máxima não assistida menor ou igual a $35 \mathrm{~mm}$, deflexão mandibular e ausência de ruídos articulares; 3) quadro clínico de artralgia: dor espontânea e/ou à palpação na ATM (aspectos lateral e/ou medial). 23

Critérios de exclusão: pronunciados sinais e/ou sintomas de DTM miogênica, ou estalido assintomático, ou evidência radiográfica de patologia articular.

\subsubsection{DTM predominantemente muscular:}

Critérios de inclusão: dor intermitente ou crônica na região dos músculos mastigatórios, e/ou dor na região dos músculos durante o exame funcional, e/ou palpação muscular.

Critérios de exclusão: pronunciados sinais e/ou sintomas de DTM artrogênica, ou evidência radiográfica de patologia articular.

\subsubsection{DTM Mista:}

Critérios de inclusão: pronunciados sinais e/ou sintomas de mais de um subgrupo de diagnóstico. 


\subsubsection{Critérios de inclusão para Grupo controle}

Ausência de qualquer sinal e/ou sintoma de DTM e idade e sexo apropriados a compor um quadro proporcionalmente semelhante à distribuição do GE.

\subsection{APLICAÇÃO DOS QUESTIONÁRIOS E REALIZAÇÃO DOS EXAMES CLÍNICO E RADIOGRÁFICO}

\subsubsection{Primeira Etapa (Examinador 1)}

Direcionada à investigação e diagnóstico de DTM (para o grupo experimental), bem como a exclusão de sinais e sintomas de DTM (para o grupo controle).

\section{a) O questionário de DTM:}

No questionário utilizado na entrevista, foram coletados os dados pessoais do paciente; histórico, constando de queixa principal, histórico da doença atual, histórico médico e odontológico além da história pessoal do paciente; relatos de sintomas de DTM, tais como ruídos articulares e abertura limitada da boca; queixas relacionadas à região da cabeça e do pescoço, descrição de aspectos quantitativos e qualitativos de dor de cabeça, na região do pescoço e ombros, bem como fatores de saúde geral (Anexo 6). Constava ainda, o motivo pelo qual o paciente decidiu procurar o tratamento, uma vez que, foi considerado um critério de exclusão a não motivação do próprio paciente pelo alívio de seus sintomas, a fim de se eliminarem do estudo pacientes que por ventura apresentassem sinais e 
sintomas de DTM mas que não se sentissem incomodados pelos mesmos, não se podendo considerá-los, portanto, doentes (GREENE; MARBACH ${ }^{32}, 1982$ ).

\section{Questionário de avaliação objetiva.}

Os participantes marcavam seu nível de dor em uma escala de análise visual.

Em seguida, preencheram um questionário de índice de DTM, composto por 10 perguntas, que permitiu a classificação do caso em relação ao grau de disfunção (Anexo 5):

1. Você sente dificuldade de abrir a boca?

2. Você sente dificuldade de movimentar sua mandíbula para os lados?

3. Você sente desconforto ou dor muscular quando mastiga?

4. Você sente dores de cabeça com freqüência?

5. Você sente dores no pescoço e/ou ombros?

6. Você sente dores de ouvido ou próximo a ele?

7. Você percebe algum ruído na ATM?

8. Você considera sua mordida "anormal"?

9. Você usa apenas um lado de sua boca para mastigar?

10. Você sente dores na face ao acordar?

Foram oferecidas três possibilidades de resposta: SIM, NÃO e ÀS VEZES. Cada "sim" recebeu o valor 2 , cada "às vezes" recebeu o valor 1 e cada "não" recebeu o valor 0 . As questões 4, 6 e 7 receberam valor 3 para cada resposta "sim" se correspondessem a sintomas bilaterais ou intensos, valor 2 , se correspondessem 
a sintomas unilaterais ou leves; receberam valor 1 para a resposta "às vezes" e valor 0 para a resposta "não" (CONTI15, 2000).

O somatório dos valores obtidos permitiu a classificação da amostra em relação ao grau de disfunção temporomandibular em:

Valores de 0a 3: não portador de DTM

Valores de 4 a 8: portador de DTM leve

Valores de 9 a 14: portador de DTM moderada

Valores de 15 a 23: portador de DTM severa.

Em seguida, foi preenchida uma ficha de exame físico de DTM.

\section{b) O exame físico de DTM:}

Foram realizadas inspeção intra e extra oral incluindo hábitos posturais e assimetrias. Exame funcional do sistema mastigatório, consistindo de análise da abertura (extensão e trajetória), palpação articular (aspectos lateral e posterior) e muscular (músculo temporal - porções anterior, média e posterior; masseter origem, corpo, inserção; esternocleidomastóideo e trapézio superior); além da observação da presença de ruídos (estalido e crepitação) (Anexo 6).

O examinador 1, o qual realizou toda a Primeira Etapa desta pesquisa, realizou calibração prévia da pressão a ser exercida durante o exame de palpação, por meio do algômetro, estabelecendo-se pressão digital de aproximadamente 1,0kg para a palpação articular e 1,5kg para a palpação muscular. 
O exame físico era complementado pela análise da radiografia panorâmica, a fim excluir patologias dento alveolares que pudessem causar sintomatologia dolorosa facial.

Foram, dessa forma, selecionados 39 indivíduos, dos quais 20 eram pacientes de DTM (12 mulheres e 8 homens) e 19 indivíduos saudáveis (11 mulheres e 9 homens). Devido ao fato de essa não ser a amostra definitiva, visto que alguns indivíduos não compareceram para a realização do exame e outros foram excluídos posteriormente ao exame polissonográfico, não foi descrita, até o momento, a idade média dos mesmos.

\subsubsection{Segunda etapa (examinador 1,2 e 3 )}

Destinada a investigar sinais de bruxismo do sono. Constou de um questionário e exame físico específicos para o diagnóstico de bruxismo ativo, aplicado por três diferentes examinadores. 0 diagnóstico clínico de bruxismo foi estabelecido, tomando-se aquele que prevaleceu, dentre os três examinadores.

\section{a) Questionário de bruxismo}

O questionário constou de 1) relato anamnésico de acordar durante a noite apertando ou rangendo os dentes (modificado do questionário sugerido por MOLINA et al.58, 1999); relato de fadiga ou dor nos músculos mastigatórios, ao acordar (LAVIGNE; ROMPRÉ; MONTPLAISIR ${ }^{42}$, 1996); relato de acordar durante a noite ou pela manhã com as articulações temporomandibulares travadas e/ou 
desconforto nos dentes ao acordar além de história nos últimos 2 meses de deslocamento repetido de restaurações definitivas (modificado de MOLINA et al. ${ }^{58}$, 1999) (Anexo 7).

A fim de reforçar a confiança no diagnóstico clínico, foi entregue a cada participante um calendário para que o mesmo e/ou um acompanhante de quarto, marcasse as noites em que houve apertamento ou ranger de dentes. Esse acompanhamento deveria ser devolvido após o período mínimo de três meses.

\section{b) Exame físico de bruxismo}

Constou de: 1) observação de desgaste dentário (facetas coincidentes) ou pontos brilhantes nas restaurações e/ou hipertrofia muscular do masseter com palpação digital (considerada positiva se o volume do músculo triplicar com apertamento voluntário em máxima intercuspidação habitual - LAVIGNE; ROMPRÉ; MONTPLAISIR ${ }^{42}$, 1996) (Anexo 7). 


\subsection{POLISSONOGRAFIA}

Em seguida, todos os pacientes foram encaminhados à realização do exame de Polissonografia, no Instituto de Medicina do Sono - Dr. Alberto Luiz Moura dos Santos, a fim de se verificar a ocorrência do hábito do bruxismo do sono e suas características.

Realizou-se o exame polissonográfico em uma noite, para cada paciente, em um quarto com temperatura controlada e sons atenuados ${ }^{42}$ (Figura 1). Os registros do sono iniciaram-se a $23,93 \mathrm{~h}( \pm 0,78 \mathrm{~h})$ em média e tiveram uma duração de 6,57h $( \pm 0,64 \mathrm{~h})$, finalizando aproximadamente à 6,0h.

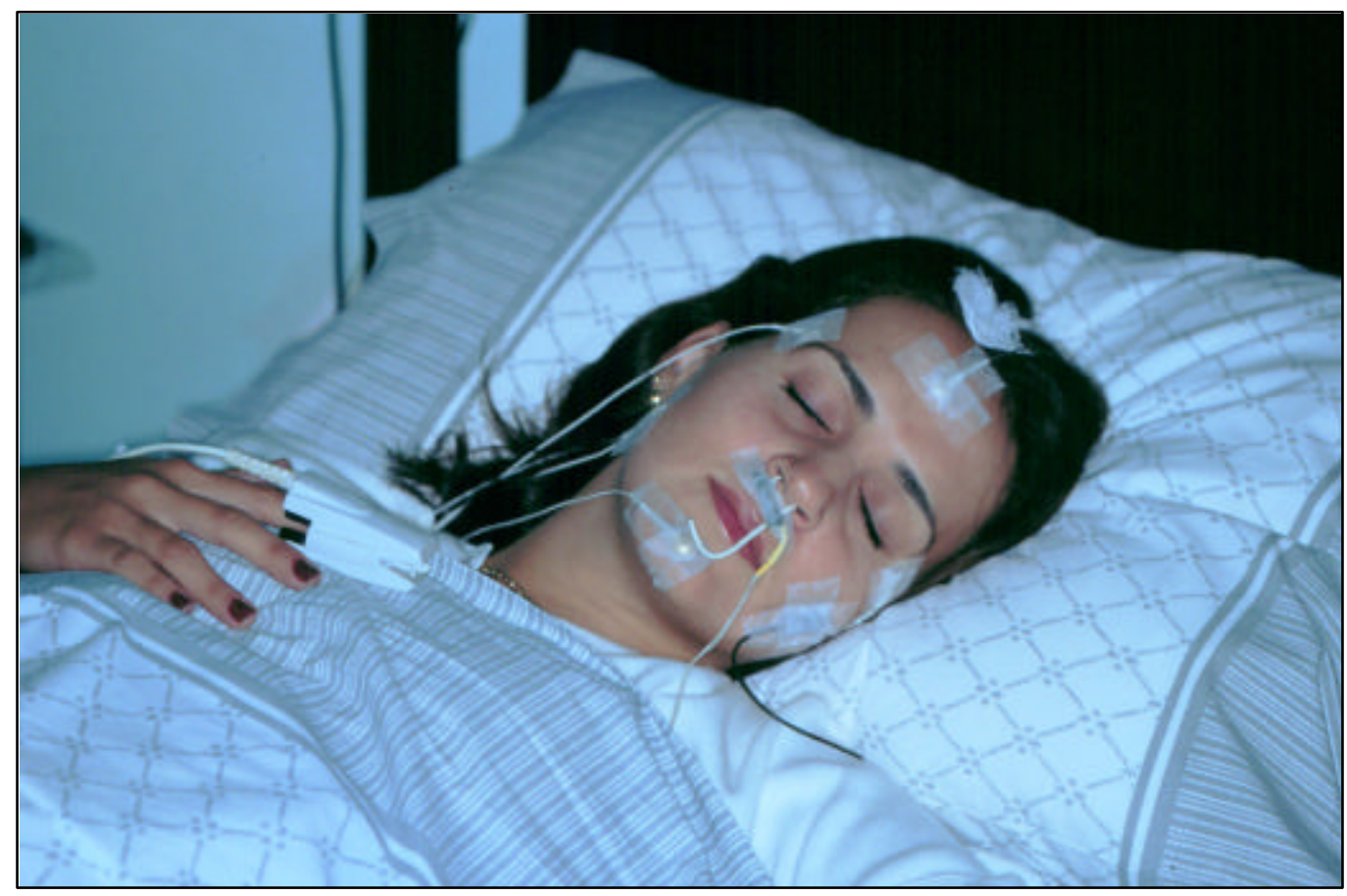

Figura 1 Representação de como o registro é realizado durante o sono. 
Foram registrados os seguintes parâmetros: pletismografia de esforço respiratório torácico e abdominal (Figura 2); captação de sons de ranger de dentes por meio de microfone fixado na região do músculo bucinador (Figura 3A) eletroencefalograma (EEG; $\mathrm{C}_{3} \mathrm{~A}_{2}, \mathrm{O}_{2} \mathrm{~A}_{1}$ ) (Figura 4), eletro-oculagramas bilaterais (EOG) (Figura 5B e C), eletrocardiograma (ECG), eletromiograma (EMG) no músculo

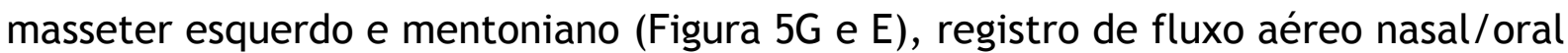
por termistor (Figura 5), , oximetria, registro de som próximo à cavidade oral (Figura 3) e análise visual por meio de câmera de vídeo (Figura 8) simultaneamente a todo o registro polissonográfico para a identificação das atividades motoras orofaciais distintas do bruxismo.

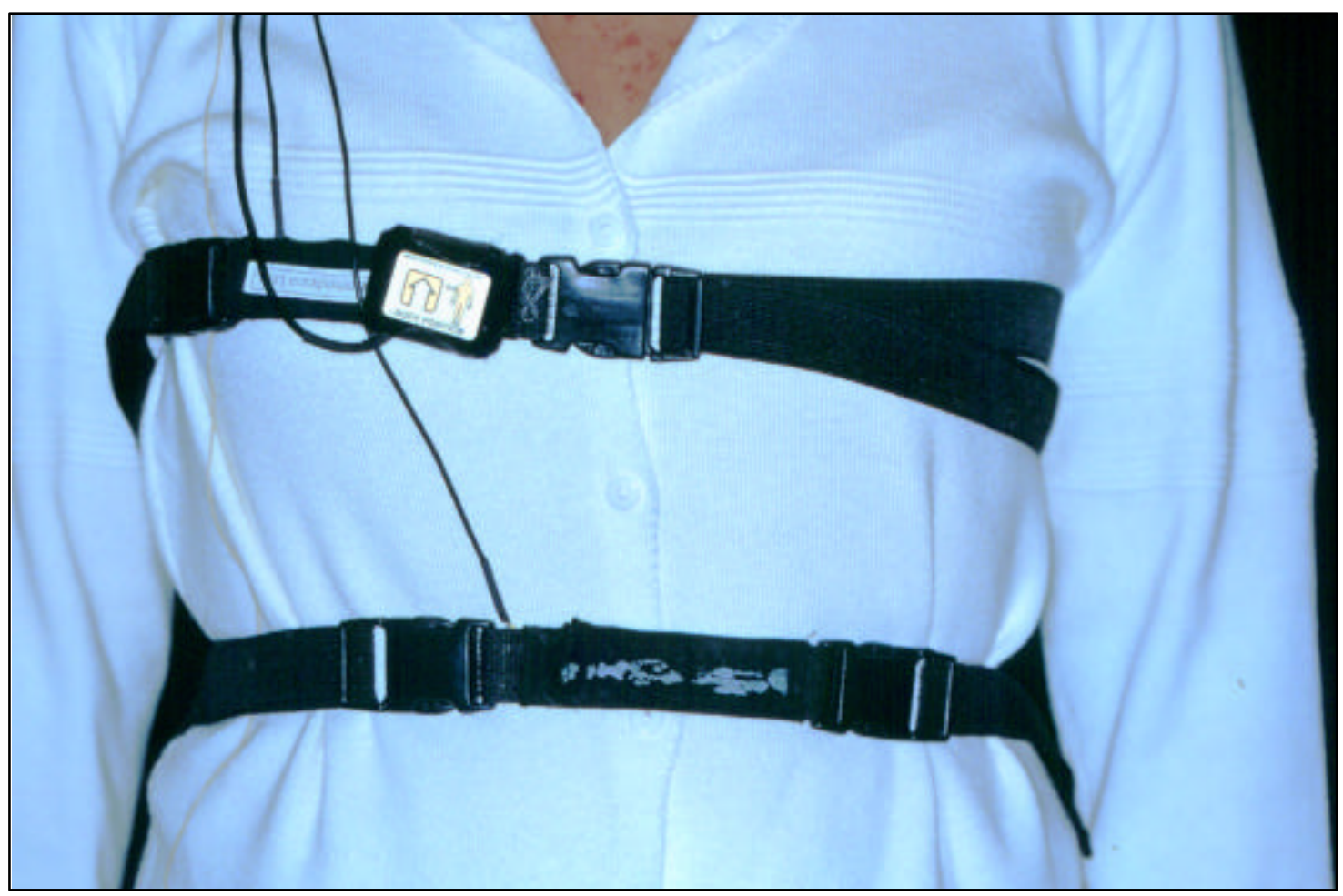

Figura 2 Pletismografia de esforço respiratório torácico e abdominal. 


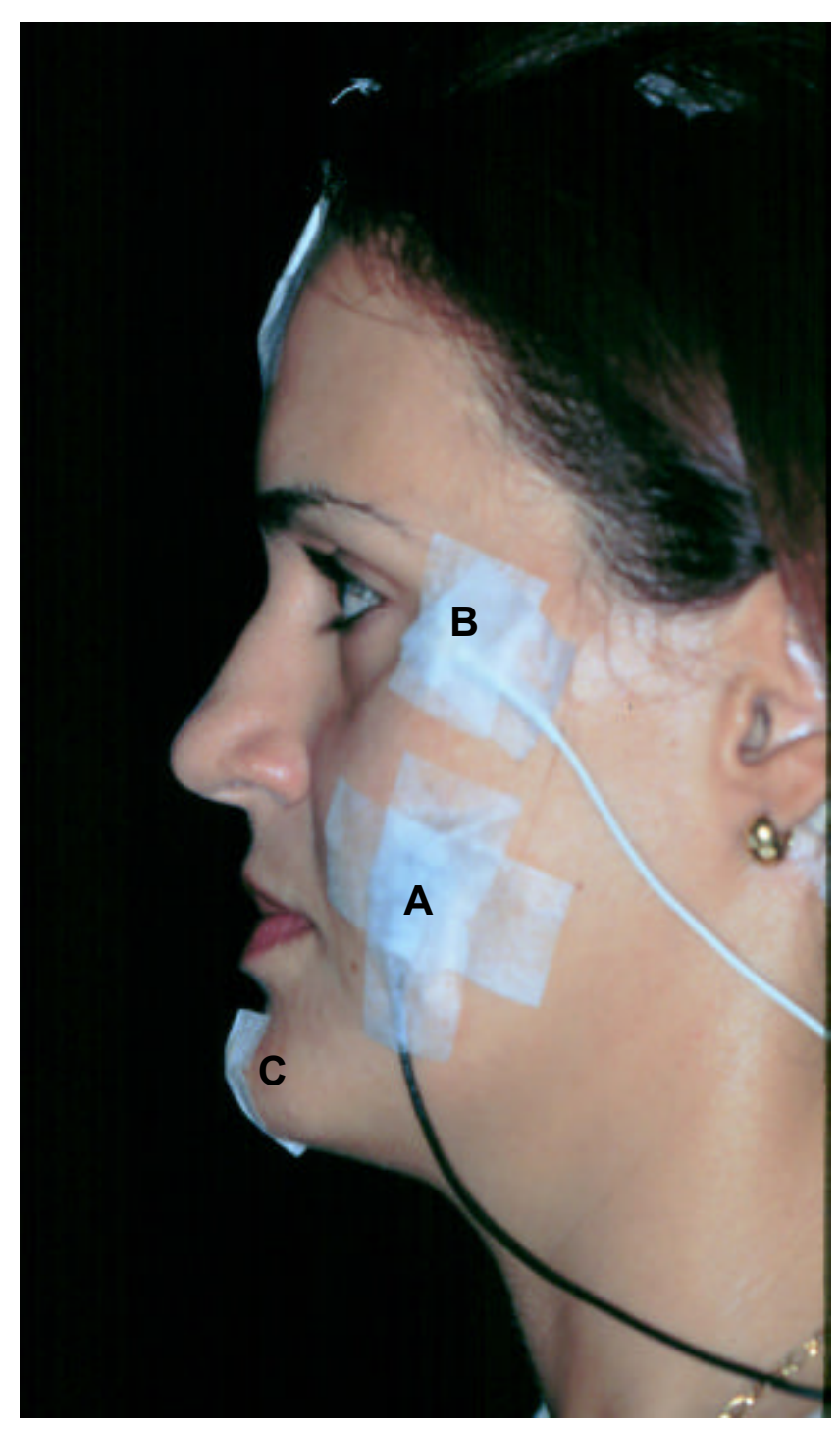

Figura 3 Microfone próximo à cavidade oral para captar sons de ranger de dentes (A); eletrodo do EOG (B); eletrodo da EMG do músculo mentoniano (C).

A pele do paciente foi limpa com água e sabão. Foram utilizados eletrodos de superfície de ouro cônicos. Os eletrodos foram embebidos em um creme eletrólito* e afixados à pele do paciente por meio de gaze ou micropore. 
Para o EEG, utilizaram-se as posições 01, OZ e 02 e C3, CZ e C4. Os eletrodos de referência foram colocados em A2 (referência auricular) (RECHTSCHAFFEN; KALES65, 1968), Para cada eletrodo, havia uma entrada individual e um canal de visualização no monitor (Figura 4).

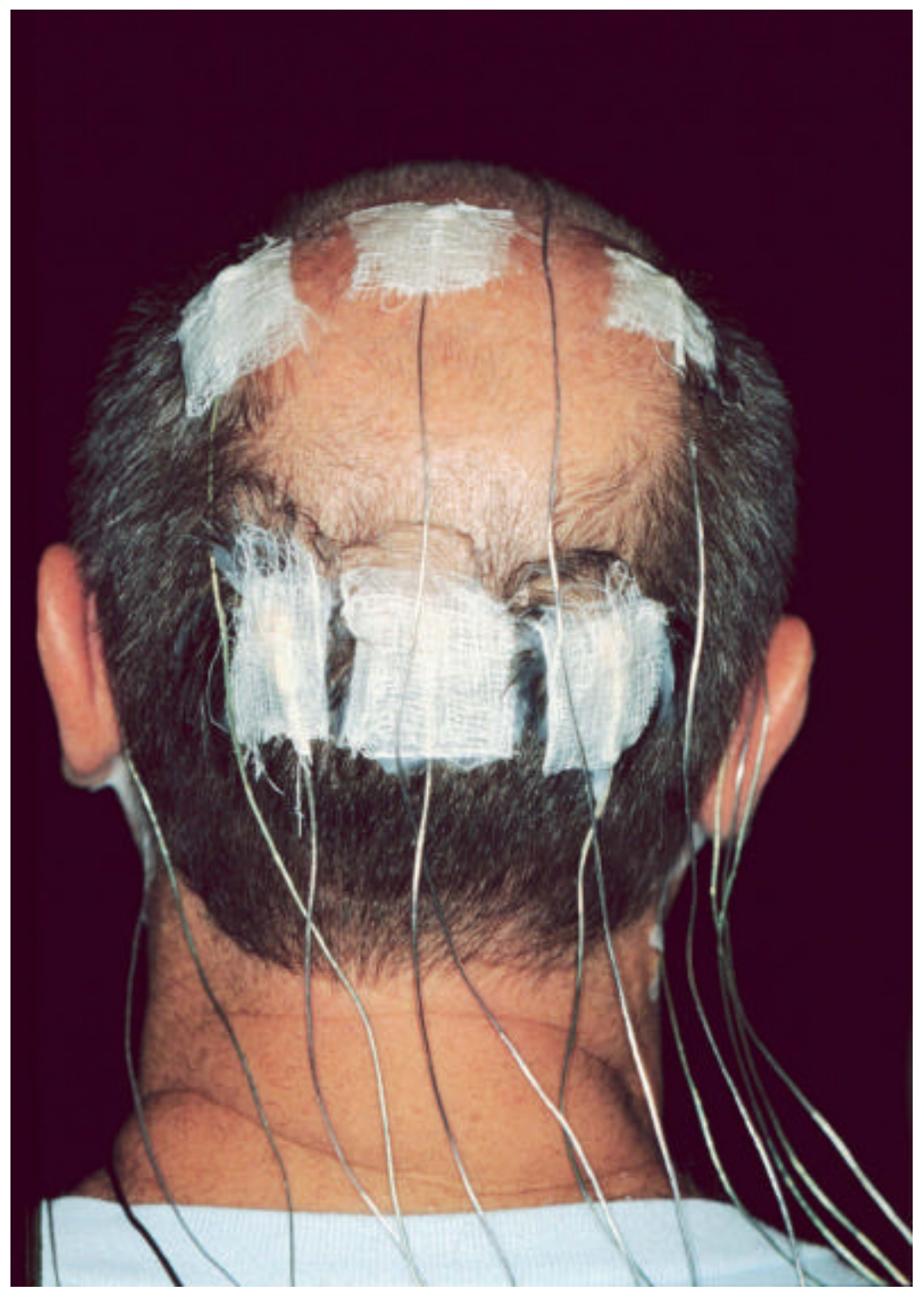

Figura 4. Fotografia representando o posicionamento dos eletrodos para o EEG. 
Para o EOC, foi obedecida a recomendação, com uma referência auricular (A1). As entradas foram Fp1 e Fp2, bem como um canal para o olho esquerdo e outro para o olho direito (Figura 5B e C).

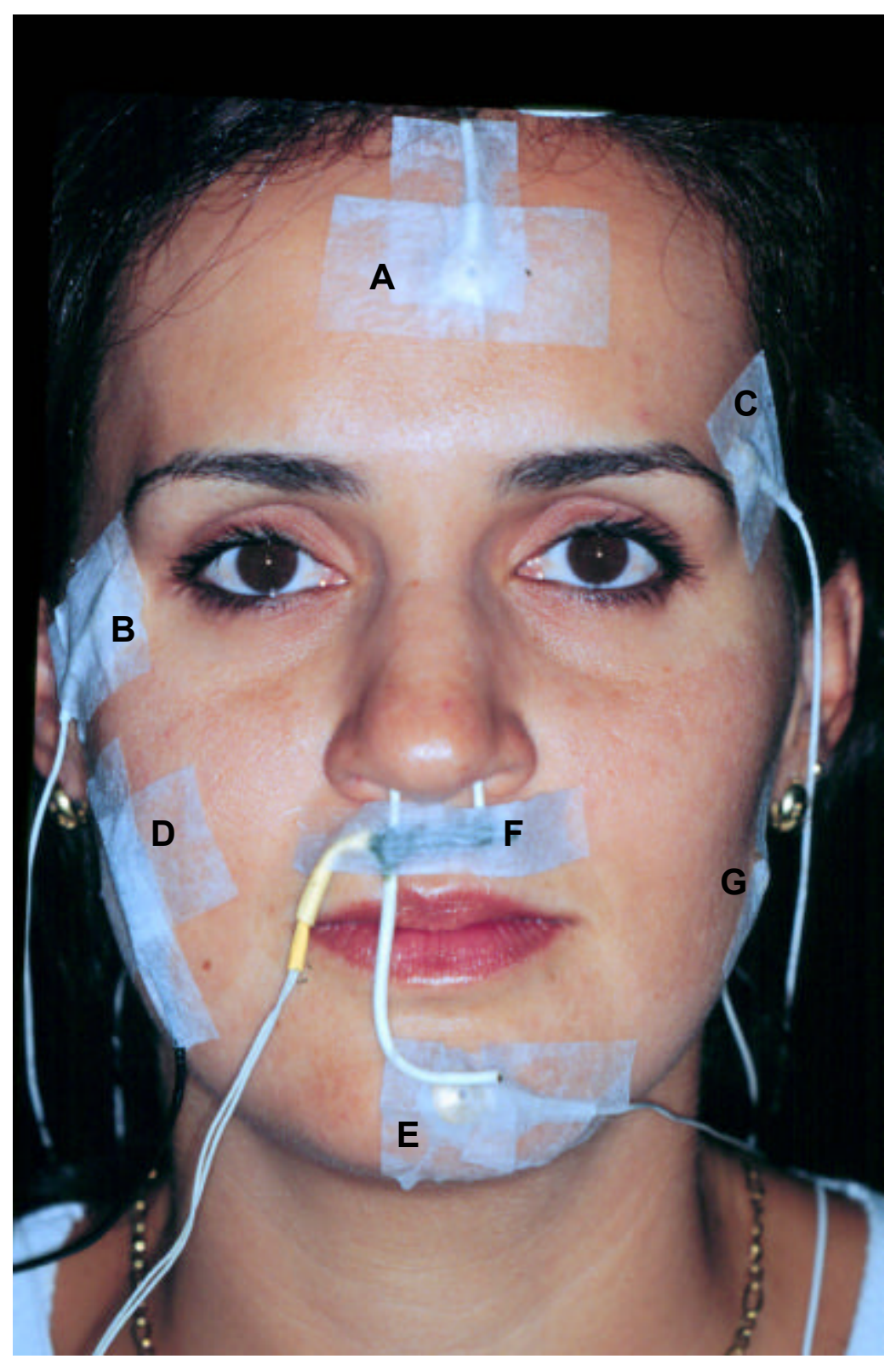

Figura 5 Posicionamento do fio terra (A); EOG (B e C); microfone (D); EMG do músculo mentoniano $(E)$; registro de fluxo aéreo oral nasal $(F)$ e eletromiografia do músculo masseter $(G)$. 
Foi realizada eletromiografia dos músculos mentoniano, masseter (esquerdo) (Figura 5E e G respectivamente) e tibiais anteriores (um em cada perna) (Figura 6), com entradas individuais e um canal de visualização para os músculos mentoniano e masseter e outro para os músculos tibiais anteriores (Figura 7).

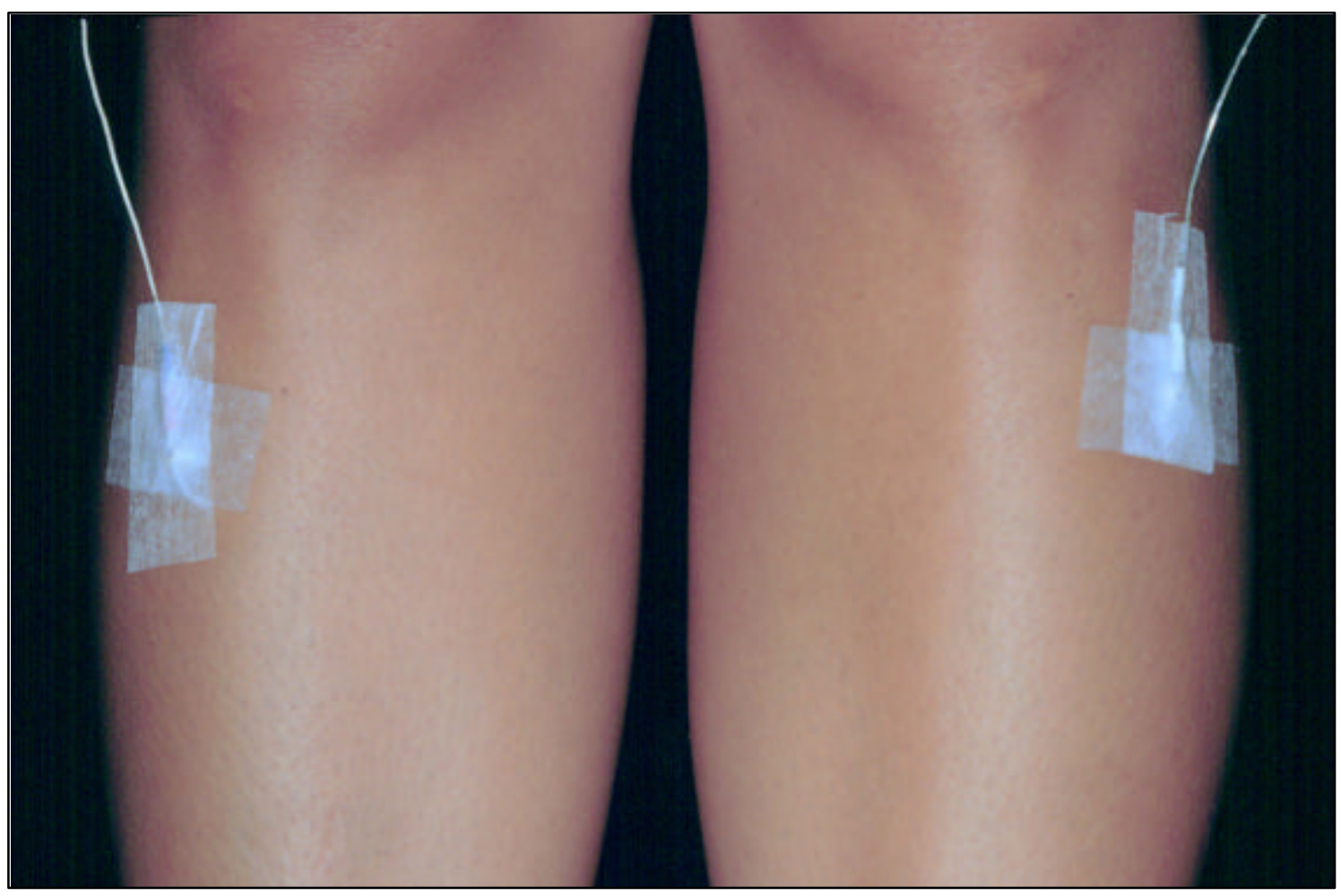

Figura 6 Posicionamento dos eletrodos para EMG dos músculos tibiais anteriores. 


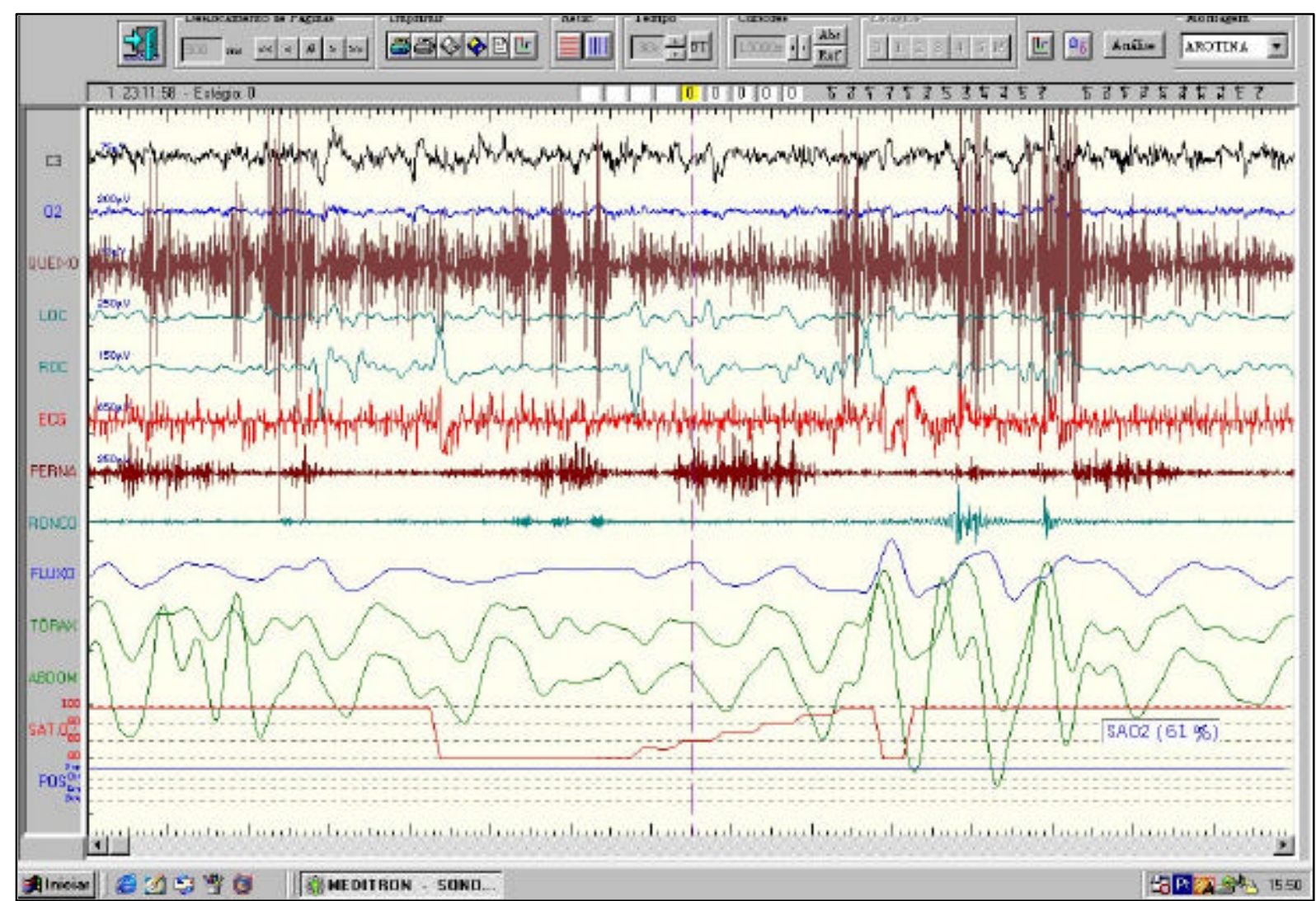

Figura 7 Exemplo da visualização dos canais de entrada no monitor. Na entrada queixo, a CVM com o indivíduo em vigília.

Antes dos registros do sono, cada paciente realizou uma série de testes de calibração fisiológica, a fim de permitir o reconhecimento do sinal voluntário de apertamento máximo (CVM), movimentos mandibulares (lateral e protrusivo), contrações rítmicas, deglutição e tosse (Figura 7, Anexo 8). 


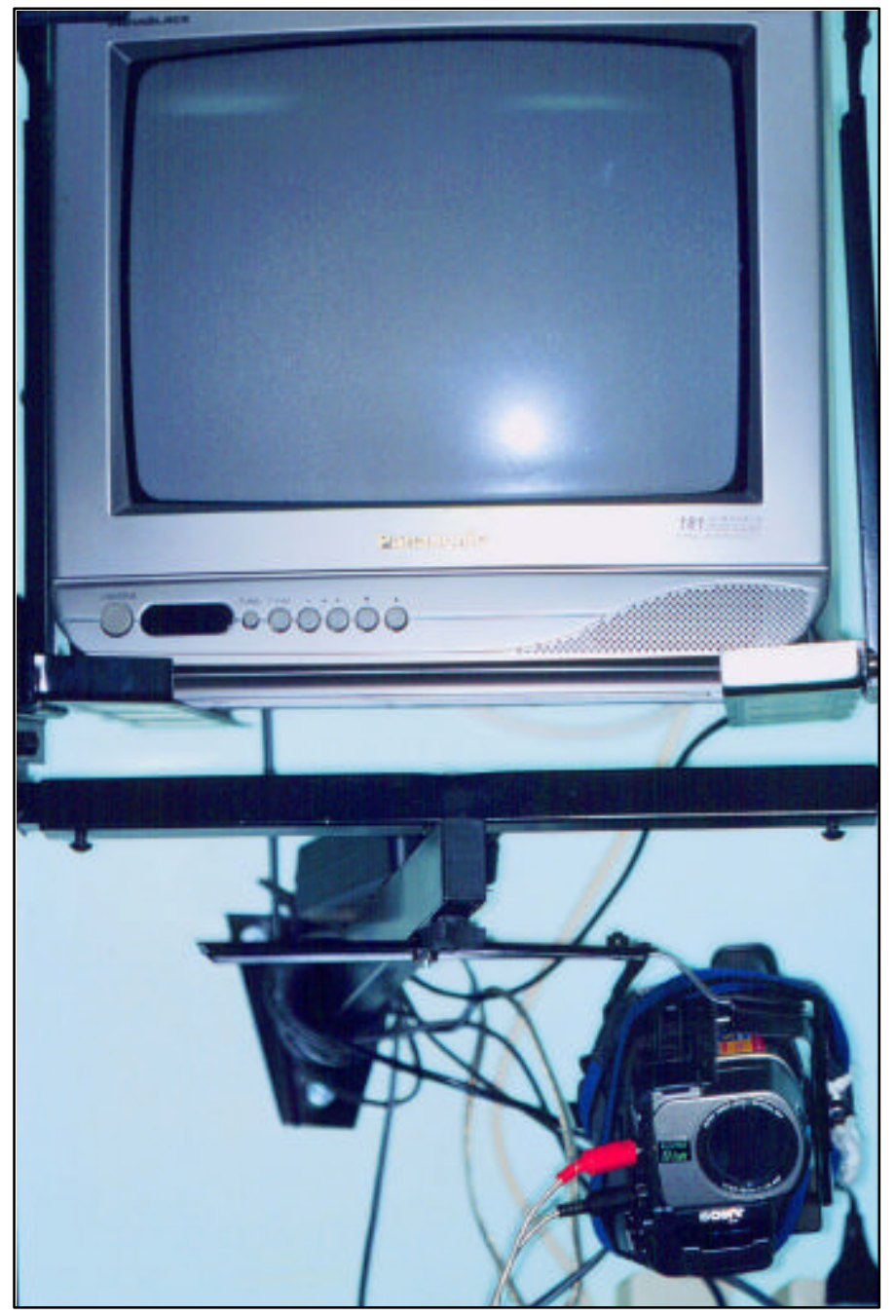

Figura 8 Câmera de vídeo para registro visual do sono e aparelho de TV para distração do paciente.

\section{Dados técnicos}

Os eletrodos da eletromiografia estavam calibrados e apresentavam impedância menor que $5 \Omega$. 0 sinal eletromiográfico foi amplificado com um ganho de 2000 vezes, sensibilidade de $150 \mu \mathrm{V} / \mathrm{cm}$, impedância de $10 \mathrm{M} \Omega$. Foram utilizados filtros de baixa freqüência de $30 \mathrm{~Hz}$ e de alta freqüência de $128 \mathrm{~Hz}$. Após amplificados e filtrados, o sinal foi digitalizado por meio de um conversor analógico 
digital $(A / D)^{\dagger}$. O sinal eletroencefalográfico foi registrado com uma sensibilidade de $75 \mu \mathrm{V} / \mathrm{cm}$. O eletrooculograma com $150 \mu \mathrm{V} / \mathrm{cm}$. O registro foi feito em épocas de 30s com uma freqüência de amostragem de $256 \mathrm{~Hz}$.(Figura 9)

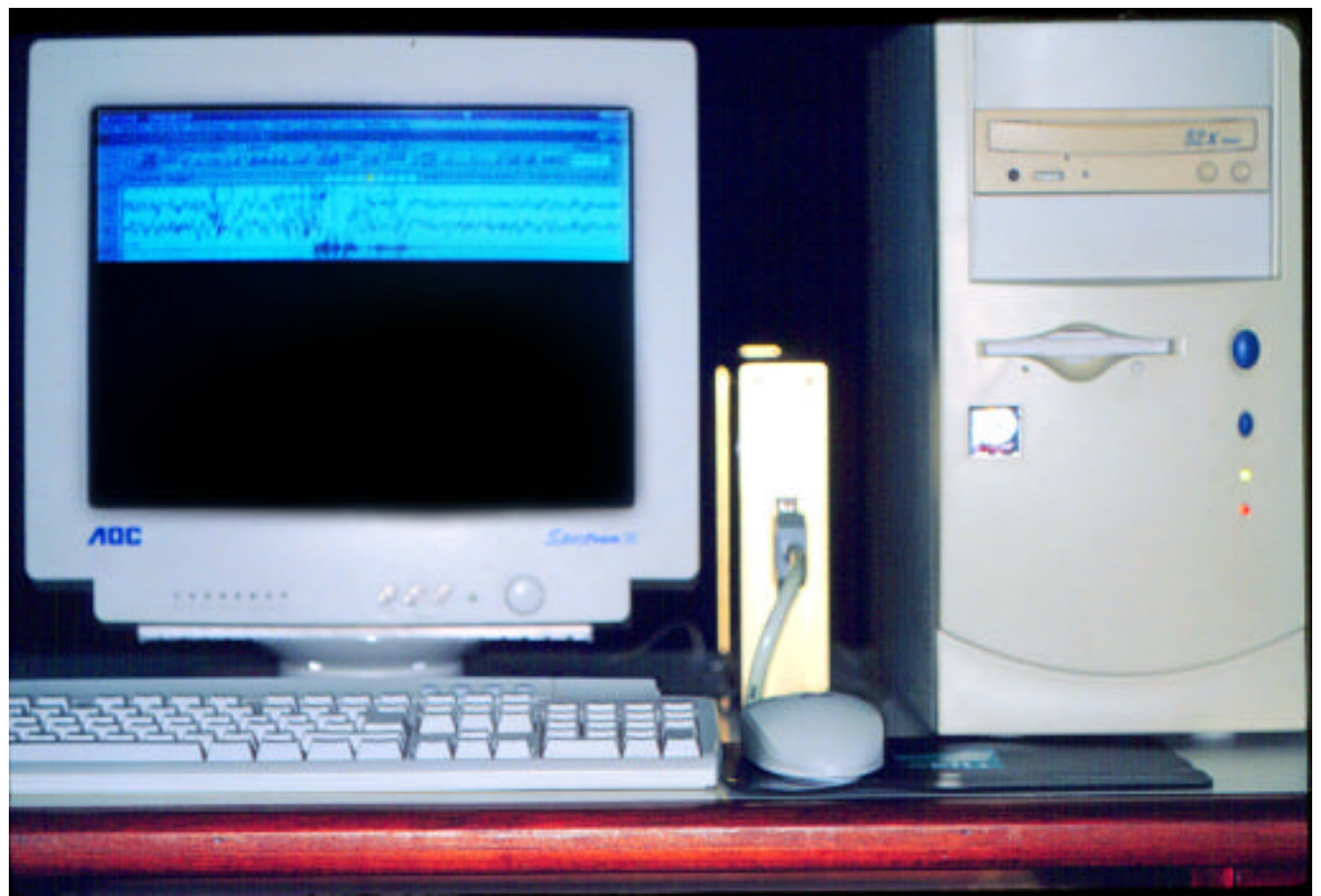

Figura 9 Computador e conversos analógico/digital por onde é realizado parte do monitoramento e a leitura dos dados polissonográficos

\footnotetext{
${ }^{\dagger}$ Meditron Eletromedicina (Santo Amaro São Paulo)
} 


\subsection{SEGUNDA CONSULTA (Examinador 1)}

Na manhã seguinte ao exame de Polissonografia, o paciente respondeu novamente ao questionário de análise objetiva de DTM, preencheu a EAV de dor $(100 \mathrm{~mm})$ e foi realizado o exame físico de DTM (palpação nos músculos temporal, masseter, esternocleidomastoideo, trapézio e aspectos lateral e posterior da ATM e teste de movimentação articular).

O examinador e o paciente desconheciam qualquer informação do exame polissonográfico, minimizando, assim qualquer tipo de indução do paciente, quanto à confiabilidade dos resultados, e do próprio examinador, quanto à imparcialidade na interpretação dos mesmos.

\subsection{ANÁLISE DOS DADOS}

Um único observador realizou a contagem visual dos eventos eletromiográficos, por meio do software, MEDITRON - SONOLAB ${ }^{\ddagger}$. O burst era contado se o mesmo apresentasse pelo menos $20 \%$ da amplitude da CVM com o indivíduo acordado (LAVIGNE; ROMPRÉ; MONTPLAISIR ${ }^{42}$, 1996). Esse valor era calculado com base no registro de calibração realizado pelo paciente ao início do exame polissonográfico (Figura 7, Anexo 8). Os eventos eletromiográficos de atividade rítmica dos músculos mastigatórios foram definidos e classificados em três diferentes tipos: fásico (rítmico); tônico (sustentado) ou misto (tanto fásico

\footnotetext{
‡ Meditron Eletromedicina (Santo Amaro São Paulo)
} 
quanto misto em um mesmo episódio). Um episódio fásico correspondia a pelo menos três bursts eletromiográficos de $0,25 \mathrm{~s}$ a 2,0 s de duração, separados por dois intervalos interburst. Um episódio tônico correspondia a um burst eletromiográfico com duração maior do que 2,0s. Considerava-se um episódio isolado, se o mesmo apresentasse um intervalo inter-episódio de pelo menos 3s de duração (Figura 10).

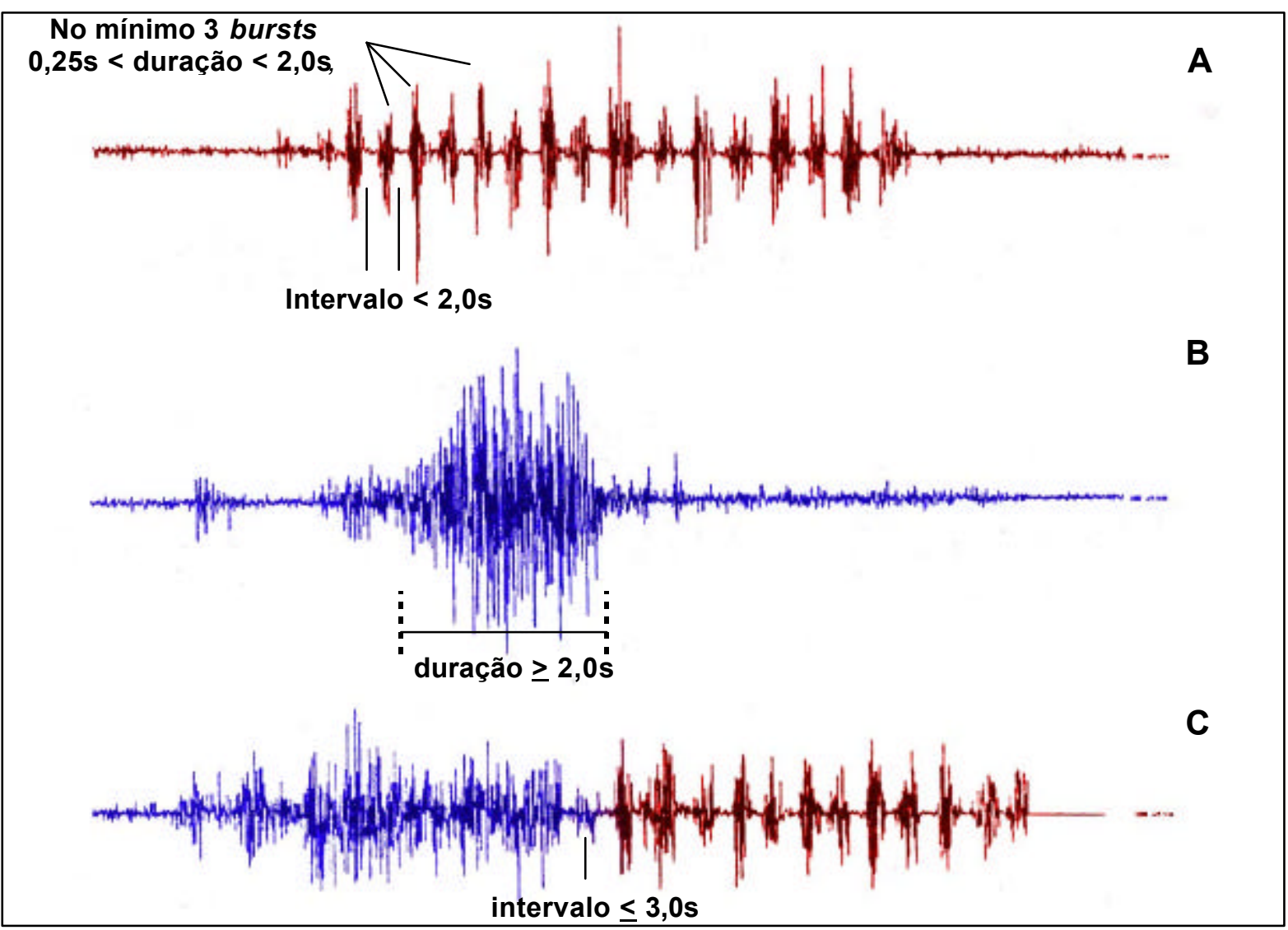

Figura 10 Exemplos de episódios de bruxismo fásico (A), tônico (B) e misto (C), registrado de um músculo masseter direito. Modificado de LAVIGNE; ROMPRÉ; MONTPLAISIR42 1996). 
Realizou-se a contagem de todos os bursts eletromiográficos (incluindo deglutição e/ou outras atividades orofaciais não específicas e não relacionadas com bruxismo) e do número de episódios de bruxismo por noite (epi/noite), episódios por hora (epi/hora); bursts por hora (b/hora) e bursts por episódios (b/epi).

Contabilizou-se também o número e a classe de episódios por fase do sono, a eficiência do sono, o número de episódios associados a microdespertar e a atividade motora das pernas.

Após a contagem, considerou-se o diagnóstico de bruxismo, por meio da polissonografia, como positivo se o número de eventos atingisse os valores de corte de 4 ou mais epi/hora ou 25 ou mais b/hora definidos por LAVIGNE; ROMPRÉ; MONTPLAISIR ${ }^{42}$, 1996. O valor de episódios com ranger de dentes não foi utilizado no diagnóstico devido a sua variabilidade. Mesmo no estudo original de LAVIGNE; ROMPRÉ; MONTPLAISIR ${ }^{42}$, alguns indivíduos controle apresentaram sons de ranger de dentes e 4 dos bruxômanos não o fizeram. Os autores atribuíram ainda a essa variabilidade, a sensibilidade do microfone, a qual poderia não se suficiente para captar sons muito suaves de ranger e que portanto, não poderiam ser contados. Além do mais, a utilização dos sons de ranger de dentes como critério de diagnóstico excluiria indivíduos com um número suficiente de ARMM mas que, naquela noite do exame, sua atividade tenha sido de apertamento e não de ranger de dentes. 


\subsection{ANÁLISE ESTATÍSTICA}

Inicialmente, foram descritas as variáveis do sono (latência do sono; latência do sono REM; eficiência do sono; tempo de sono nos estágios $1,2,3 / 4$ e REM e número de microdespertares por hora) de todos os participantes.

Para verificar a concordância entre os três examinadores que realizaram o exame clínico de bruxismo, aplicou-se o teste de concordância Kappa entre os examinadores 1 e 2, 1 e 3 e 2 e 3 . Em seguida, calculou-se a sensibilidade e a especificidade do exame clínico de BS em relação ao exame polissonográfico.

Foi descrito o número de indivíduos diagnosticados como bruxômanos, por ambos os métodos, clínico e PSG.

Descreveu-se a prevalência de indivíduos com bruxismo clínico e PSG dentre a população com e sem DTM e com e sem dor matinal à palpação, além da realização do teste Qui-quadrado de associação, para verificar a presença de associação entre bruxismo (clínico ou PSG) e DTM ou dor matinal à palpação (Tabelas 1, 2, 3 e 4).

Em seguida, realizou-se o teste de distribuição de freqüência para a verificação da normalidade da distribuição das variáveis, em todas as variáveis a distribuição foi não normal. 
Aplicou-se o teste de Mann-Whitney para verificar a diferença entre o número das variáveis de corte utilizadas como diagnóstico de bruxismo-PSG entre os indivíduos diagnosticados com e sem bruxismo-PSG (Tabela 5).

Aplicou-se o teste Mann-Whitney, visto que a distribuição da freqüência das variáveis foi não normal, para verificar se havia diferenças entre as variáveis do sono (latência, eficiência e tempo em cada estágio); o número de microdespertares por hora (Tabela 7); os valores percentuais da ocorrência dos episódios e dos bursts nas diferentes fases do sono; bem como os tipos de episódios (fásicos, tônico ou misto) e bursts (fásico ou tônico); além do número percentual de episódios associados a microdespertar e o número de atividades oromotoras (Tabela 6) entre os indivíduos com e sem bruxismo-PSG.

Verificou-se também, por meio do teste Mann-Whitney, a existência de diferenças entre as variáveis oromotoras de corte (epi/noite, epi/hora, b/hora e b/epi) dos indivíduos diagnosticados com e sem bruxismo clínico (Tabela 8).

Aplicou-se o teste Mann-Whitney para verificar se havia diferenças entre a ocorrência das variáveis do sono (latência, eficiência, tempo em cada estágio do sono e número de microdespertares por hora) (Tabela 10) e das variáveis motoras (epi/noite; epi/hora; b/hora; b/epi; episódios associados a microdespertar; número de episódios na fase 1, 2, 3/4e REM; número de episódios fásicos, tônicos e mistos e número de bursts fásicos e tônicos) entre os indivíduos com e sem DTM (Tabela 11). Verificou-se ainda a presença de diferenças nos valores das variáveis 
oromotoras dos indivíduos com e sem dor na EAV, e com e sem dor à palpação na manhã seguinte à realização da polissonografia (Tabelas 12 e 13)

Realizou-se o teste de correlação de Spearman, para verificar a presença de correlação entre as variáveis oromotoras de corte e os valores da EAV e entre as variáveis oromotoras de corte e o índice de DTM (Tabelas 15, 16 e 17).

O nível de significância de 5\% foi adotado para todos os testes. 
RESULTADOS 


\section{5 - ResUltados}

Após a realização de todo o procedimento, dentre os 20 pacientes com DTM, 2 pacientes não compareceram, em 2 exames polissonográficos a leitura da eletromiografia não foi possível devido à presença de interferências, 1 paciente apresentou apnéia obstrutiva moderada (24 eventos de apnéia/hipopnéia/hora), e ainda, 1 indivíduo teve seu quadro clínico de DTM convertido em assintomático após o exame, porém com permanência do estalido (presença de estalido assintomático era um dos critérios de exclusão). Dos 19 indivíduos do grupo controle, 1 indivíduo não compareceu ao exame polissonográfico, 1 apresentou PLM severa (55,8 eventos/hora), e em 6 a eletromiografia não pôde ser lida na sensibilidade padronizada de $75 \mu \mathrm{V} / \mathrm{cm}$, devido à presença de ruído no sinal.

Assim, a amostra definitiva foi composta por 26 indivíduos, dos quais 14 eram pacientes de DTM (8 mulheres e 6 homens), com idade média de 27,14 \pm 7,4 (17-40 anos) e 12 eram indivíduos controle (6 mulheres e 6 homens), com idade média de 27,42 + 5,265 (22-40 anos).

\subsection{Do quadro clínico de DTM}

O Anexo 10 apresenta um resumo do quadro clínico de cada participante da pesquisa, no primeiro e no segundo exame clínico de DTM. Verificou-se que 5 indivíduos, inicialmente pertencentes ao grupo controle (fichas 18, 20, 24, 29 e 32) 
apresentaram sinais e/ou sintomas de DTM ao reexame na manhã seguinte da PSG. Apesar da sintomatologia matinal, esses indivíduos não apresentavam como queixa principal a dor. Quando havia alguma queixa, relacionava-se ao hábito do bruxismo e ao desgaste dentário por ele proporcionado. Como eles não poderiam ser considerados doentes, visto que não procuraram tratamento, os mesmos permaneceram no grupo controle.

\subsection{Do diagnóstico de bruxismo}

No Anexo 11 encontram-se os diagnósticos clínicos de bruxismo realizados pelos três examinadores. Considerou-se como diagnóstico clínico definitivo para esta pesquisa aquele predominante dentre os três examinadores.

0 índice de concordância Kappa entre os examinadores foi de 0,448 ( $p=$ 0,009) para os examinadores 1 e 2, representando uma concordância justa7; de 0,320 ( $p=0,051)$ para os examinadores 1 e 3 (representando uma concordância baixa $^{7}$ ) e de 0,606 ( $\left.p=0,0007\right)$ para os examinadores 2 e 3 (representando uma concordância justa7). 
Dezessete indivíduos foram clinicamente diagnosticados como portadores de bruxismo, dos quais $11(64,7 \%)$ pertenciam ao grupo com DTM e 6 $(35,3 \%)$ ao grupo controle. Apenas 10 dos 26 participantes devolveram o acompanhamento de bruxismo, sendo que, em 7 deles, houve relato significativo da ocorrência de bruxismo, confirmando o diagnóstico clínico já estabelecido.

Mesmo havendo uma maior concentração de indivíduos com DTM dentre os indivíduos com BC (11 de 17, 64,7\%) e, maior concentração de indivíduos com BC no grupo com DTM (11 de 14, 78,57\%), estatisticamente não houve associação positiva entre essas variáveis, visto que o Qui-quadrado entre BCo e DTM foi de 1,239 $(p=0,265)($ Tabela 1).

Tabela 1 Tabela de associação $2 \times 2$ entre bruxismo clínico e DTM, com valores percentuais sobre a linha (DTM e controle).

\begin{tabular}{cccccc}
\hline & $\begin{array}{c}\text { COM bruxismo } \\
\text { clínico }\end{array}$ & $\begin{array}{c}\text { SEM bruxismo- } \\
\text { clínico }\end{array}$ & Total & Qui-quadrado & p \\
\cline { 2 - 5 } DTM & $11(78,57 \%)$ & $3(21,4 \%)$ & $14(100,0 \%)$ & 1,239 & 0,265 \\
Controle & $6(50,0 \%)$ & $6(50,0 \%)$ & $12(100,0 \%)$ & \\
Total & $17(65,4 \%)$ & $9(34,6 \%)$ & $26(100,0 \%)$ & \\
\hline
\end{tabular}


Alguns indivíduos, inicialmente pertencentes ao grupo controle, manifestaram sintomatologia à palpação na segunda consulta. Realizou-se então o teste Qui-quadrado, entre bruxismo clínico e dor à palpação na segunda consulta a fim de averiguar a associação dessa sintomatologia matinal com a atividade parafuncional. O teste demonstrou não haver associação positiva, visto que o valor de Qui-quadrado foi de 2,389 ( $p=0,122)$. Ao se tomarem valores percentuais, dos 18 indivíduos com dor à palpação na segunda consulta, 14 (77,8\%) foram diagnosticados como bruxômanos (Tabela 2) e 14 indivíduos dos 17 com bruxismo clínico $(82,35 \%)$, apresentaram dor à palpação na segunda consulta.

Tabela 2 Tabela de associação 2x2 entre bruxismo clínico e dor à palpação, com valores percentuais sobre a linha (COM e SEM dor à palpação)

\begin{tabular}{cccccc}
\hline & $\begin{array}{c}\text { COM bruxismo } \\
\text { clínico }\end{array}$ & $\begin{array}{c}\text { SEM bruxismo- } \\
\text { clínico }\end{array}$ & Total & Qui-quadrado & p \\
\cline { 2 - 6 } COM dor à palpação & $14(77,8 \%)$ & $4(22,2 \%)$ & $18(100,0 \%)$ & 2,389 & 0,122 \\
SEM dor à palpação & $3(37,5 \%)$ & $5(62,5 \%)$ & $8(100,0 \%)$ & & \\
Total & $17(65,4 \%)$ & $9(34,6 \%)$ & $26(100,0 \%)$ & & \\
\hline
\end{tabular}

Testou-se a sensibilidade e especificidade do exame clínico com relação ao exame polissonográfico e verificou-se que o exame clínico apresentou sensibilidade de $75 \%$ e especificidade de $57 \%$. 


\subsubsection{Diagnóstico polissonográfico de bruxismo}

Ao exame eletromiográfico, foram contabilizados os seguintes parâmetros: as variáveis oromotoras de corte (ARMM), expressas como epi/noite, epi/hora, b/hora e b/epi; o valor percentual de episódios em geral nas várias fases do sono; o valor percentual dos bursts nas fases do sono; o tipo de episódio (fásico, tônico ou misto) e sua distribuição nas fases do sono; o tipo de burst (fásico ou tônico) e sua distribuição; o valor percentual de episódios associados a microdespertar e o número total de atividade oromotora (o que inclui qualquer ativação eletromiográfica, mesmo as que não foram contabilizadas para o escore de bruxismo).

Como variáveis do sono, foram contabilizados o tempo total de sono, sua eficiência e o valor percentual do tempo em cada estágio.

O Anexo 9 apresenta o diagnóstico de DTM (Sim ou Não), os valores das variáveis oromotoras de corte (epi/noite, epi/hora, b/hora e b/epi) de cada participante, o diagnóstico de bruxismo clínico e pela PSG, a presença ou ausência de dor na EAV (na manhã seguinte à PSG) e a presença ou ausência de dor à palpação (na manhã seguinte à PSG).

Após a leitura dos exames polissonográficos, realizou-se o diagnóstico de bruxismo de acordo com a contagem das variáveis oromotoras de corte, definidas para essa função. Seguindo o critério de diagnóstico proposto por LAVIGNE; ROMPRÉ; MONTPLAISIR ${ }^{42}$ de pelo menos 4 episódios de ARMM por hora ou 25 bursts 
de ARMM por hora, doze indivíduos (7 do grupo com DTM $(58,3 \%)$ e $5(41,6 \%)$ do grupo controle) foram diagnosticados como portadores de bruxismo do sono. Ao se tomar a população com DTM $(n=14)$, que é a que busca tratamento, e calcular o percentual de indivíduos com bruxismo-PSG, verifica-se que 8 (57,14\%) apresentaram bruxismo polissonográfico (Tabela 3).

Tabela 3 Tabela de associação $2 \times 2$ entre bruxismo-PSG e DTM, com valores percentuais sobre a linha (DTM e controle)

\begin{tabular}{cccccc}
\hline & $\begin{array}{c}\text { COM bruxismo } \\
\text { PSG }\end{array}$ & $\begin{array}{c}\text { SEM bruxismo- } \\
\text { PSG }\end{array}$ & Total & Qui-quadrado & p \\
\cline { 2 - 6 } DTM & $8(57,1 \%)$ & $6(42,9 \%)$ & $14(100,0 \%)$ & 0,672 & 0,413 \\
Controle & $4(33,3 \%)$ & $8(66,7 \%)$ & $12(100,0 \%)$ & & \\
Total & $12(46,2 \%)$ & $14(53,8 \%)$ & $26(100,0 \%)$ & & \\
\hline
\end{tabular}

Devido ao fato de 5 indivíduos inicialmente pertencentes ao grupo controle terem apresentado sintomatologia à palpação na segunda consulta, realizou-se o teste do Qui-quadrado entre a dor à palpação e o bruxismo-PSG. 0 valor de Qui-quadrado foi de 0,027 ( $p=0,869)$ (Tabela 4).

Tabela 4 Tabela de associação $2 \times 2$ entre bruxismo-PSG e dor à palpação, com valores percentuais sobre a linha (COM e SEM dor à palpação)

\begin{tabular}{cccccc}
\hline & $\begin{array}{c}\text { COM bruxismo } \\
\text { PSG }\end{array}$ & $\begin{array}{c}\text { SEM bruxismo- } \\
\text { PSG }\end{array}$ & Total & Qui-quadrado & p \\
\cline { 2 - 6 } COM dor à palpação & $8(44,4 \%)$ & $10(55,6 \%)$ & $18(100 \%)$ & 0,027 & 0,869 \\
SEM dor à palpação & $4(50,0 \%)$ & $4(50,0 \%)$ & $8(100 \%)$ & & \\
Total & $1246,2 \%$ & $1453,8 \%$ & $26(100 \%)$ & & \\
\hline
\end{tabular}


A Figura 11 apresenta a diferença na prevalência de bruxismo do sono quando diagnosticado clinicamente e quando diagnosticado pela PSG nos grupos com DTM e com sintomatologia, ou seja, dor à palpação. Nota-se a ocorrência de maior concentração de indivíduos com bruxismo, quando do diagnóstico clínico, nos grupos com DTM e com dor à palpação, do que quando o diagnóstico é realizado apenas pelo critério polisssonográfico.

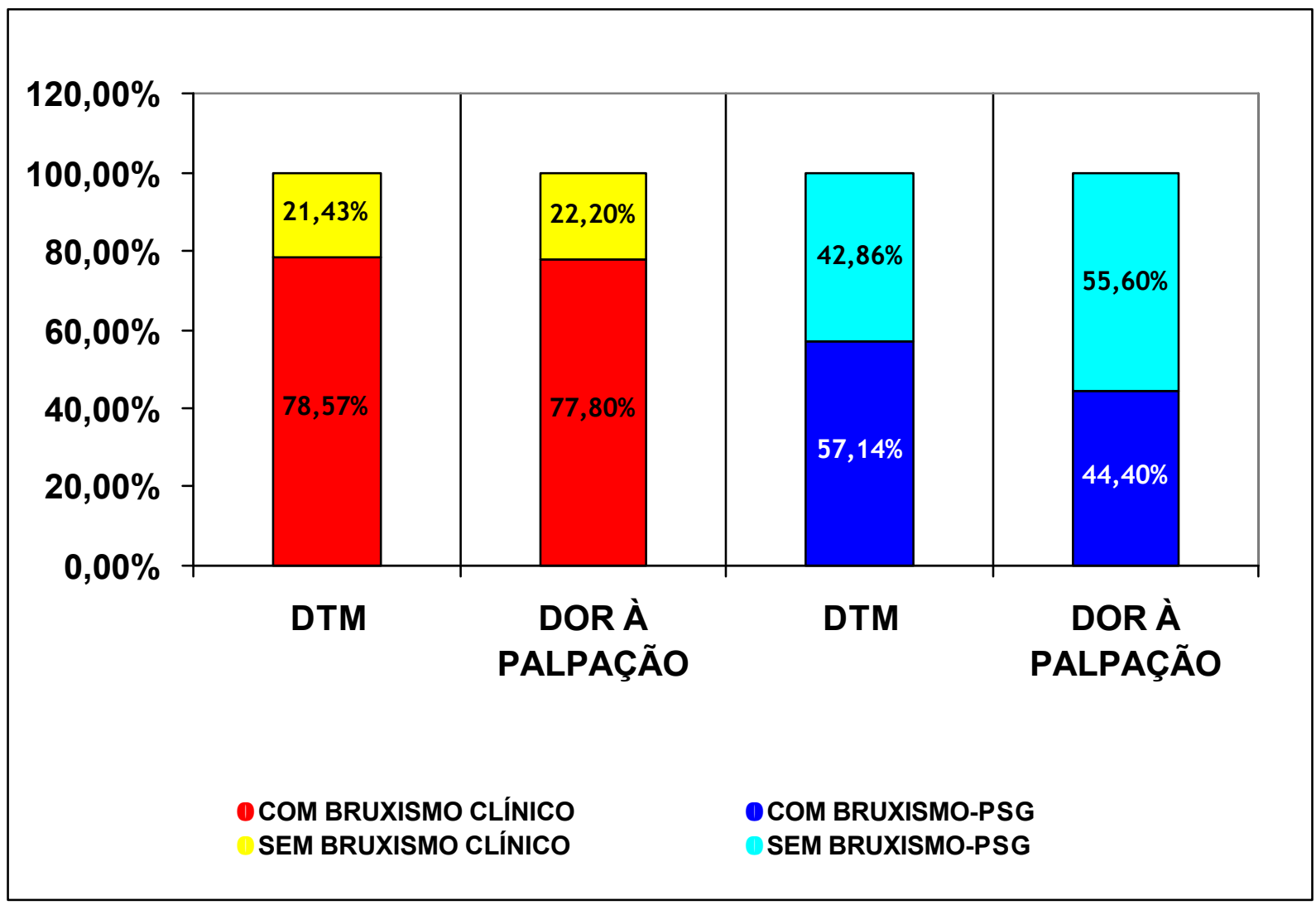

Figura 11 Distribuição dos indivíduos com bruxismo clínico e PSG nas populações com DTM e com dor à palpação. 


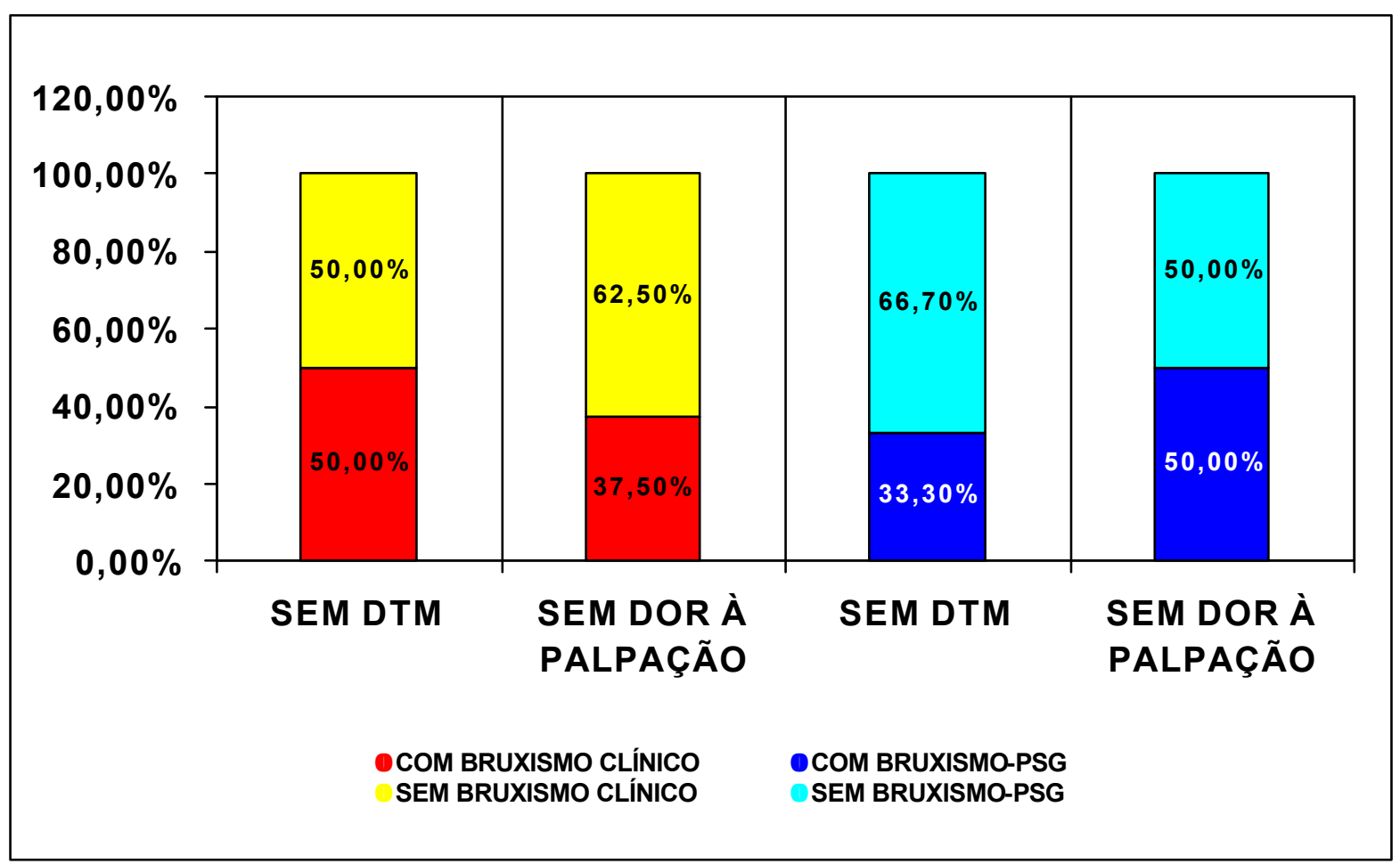

Figura 12 Distribuição dos indivíduos com bruxismo clínico e polissonográfico nas populações sem DTM e sem dor à palpação.

A Figura 12 apresenta os valores da prevalência de bruxismo do sono quando diagnosticado clinicamente e pela PSG na população sem DTM e sem sintomatologia, ou seja, sem dor à palpação. Vê-se que, apesar da concentração de indivíduos com bruxismo clínico na população com DTM (Figura 11), a ausência de associação entre essas duas entidades deve-se à distribuição equilibrada de indivíduos com bruxismo na população saudável (Figura 12). Entretanto, quanto à relação entre bruxismo clínico e dor à palpação, apesar da ausência de associação, vê-se que os gráficos da prevalência de indivíduos com bruxismo clínico na população com e sem sintomatologia tendem a se complementarem, ou seja, $77,8 \%$ dos indivíduos com dor à palpação apresentaram bruxismo clínico (Figura 11) e 62,50\% dos indivíduos sem dor à palpação não apresentaram bruxismo clínico 
(Figura 12). Essa mesma observação vale, embora de forma menos acentuada para a representação gráfica dos indivíduos com bruxismo-PSG na população com DTM (Figura 11) e na população sem DTM (Figura 12).

A Tabela 5 apresenta as médias e desvio padrão dos valores das variáveis de corte e mostra que houve significativas diferenças estatísticas entre os indivíduos diagnosticados com e sem bruxismo, segundo os critérios polissonográficos.

Tabela 5 Médias e desvio padrão das variáveis oromotoras de corte para o diagnóstico de bruxismo dos grupos com e sem bruxismo, segundo o critério polissonográfico.

\begin{tabular}{lccc}
\hline & C/ BRUXISMO-PSG & S/ BRUXISMO-PSG & $\mathbf{p}^{*}$ \\
\cline { 2 - 4 } & Média e DP & Média e DP & (Mann-Whitney) \\
\cline { 2 - 4 } Epi/noite & $30,750 \pm 8,170$ & $12,143 \pm 4,833$ & $0,000009^{\#}$ \\
Epi/hora & $5,333 \pm 1,164$ & $2,138 \pm 0,850$ & $0,000007^{\#}$ \\
B/hora & $22,992 \pm 5,533$ & $7,864 \pm 4,030$ & $0,000012^{\#}$ \\
B/epi & $4,250 \pm 1,033$ & $3,914 \pm 1,532$ & 0,5192 \\
\hline
\end{tabular}

* hipótese de que sem bruxismo < com bruxismo

\# estatisticamente significativo 
De um modo geral, não houve diferenças estatísticas na distribuição das variáveis motoras (episódos e/ou bursts de ARMM) com relação aos estágios do sono entre os grupos com e sem bruxismo-PSG. Também não houve diferenças quanto aos tipos de episódios ou burts (fásico ou tônico) entre os grupos, exceto pelo fato de que os indivíduos com bruxismo apresentaram um número significativamente maior de epísódios do tipo misto $(p=0,045)$ e de atividades oro-motoras gerais $(p=0,017)($ Tabela 6).

Tabela 6 Médias e desvio padrão das variáveis oromotoras e sua distribuição com relação aos estágios do sono dos grupos com e sem bruxismo definido pelo critério polissonográfico.

\begin{tabular}{lccc}
\hline & C/ BRUXISMO-PSG & S/ BRUXISMO-PSG & p \\
\cline { 2 - 4 } & Média e DP & Média e DP & (Mann-Whitney) \\
\cline { 2 - 4 } Episódios fase 1(\%) & $20,26 \pm 14,356$ & $19,22 \pm 14,295$ & $0,958^{*}$ \\
Episódios fase 2(\%) & $55,95 \pm 11,779$ & $52,56 \pm 18,919$ & $0,855^{*}$ \\
Episódios fase 3/4(\%) & $6,02 \pm 4,753$ & $12,07 \pm 20,001$ & $0,852^{*}$ \\
Episódios fase REM (\%) & $17,76 \pm 14,732$ & $16,17 \pm 9,947$ & $1,0^{*}$ \\
Bursts na fase 1(\%) & $21,07 \pm 16,907$ & $13,57 \pm 12,933$ & $0,309^{*}$ \\
Bursts na fase 2(\%) & $54,46 \pm 15,857$ & $51,21 \pm 23,061$ & $0,876^{*}$ \\
Bursts na fase 3/4\%) & $8,27 \pm 9,745$ & $17,08 \pm 27,281$ & $0,936^{*}$ \\
Bursts na fase REM (\%) & $15,85 \pm 15,187$ & $17,75 \pm 11,255$ & $0,795^{\star}$ \\
Episódios fásicos (\%) & $69,35 \pm 16,114$ & $63,95 \pm 26,061$ & $0,677^{*}$ \\
Episódios tônicos (\%) & $21,93 \pm 14,925$ & $30,51 \pm 24,095$ & $0,420^{*}$ \\
Episódios mistos (\%) & $12,80 \pm 9,301$ & $5,55 \pm 7,950$ & $0,045^{\star *}$ \\
Bursts fásicos (\%) & $91,58 \pm 6,425$ & $86,31 \pm 14,955$ & $0,735^{*}$ \\
Bursts tônicos (\%) & $8,49 \pm 6,596$ & $13,64 \pm 14,932$ & $0,735^{\star}$ \\
Episódios em micro & $67,35 \pm 11,844$ & $60,25 \pm 17,25$ & $0,249^{* *}$ \\
despertar(\%) & $62,64 \pm 31,484$ & $39,27 \pm 19,514$ & $0,017^{* * \#}$ \\
\hline Atividades oro-motoras & & & \\
\hline
\end{tabular}

\footnotetext{
* hipótese de que sem bruxismo $\neq$ com bruxismo

** hipótese de que sem bruxismo < com bruxismo

\# estatisticamente significativo
} 
Com relação à macroestrutura do sono, não houve diferenças significativas entre os grupos com e sem bruxismo, exceto pelo número de microdespertares por hora, o qual foi maior no grupo com bruxismo $(p=0,032)$ (Tabela 7).

Tabela 7 Variáveis convencionais do sono de indivíduos diagnosticados com e sem bruxismo, segundo o critério polissonográfico.

\begin{tabular}{lccc}
\hline & C/ BRUXISMO-PSG & S/ BRUXISMO-PSG & p \\
\cline { 2 - 4 } & Média e DP & Média e DP & Mann-Whitney \\
\cline { 2 - 4 } Latência do sono $\left(\mathbf{h}^{\S}\right)$ & $0,270 \pm 0,286$ & $0,509 \pm 0,391$ & $0,029^{*}$ \\
Latência do sono REM $\left(\mathbf{h}^{\S}\right)$ & $2,035 \pm 0,793$ & $2,156 \pm 0,981$ & $0,815^{*}$ \\
Eficiência do sono $(\%)$ & $87,518 \pm 9,860$ & $86,553 \pm 8,083$ & $0,516^{*}$ \\
Tempo de sono fase 1 (\%) & $8,573 \pm 3,322$ & $8,420 \pm 3,365$ & $0,917^{\star}$ \\
Tempo de sono fase 2 (\%) & $60,136 \pm 8,188$ & $60,347 \pm 9,178$ & $0,979^{*}$ \\
Tempo de sono fase $3 / 4(\%)$ & $15,209 \pm 8,437$ & $14,033 \pm 9,017$ & $0,715^{\star}$ \\
Tempo de sono fase REM (\%) & $16,255 \pm 5,269$ & $17,200 \pm 8,832$ & $0,795^{*}$ \\
Micro despertar/hora & $6,536 \pm 2,908$ & $4,207 \pm 1,733$ & $0,032^{* \star \#}$ \\
\hline
\end{tabular}

*hipótese de sem bruxismo -PSG $\neq$ com bruxismo -PSG

**hipótese sem bruxismo -PSG < com bruxismo -PSG

\# estatisticamente significativo

$\S$ O tempo em horas está expresso em valores decimais. 
Três das quatro variáveis oromotoras de corte não mostraram diferenças significativas entre os grupos com e sem bruxismo diagnosticado clinicamente. Houve diferença significativa apenas entre os valores de episódios de ARMM por noite(Tabela 8)

Tabela 8 Médias e desvio padrão das variáveis motoras de corte para o diagnóstico de bruxismo dos grupos com e sem bruxismo diagnosticado clinicamente.

\begin{tabular}{lccc}
\hline & C/ BRUXISMO CLÍNICO & S/ BRUXISMO CLÍNICO & $\mathbf{p}^{*}$ \\
\cline { 2 - 4 } & Média e DP & Média e DP & $\begin{array}{c}\text { Mann- } \\
\text { Whitney }\end{array}$ \\
\cline { 2 - 4 } Epi/noite & $23,529 \pm 11,932$ & $15,44 \pm 8,74$ & $0,035^{\#}$ \\
Epi/hora & $4,084 \pm 1,977$ & $2,72 \pm 1,450$ & 0,089 \\
B/hora & $16,000 \pm 8,276$ & $11,73 \pm 9,285$ & 0,058 \\
B/epi & $3,959 \pm 0,938$ & $4,278 \pm 1,885$ & 0,499 \\
\hline
\end{tabular}

* hipótese de que sem bruxismo clínico < com bruxismo clínico

\# estatisticamente significativo

Reforçando essa discrepância, também não houve associação entre os diagnósticos de bruxismo pelo exame clínico e pelo exame polissonográfico, visto que o valor de qui-quadrado entre os dois exames foi de 0,292, com $p=0,588$. 
Em 8 indivíduos, embora diagnosticados clinicamente como portadores de bruxismo ativo, a PSG não evidenciou atividade oro-motora significativa. Sendo que, em 3 deles, o diagnóstico clínico foi reforçado pelo acompanhamento de bruxismo devolvido, onde constava a freqüência semanal de relato de apertar e/ou ranger os dentes (Tabela 9)

Tabela 9 Diagnóstico clínico de bruxismo positivo (reforçado pelo acompanhamento de bruxismo) discrepante do diagnóstico polissonográfico.

\begin{tabular}{lccc}
\hline & FICHA & \multicolumn{3}{c}{ DIAGNÓSTICO DE BRUXISMO } \\
\cline { 2 - 4 } & $\begin{array}{c}\text { ACOMPANHAMENTO } \\
\text { (noites/semana) }\end{array}$ & CLÍNICO & PSG \\
\cline { 2 - 4 } $\mathbf{7}$ & 5,0 & $\mathrm{~S}$ & $\mathrm{~N}$ \\
$\mathbf{1 0}$ & 1,8 & $\mathrm{~S}$ & $\mathrm{~N}$ \\
$\mathbf{1 2}$ & 2,0 & $\mathrm{~S}$ & $\mathrm{~N}$ \\
\hline
\end{tabular}




\subsection{Variáveis oro-motoras e DTM}

Ao se analisarem as variáveis de sono nos grupos de indivíduos previamente diagnosticados como portadores ou livres de DTM, verificou-se que não houve diferenças estatísticas entre os grupos (Tabela 10).

Tabela 10 Médias com desvio padrão das variáveis de sono, seguidas dos valores de $\mathrm{p}$, após realização do teste Mann-Whitney para comparação dos grupos.

\begin{tabular}{lccc}
\hline & C/ DTM & S/ DTM & $\mathbf{p}^{*}$ \\
\cline { 2 - 4 } & (média e DP) & (média e DP) & Mann-Whitney \\
\cline { 2 - 4 } Latência do sono $\left(\mathbf{h}^{* *}\right)$ & $0,445 \pm 0,416$ & $0,365 \pm 0,306$ & 0,796 \\
Latência do sono REM $\left(\mathbf{h}^{* *}\right)$ & $2,147 \pm 1,118$ & $2,055 \pm 0,585$ & 0,979 \\
Eficiência do sono (\%) & $86,543 \pm 10,037$ & $87,450 \pm 7,249$ & 0,958 \\
Tempo de sono estágio 1 (\%) & $8,543 \pm 3,363$ & $8,417 \pm 3,329$ & 0,877 \\
Tempo de sono estágio 2 (\%) & $60,429 \pm 9,212$ & $60,058 \pm 8,235$ & 0,877 \\
Tempo de sono estágio 3/4(\%) & $13,879 \pm 8,656$ & $15,292 \pm 8,905$ & 0,776 \\
Tempo de sono estágio REM (\%) & $17,164 \pm 5,362$ & $16,375 \pm 5,891$ & 0,857 \\
Microdespertar/hora & $5,679 \pm 2,654$ & $4,625 \pm 2,380$ & 0,367 \\
\hline
\end{tabular}

* hipótese de que sem DTM $\neq$ com DTM 
Não houve diferenças estatísticas entre as variáveis oromotoras - tanto aquelas utilizadas como limítrofes ou de corte para o diagnóstico de bruxismo, quanto a distribuição dos episódios e/ou bursts nas diferentes fases do sono. Também não houve diferença entre a ocorrência de episódos e/ou bursts dos tipos fásico, tônico ou misto nos grupos com e sem DTM (Tabela 11).

Tabela 11 Médias com desvio padrão das variáveis oromotoras, seguidas dos valores de $\mathrm{p}$, após realização do teste Mann-Whitney para comparação dos grupos com e sem DTM.

\begin{tabular}{lccc}
\hline & C/ DTM & S/ DTM & p \\
\cline { 2 - 4 } & Média e DP & Média e DP & Mann-Whitney \\
\cline { 2 - 4 } Epi/noite & $21,43 \pm 10,457$ & $19,92 \pm 12,930$ & 0,588 \\
Epi/hora & $3,76 \pm 1,887$ & $3,44 \pm 1,985$ & 0,738 \\
B/hora & $16,17 \pm 9,489$ & $12,60 \pm 7,627$ & 0,328 \\
B/epi & $4,30 \pm 1,253$ & $3,80 \pm 1,385$ & 0,302 \\
Episódios ARMM estágio 1(\%) & $18,73 \pm 9,524$ & $20,75 \pm 18,397$ & 0,796 \\
Episódios ARMM estágio 2(\%) & $58,02 \pm 10,673$ & $49,29 \pm 20,221$ & 0,198 \\
Episódios ARMM estágio $3 / 4 \%)$ & $6,74 \pm 6,710$ & $12,73 \pm 21,828$ & 0,958 \\
Episódios ARMM estágio REM (\%) & $16,49 \pm 12,059$ & $17,27 \pm 11,889$ & 0,857 \\
Bursts no estágio 1(\%) & $15,14 \pm 9,701$ & $18,61 \pm 19,671$ & 0,876 \\
Bursts no estágio 2(\%) & $56,76 \pm 15,303$ & $47,97 \pm 24,262$ & 0,226 \\
Bursts no estágio 3/4\%) & $10,04 \pm 13,162$ & $17,22 \pm 29,040$ & 0,792 \\
Bursts no estágio REM (\%) & $17,59 \pm 12,199$ & $16,22 \pm 13,999$ & 0,857 \\
Episódios fásicos (\%) & $71,61 \pm 21,152$ & $59,96 \pm 22,557$ & 0,172 \\
Episódios tônicos (\%) & $22,70 \pm 20,279$ & $31,75 \pm 21,207$ & 0,267 \\
Episódios mistos (\%) & $8,27 \pm 10,135$ & $9,03 \pm 8,225$ & 0,671 \\
Bursts fásicos (\%) & $91,71 \pm 9,160$ & $84,85 \pm 14,54$ & 0,172 \\
Bursts tônicos (\%) & $8,27 \pm 9,106$ & $15,18 \pm 14,580$ & 0,165 \\
Episódios em micro despertar(\%) & $68,41 \pm 15,177$ & $57,24 \pm 28,001$ & 0,381 \\
Atividades oro-motoras & $51,07 \pm 20,484$ & $46,92 \pm 34,566$ & 0,410 \\
\hline hipótse & &
\end{tabular}

* hipótese de que sem DTM < com DTM 
Com relação à associação entre atividade motora, que pode ser traduzida como bruxismo, e sintomatologia, não foi verificada associação entre bruxismo (diagnosticado pela PSG) e o diagnóstico prévio de DTM, visto que o Quiquadrado entre os grupos foi $0,672(p=0,413)$. 
Em relação à sintomatologia apresentada pelo paciente na manhã seguinte ao exame polissonográfico, não houve diferença entre as médias das variáveis oro-motoras de corte dos grupos com e sem dor na EAV (Tabela 12), nem nos grupos com e sem dor à palpação nos músculos e/ou na ATM (Tabela 13).

Tabela 12 Médias com desvio padrão das variáveis oromotoras, seguidas dos valores de $\mathrm{p}$, após realização do teste Mann-Whitney para comparação dos grupos com e sem dor na EAV, na manhã seguinte ao exame polissonográfico.

\begin{tabular}{lccc}
\hline & C/ DOR (EAV) & S/ DOR (EAV) & p $^{*}$ \\
\cline { 2 - 4 } & Média e DP & Média e DP & \\
\cline { 2 - 4 } Epi/noite & $21,222 \pm 6,300$ & $20,471 \pm 13,588$ & 0,209 \\
Epi/hora & $3,878 \pm 1,423$ & $3,472 \pm 2,137$ & 0,209 \\
B/hora & $16,111 \pm 8,209$ & $13,682 \pm 9,079$ & 0,172 \\
B/epi & $4,067 \pm 1,251$ & $4,071 \pm 1,383$ & 0,657 \\
\hline
\end{tabular}

*hipótese de que sem dor < com dor

Tabela 13 Médias com desvio padrão das variáveis oromotoras, seguidas dos valores de $\mathrm{p}$, após realização do teste Mann-Whitney para comparação dos grupos com e sem dor à palpação, na manhã seguinte ao exame polissonográfico.

\begin{tabular}{lccc}
\hline & C/ dor à palpação & S/ dor à palpação & p $^{*}$ \\
\cline { 2 - 4 } & Média e DP & Média e DP & \\
\cline { 2 - 4 } Epi/noite & $19,889 \pm 10,442$ & $22,625 \pm 14,040$ & 0,609 \\
Epi/hora & $3,563 \pm 1,931$ & $3,725 \pm 1,953$ & 0,641 \\
B/hora & $15,306 \pm 9,458$ & $12,763 \pm 6,932$ & 0,235 \\
B/epi & $4,244 \pm 1,321$ & $3,675 \pm 1,289$ & 0,194 \\
\hline
\end{tabular}

*hipótese de que sem sensibilidade < com sensibilidade 
Entretanto, ao se tomar apenas a população com bruxismo diagnosticado pela PSG (B-PSG), vê-se que os indivíduos com B-PSG e dor à palpação apresentaram um número significativamente maior de burst/hora do que os indivíduos com B-PSG sem dor à palpação (Tabela 14).

Tabela 14 Médias com desvio padrão das variáveis oromotoras, seguidas dos valores de $\mathrm{p}$, após realização do teste Mann-Whitney para comparação dos indivíduos com bruxismo-PSG com e sem dor à palpação na manhã seguinte ao exame polissonográfico.

\begin{tabular}{|c|c|c|c|}
\hline & B-PSG c/ dor à palpação & B-PSG s/ dor à palpação ${ }^{\S}$ & $p^{*}$ \\
\hline & Média e DP & Média e DP & \\
\hline Epi/noite & $29,250 \pm 7,887$ & $33,750 \pm 9,0323$ & 0,633 \\
\hline Epi/hora & $5,350 \pm 1,313$ & $5,300 \pm 0,969$ & 0,567 \\
\hline B/hora & $24,038 \pm 6,055$ & $18,800 \pm 1,525$ & $0,044^{\#}$ \\
\hline B/epi & $4,550 \pm 1,048$ & $3,650 \pm 0,793$ & 0,063 \\
\hline
\end{tabular}


$\mathrm{Na}$ tentativa de melhor explicar o comportamento paradoxal de alguns indivíduos, examinaram-se os casos de $B C$ individualmente $(n=17)$ e verificou-se que:

1) No grupo controle, havia 4 indivíduos com BC confirmado pela PSG (fichas 17, 19, 23 e 33), mas sem dor à palpação na manhã seguinte do exame.

2) $\quad \mathrm{Na}$ amostra total, 7 indivíduos com BC não confirmado pela PSG - 4 do GE (fichas $6,7,10,12$ ) e 3 do GC (fichas 18, 29, 32) - ou seja, com baixa atividade oromotora durante a noite, apresentaram dor à palpação na manhã seguinte ao exame.

A Tabela 15 mostra a diferença na atividade oromotora entre ambos os grupos.

Tabela 15 Valores das médias e desvio padrão das variáveis oromotoras de corte de 7 indivíduos com dor matinal à palpação e de 4 indivíduos sem dor matinal à palpação.

\begin{tabular}{lccc}
\hline & C/ dor à palpação & S/ dor à palpação** & p* $^{*}$ \\
\cline { 2 - 4 } & Média e DP & Média e DP & Mann-Whitney \\
\cline { 2 - 4 } Epi/noite & $12,86 \pm 4,7$ & $33,75 \pm 9,03$ & $0,004^{\#}$ \\
Epi/hora & $2,21 \pm 0,86$ & $5,30 \pm 0,97$ & $0,004^{\#}$ \\
B/hora & $9,36 \pm 4,64$ & $18,80 \pm 1,52$ & 0,07 \\
B/epi & $4,21 \pm 1,10$ & $3,65 \pm 0,79$ & 0,75 \\
\hline
\end{tabular}

$\S \mathrm{n}=7$, com bruxismo clínico não confirmado pela PSG.

** $n=4$, com bruxismo clínico confirmado pela PSG.

* hipótese de que com dor à palpação < sem dor à palpação.

\# estatisticamente significativo 
Pelo fato de a maioria dos indivíduos com BC (11 de 17) e com bruxismoPSG (8 de 12) encontrarem-se no grupo com DTM, foram realizados testes de correlação de Spearman entre os valores das variáveis motoras de corte e o índice de DTM resultado do questionário de avaliação objetiva de DTM.

Quando o teste foi realizado na amostra como um todo, não houve correlação entre qualquer das variáveis (epi/noite, epi/hora, b/hora e b/epi) e o índice de DTM (Tabela 16).

Tabela 16 Índice de correlação de Spearman entre as variáveis oromotoras de corte e o índice de DTM na amostra total

\begin{tabular}{lcc}
\hline & Índice de Correlação de Spearman & $\mathbf{p}$ \\
\cline { 2 - 3 } Epi/noite x índice de DTM & 0,07 & 0,706 \\
Epi/hora x índice de DTM & 0,04 & 0,821 \\
B/hora x índice de DTM & 0,11 & 0,569 \\
B/epi x índice de DTM & 0,16 & 0,421 \\
\hline
\end{tabular}

Ao realizar-se o teste de correlação de Spearman entre as variáveis oromotoras e o índice de DTM apenas dos indivíduos com DTM, também não houve correlação (Tabela 17).

Tabela 17 Índice de correlação de Spearman entre as variáveis oromotoras de corte e o índice de DTM dos indivíduos com DTM

\begin{tabular}{lcc}
\hline & Índice de Correlação de Spearman & $\mathbf{p}$ \\
\cline { 2 - 3 } Epi/noite x índice de DTM & $-0,065$ & 0,82 \\
Epi/hora x índice de DTM & $-0,061$ & 0,83 \\
B/hora x índice de DTM & 0,01 & 0,97 \\
B/epi x índice de DTM & 0,08 & 0,78 \\
\hline
\end{tabular}


Sabendo-se que alguns indivíduos com forte evidência clínica de bruxismo não apresentaram bruxismo-PSG, realizou-se o teste de correlação de Spearman entre as variáveis oromotoras e o índice de DTM apenas dos indivíduos com bruxismo-PSG e DTM. Os dados da Tabela 18 mostram que, novamente, não houve correlação entre a intensidade da atividade rítmica dos músculos mastigatórios (epi/noite, epi/hora e b/epi) e o índice de DTM dos indivíduos com DTM e com bruxismo-PSG. Houve apenas uma correlação fraca e negativa entre o número de b/hora e o índice de DTM dos indivíduos com DTM e bruxismo-PSG.

Tabela 18 Correlação de Spearman entre as variáveis oromotoras de corte e o índice de DTM dos indivíduos com DTM e bruxismo-PSG.

\begin{tabular}{lcc}
\hline & Índice de Correlação de Spearman & $\mathbf{p}$ \\
\cline { 2 - 3 } Epi/noite x índice de DTM & $-0,09$ & 0,846 \\
Epi/hora x índice de DTM & $-0,19$ & 0,670 \\
B/hora x índice de DTM & $-0,48$ & $0,268^{*}$ \\
B/epi x índice de DTM & $-0,12$ & 0,787 \\
\hline *correlaçäo fraca e negativa & &
\end{tabular}

A Tabela 19 mostra que também não houve correlação entre o número das variáveis oromotoras de corte e a intensidade de dor medida por meio de Escala de Análise Visual (EAV).

Tabela 19 Índice de correlação de Spearman entre as variáveis oromotoras de corte e a intensidade da dor medida por meio da EAV da amostra total.

\begin{tabular}{lcc}
\hline & Índice de Correlação de Spearman & $\mathbf{p}$ \\
\cline { 2 - 3 } Epi/noite x índice de DTM & 0,15 & 0,44 \\
Epi/hora x índice de DTM & 0,16 & 0,40 \\
B/hora x índice de DTM & 0,22 & 0,27 \\
B/epi x índice de DTM & $-0,036$ & 0,86 \\
\hline
\end{tabular}


DISCUSSÃO 


\section{6 - DisCUSSÃO}

\subsection{Diagnóstico de Bruxismo}

Apesar de IKEDA et al. 35 terem afirmado que a natureza variável do bruxismo muitas vezes resultou em registros improdutivos durante as duas primeiras noites de registro e de considerarem 20\% da CVM valores elevados para serem utilizados como limite mínimo para a detecção dos eventos de bruxismo, foi possível realizar, no presente estudo, registros válidos dessa atividade, visto que 12 indivíduos (46\% da amostra) apresentaram ARMM acima do limiar de diagnóstico proposto por LAVIGNE; ROMPRÉ; MONTPLAISIR42, portanto, diagnosticados como bruxômanos.

Entretanto, o fato de 6 indivíduos com evidências clínicas de bruxismo (fichas 7, 10, 12, 18, 29 e 32) não terem sido diagnosticados como portadores reflete bem a variação do bruxismo com o tempo68 42 - mesmo em períodos de atividade. Isso indica que quanto maior o número de noites avaliadas, menor o risco de ocorrerem resultados falsos negativos, indo ao encontro da observação de IKEDA et al. ${ }^{35}$, da ocorrência de um pequeno, mas consistente aumento no nível de bruxismo ao longo das 4 noites de avaliação em seu estudo. Além do mais os próprios proponentes dos valores de corte ${ }^{42}$, alertaram que esses valores não são números absolutos e que não deveriam ser usados sem uma avaliação completa do paciente. Mesmo utilizando apenas uma noite de exame polissonográfico, o critério de diagnóstico sugerido por LAVIGNE; ROMPRÉ; MONTPLAISIR ${ }^{42}$ mostrou-se de 
grande valor, concordando com outros estudos 43,49 de diagnóstico de bruxismo, que utilizaram o mesmo critério. Vê-se na Tabela 5 que houve diferenças significativas entre as médias dos valores de corte (epi/noite, epi/hora e b/hora) dos indivíduos diagnosticados com e sem bruxismo pela PSG.

Notou-se que a população com e sem bruxismo-PSG exibiu principalmente episódios do tipo fásico $(91,58 \%$ e $86,31 \%$ respectivamente), tendo ocorrido também a predominância desse tipo de episódio no estudo de LAVIGNE; ROMPRÉ; MONTPLAISIR41.

WARE; RUGH86 relataram que os indivíduos bruxômanos com dor apresentam mais atividade de bruxismo $(\mathrm{s} / \mathrm{h})$ durante a fase REM do que bruxômanos livres de dor. Nesta pesquisa não foi calculado o tempo em segundos de ARMM, entretanto comparou-se o número percentual de episódios na fase REM para o grupo com bruxismo-PSG com e sem DTM e verificou-se que, para o primeiro, o valor percentual de episódios foi de $18,03 \% \pm 17,75$ e, para o grupo com bruxismo-PSG e sem DTM foi de $17,44 \% \pm 12,189$, sem diferença significativa entre eles, pelo teste de Mann-Whitney $(Z=0,18$ e $p=0,57)$. 


\section{Critérios de Diagnóstico Polissonográfico}

Quanto à detecção dos episódios de bruxismo, consideram-se os seguintes aspectos:

\section{a) Intensidade de contração}

Ao se iniciarem os estudos de atividade eletromiográfica dos músculos mastigatórios, com os estudos de RUGH; SOLBERG69, em 1975, considerava-se $20 \mu \mathrm{V}$ a atividade mínima, a partir da qual, o paciente apresentava atividade de bruxismo, não se levando em conta, no entanto, a duração ou os intervalos entre as elevações eletromiográficas. Essa limitação foi compensada em 1981 por WAGNER ${ }^{85}$, quando o mesmo considerou como atividade de bruxismo qualquer elevação superior a $5 \mathrm{~h}$, mas com intervalos mínimos de 3 segundos entre elas. IKEDA et al.35, em 1996, sugeriram a utilização da elevação eletromiográfica que correspondesse a $10 \%$ da contração voluntária máxima do paciente. Discordando do que fizeram OKESON et al.60, em 1990 e VELLY-MIGUEL et al.84, em 1992, os quais consideraram um evento de bruxismo aquele que excedesse $40 \%$ da força de contração voluntária máxima. LAVIGNE; ROMPRÉ; MONTPLAISIR42, em 1996, retiveram para análise em seu estudo todos os potenciais eletromiográficos com amplitude mínima de $20 \%$ da contração voluntária máxima por ser essa a amplitude que correspondeu em uma análise preliminar ao sinal eletromiográfico suavizado mais freqüentemente associado ao início dos episódios de bruxismo, quando eram controlados os sinais com áudio e vídeo. IKEDA et al. ${ }^{35}$ avaliaram os diferentes 
níveis de contração apresentados pela amostra e escolheram o valor mais freqüente na população estudada. Elegeu-se $10 \%$ da contração voluntária máxima como um limite mínimo, uma vez que, segundo eles, $20 \%$ e, mais seguramente, $40 \%$ tratamse de valores elevados para serem utilizados como limite mínimo para a detecção de eventos de bruxismo, em particular se se utiliza o método de média eletromiográfica integral suavizada. Optou-se, neste estudo, por contabilizar apenas as elevações com, no mínimo, $20 \%$ da CVM, seguindo a recomendação LAVIGNE; ROMPRÉ; MONTPLAISIR42 a fim de compatibilizar a técnica de leitura ao escore (valores de corte) sugerido pelos autores, além de ser, atualmente, o valor mais utilizado na literatura.

\section{b) Duração dos bursts}

PICCIONE et al.61, em 1982 definiram que um evento de bruxismo deveria apresentar no mínimo 0,5 segundo e no máximo 1,5 segundo, excluindo-se da análise as contrações com maior duração. Enquanto outros75 60 definiram como critério que os bursts deveriam durar no mínimo 2 segundos. WARE; RUGH ${ }^{86}$, em 1988; VELLY-MIGUEL et al.84, em 1992 LAVIGNE; ROMPRÉ; MONTPLAISIR ${ }^{42}$, em 1996 consideraram o tempo de 0,25 segundo como o mínimo necessário para caracterizar um burst fásico de bruxismo e 2 segundos como o tempo mínimo necessário para caracterizar um burst tônico de bruxismo. A exclusão de bursts menos demorados eliminava possíveis contrações musculares diversas da atividade de bruxismo. IKEDA et al. ${ }^{35}$, em 1996, eliminaram quaisquer bursts de duração inferior a 3 segundos, com o objetivo de excluir artefatos ou mioclonia. Optou-se neste estudo, por 
adotar o critério utilizado pela maioria dos autores (WARE; RUGH86, VELLY-MIGUEL et al. 84 e LAVIGNE; ROMPRÉ; MONTPLAISIR ${ }^{42}$ ).

\section{c) Intervalos entre os episódios}

WAGNER ${ }^{85}$, em 1981 e WARE e RUGH86, em 1988, VELLY-MIGUEL et al. 84, em 1992 e LAVIGNE; ROMPRÉ; MONTPLAISIR42, em 1996 consideraram como intervalo entre os episódios de bruxismo, o tempo de mínimo de 3 segundos. Muito embora PICCIONE et al.61, em 1982, STOCK e CLARKE75, em 1983 e OKESON et al.60, em 1990 tenham reduzido esse período de silêncio entre os episódios para o tempo mínimo de 2,5; 1 e 2 segundos, respectivamente. Se os bursts apresentassem intervalos inferiores a esses períodos, os mesmos eram consideradas unidos em um único episódio de bruxismo. No trabalho de IKEDA et al. ${ }^{35}$, em 1996, os autores sugeriram uma associação de critérios para a detecção de eventos de bruxismo, dentre eles, o intervalo mínimo entre episódios de 5 segundos. 0 critério desta pesquisa segue a orientação de WARE; RUGH86 e VELLY-MIGUEL et al. ${ }^{84}$ e LAVIGNE; por tratar-se do conjunto de critérios que predominou, além de ser adotado também por ROMPRÉ; MONTPLAISIR ${ }^{42}$, em cujo trabalho de validação da PSG baseou-se o presente estudo.

\section{d) Ocorrência de eventos para diagnóstico}

LAVIGNE; ROMPRÉ; MONTPLAISIR42 (1996) utilizaram os critérios de WARE; RUGH86, (1988) quanto à duração e ao intervalo entre os bursts e episódios, desconsiderando aqueles com intensidade inferior a $20 \%$ da contração voluntária 
máxima (CVM). Os autores verificaram a confiabilidade, em se diagnosticar bruxismo - quanto à sensibilidade e especificidade - das seguintes ocorrências: "episódios de bruxismo por noite", "episódios de bruxismo por hora", "bursts de bruxismo por episódio", "bursts de bruxismo por hora" e "episódios de bruxismo acompanhados de sons de ranger de dentes". Usando os dados derivados das análises dos pacientes com bruxismo e controle, delinearam-se curvas receptoroperador (ROC) e então se escolheram os valores de corte: (1) 30 episódios de bruxismo por noite ou 4 episódios de bruxismo por hora de sono; (2) 6 bursts por episódio de bruxismo e/ou 25 bursts por hora de sono e (3) presença, em cada caso, de pelo menos 2 episódios de ranger de dentes. Calcularam-se os valores de previsibilidade positiva e negativa desses valores de corte com relação à análise clínica. Utilizando-se esses valores de corte, a polissonografia alcançou $92,9 \%$ de previsibilidade positiva e $76 \%$ de previsibilidade negativa. Por essa razão, utilizouse a PSG como método gold standard de diagnóstico de bruxismo, na verificação da confiabilidade (sensibilidade e especificidade) do exame clínico.

\section{e) Numero de noites de registro polissonográfico}

WARE; RUGH86, em 1988, não estabeleceram, em seu estudo, um número de noites para todos os pacientes, mas relataram que, como alguns pacientes realizaram o exame polissonográfico por apenas uma noite, considerouse apenas a primeira noite de estudo para as análises de correlação entre severidade do quadro clínico relacionada ao bruxismo e os estágios do sono. A Associação Americana de Desordens do Sono (THORPY82, 1990) recomenda a 
utilização de duas noites consecutivas para a análise do bruxismo, sendo a primeira utilizada para a adaptação do paciente ao ambiente bem como registrar qualquer outra desordem do sono, e a segunda para a coleta dos dados experimentais. Essas recomendações foram seguidas nos estudos de VELLY-MIGUEL et al.84, 1992 e LAVIGNE; ROMPRÉ; MONTPLAISIR42, em 1996. LAVIGNE; ROMPRÉ; MONTPLAISIR42 associam o não registro de barulho de ranger de dentes em 4 pacientes, dentre 18 com bruxismo, à incapacidade do microfone de captar ruídos muito baixos e ao curto período da análise, visto que a atividade de bruxismo flutua ao longo do tempo. Por essa razão, não se utilizou, na presente pesquisa, o critério de diagnóstico sugerido por LAVIGNE; ROMPRÉ; MONTPLAISIR 42 de, no mínimo dois episódios de bruxismo associados a barulho de ranger de dentes.

IKEDA et al. ${ }^{35}$, em 1996 realizaram um estudo, em que nove indivíduos (cinco homens e quatro mulheres) realizaram exame polissonográfico por 4 noites consecutivas no ambiente domiciliar dos mesmos. Os autores relatam que a natureza variável do bruxismo muitas vezes resultou em registros improdutivos durante as duas primeiras noites de registro e que houve um pequeno, mas consistente, aumento no nível de bruxismo ao longo das 4 noites estudadas. Ao passo que LAVIGNE; ROMPRÉ; MONTPLAISIR 43 em seu estudo de comparação das características eletrofisiológicas da ARMM e das variáveis do sono em uma população de 82 indivíduos controle e 33 indivíduos com bruxismo do sono, utilizaram apenas uma noite de registro para cada indivíduo. Com base nesse último estudo, optou-se por realizar a presente pesquisa com apenas uma noite de exame polissonográfico. 


\subsection{PREVALÊNCIA DE BRUXISMO NOS GRUPOS E SUA ASSOCIAÇÃO COM DTM}

A crença de que o bruxismo está envolvido na predisposição, iniciação, e perpetuação da DTM em geral mantida, principalmente porque o bruxismo definido clinicamente é mais prevalente nos pacientes com DTM do que na população geral 5 , 39 . Consequentemente, tem-se hipotetizado que bruxismo intenso resulta em dor miofascial, sons na ATM (estalido, crepitação), limitação dos movimentos mandibulares e cefaléia tensional68.

Ao se observarem os valores percentuais de indivíduos com bruxismo clínico em um grupo com DTM $(78,6 \%)$ e em um grupo com dor matinal à palpação (77,8\%), e ainda, os valores de bruxismo-PSG no grupo com DTM $(57,1 \%)$ e no grupo com dor matinal à palpação $(44,4 \%)$ deve ser considerada uma série de aspectos: Primeiro, ao se tentar determinar uma relação de associação com base em dados de prevalência, principalmente quando se toma como referência apenas a população doente, pode-se visualizar um quadro irreal. Visto ser essa a população que procura tratamento e a alta freqüência de história e sinais de bruxismo a ela relacionada no ambiente clínico, facilmente se considera como real essa associação.

Uma situação diferente torna-se visível diante dos valores percentuais de indivíduos sem DTM e com bruxismo clínico (50,0\%) (Figura 12) e sem dor à palpação com bruxismo-PSG (50,0\%) (Figura 12) e ainda, dos valores percentuais de indivíduos com DTM ou dor à palpação sem bruxismo-PSG (42,86\% e 55,6\% 
respectivamente) (Figura 11). Ao se examinar a associação entre duas entidades, é imprescindível que se observe não apenas a população doente, mas também a população saudável.

Por essa razão, os valores numéricos de qui-quadrado, os quais tomam por base a população também saudável, não verificaram a existência de associação entre bruxismo clínico e DTM e/ou dor matinal à palpação. Merece menção, portanto, que pode se dever a essa "ilusão de óptica numérica" o fato de alguns autores 13, 39, 57 considerarem como verdadeira ou significativa a inter-relação entre bruxismo e disfunção, creditando, muitas vezes, ao primeiro o papel de fator etiológico da segunda.

Deve-se salientar, entretanto, que é nítida a maior concentração de casos com bruxismo clínico e PSG no grupo com DTM e que os altos índices de prevalência de indivíduos com bruxismo clínico na população com dor à palpação $(77,80 \%)$ (Figura 11) encontra complemento ao se examinar o percentual de indivíduos com bruxismo clínico na população sem dor matinal à palpação $(37,50 \%)$ (Figura 12). Outro detalhe que deve ser observado é que o valor de qui-quadrado quando se testou a existência de associação entre BC e dor à palpação foi de 2,389, o maior dentre os valores obtidos. Para que haja associação entre duas entidades, o valor de qui-quadrado aceito como mínimo é de 3,84. Apesar disso não fornecer evidência da existência de associação e, muito menos de relação de causa-e-efeito entre essas duas entidades, pode-se questionar se a ausência de associação entre bruxismo clínico e dor à palpação não se deveria ao tamanho reduzido da amostra. 
$\mathrm{E}$, mesmo não havendo tal associação, ainda que em amostras mais significativas, os índices de prevalência apontam para a necessidade de elucidação do papel exercido pelo bruxismo do sono ante a sintomatologia de DTM.

WILDMALM et al.87 reconhecem que uma associação significativa não prova a existência da relação causa-e-efeito, mas que pode atuar como possível fator de risco. LOCKER; SLADE ${ }^{47}$, que encontraram correlação positiva entre fatores de risco, como o bruxismo e sinais de DTM, indicaram cautela na interpretação desses achados, uma vez que uma relação temporal de causa-e-efeito não pode ser estabelecida com base em um modelo de estudo transversal.

Um ponto ainda a ser considerado é que, neste estudo, dos 14 pacientes com DTM, 13 apresentaram dor à palpação no segundo exame, independente de terem apresentado ou não atividade de bruxismo. Desses 14 pacientes, o único que não apresentou dor à palpação (ficha 34), apesar de ter sido diagnosticado clinicamente como bruxômano, não realizou atividade parafuncional na noite do exame polissonográfico. Já os demais pacientes onde a mesma situação ocorreu (bruxismo diagnosticado apenas clinicamente, mas sem atividade parafuncional na noite do exame ( $\mathrm{n}=4$ - fichas $6,7,10$ e 12) apresentaram dor matinal à palpação, sendo que os pacientes 6 e 10 apresentaram ainda piora do quadro clínico, expressa no índice de DTM para ambos e também na EAV para o paciente 6 (Anexo 10). Em 2 pacientes (fichas 3 e 15) o bruxismo não foi diagnosticado clinicamente nem pela PSG mas, mesmo assim apresentaram dor à palpação no segundo exame, sendo que o paciente 3 apresentou piora do quadro clínico, expresso no índice de DTM e o 
paciente 15 passou a apresentar estalido e leve aumento do índice de DTM. Do mesmo modo, os 6 pacientes (fichas 1, 5, 9, 11, 13 e 14) com bruxismo diagnosticado por ambos os métodos também apresentaram dor à palpação no segundo exame, sendo que, o paciente 1 apresentou piora no índice de DTM; o paciente 5 e 9 apresentavam-se sem dor na EAV no segundo exame, apesar do quadro clínico geral permanecer estável; o paciente 11 apresentou melhora do quando clínico e remissão da dor na EAV; o paciente 13 apresentou leve melhora, a dor na EAV reduziu aproximadamente $50 \%$ e o índice de DTM baixou de 8 para 4, apesar de ter sentido dor à palpação articular e o paciente 14 apresentou piora do quadro clínico expressa no índice de DTM. Por fim, apenas 1 paciente (ficha 8) teve bruxismo diagnosticado pela PSG mas não o havia sido clinicamente, este paciente apresentou significativa melhora do quadro, tanto pela redução da dor na EAV quanto no índice de DTM, de 10 para 2.

Apesar de não ter havido associação entre DTM e bruxismo diagnosticado por qualquer dos métodos, observa-se que houve um maior concentração de indivíduos com bruxismo clínico no grupo com DTM do que quando o bruxismo foi diagnosticado pela PSG. Isso leva a duas considerações: 1) É possível que os indivíduos com DTM percebam melhor ou estejam mais atentos à sua atividade parafuncional do que os indivíduos sem qualquer sintomatologia e, por isso, relatem o bruxismo com maior freqüência, podendo até considerarem-se bruxômanos sem, na verdade o serem. 2) Que em alguns casos de bruxismo realmente presente, a polissonografia não o tenha detectado, pela realização da PSG em apenas uma noite, associado à variabilidade inerente a essa atividade. É 
provável que, com a realização da PSG em um maior número de noites consecutivas, aliada a uma amostra mais significativa, essa dúvida se dissipasse, podendo ocorrer a confirmação do equilíbrio da casuística de bruxismo entre os grupos ou da sua concentração no grupo com DTM. Um problema metodológico relacionado ao diagnóstico clínico do bruxismo trata-se do auto relato dessa atividade. De acordo com LIPINSKI; NELSON44 auto-relatos de qualquer comportamento são tipicamente não confiáveis e, no mínimo, correm o risco de serem tendenciosos para uma super ou subestimativa. Por essa razão buscou-se determinar, sempre que possível na presente pesquisa, como os indivíduos sabiam que eram bruxômanos. LOBBEZOO; LAVIGNE45 recomendam que, preferivelmente, múltiplas técnicas de diagnóstico deveriam ser usadas para verificar o bruxismo. Seguindo essa recomendação, o diagnóstico de bruxismo em geral, constou de questionário (auto relato) - executado por três examinadores, acompanhamento de bruxismo pelo próprio paciente ou, preferencialmente por um companheiro de quarto (infelizmente devolvido por poucos), exame físico executado por três examinadores e ainda o exame polissonográfico.

O exame físico consistia de avaliação do desgaste oclusal, de pontos brilhantes em restaurações metálicas e da hipertrofia do masséter. Sabe-se que o desgaste oclusal por atrição, seja ele avaliado por meio de modelos de estudo ou por avaliação direta na boca13, como foi feito neste trabalho, na verdade representa o resultado cumulativo de desgaste funcional e parafuncional, não fornece evidência de que o hábito esteja ativo, além de ser dependente de fatores como idade e a forma como a relação oclusal ocorre ${ }^{71}$. Além do mais, no que tange 
à atividade parafuncional, as medidas de desgaste dentário fornecem dados apenas da atividade de ranger, desconsiderando a atividade de apertamento. Tudo isso faz com que o desgaste dentário torne-se uma medida de bruxismo menos confiável e menos válida do que o desejável45. As técnicas de avaliação de atividade, por meio do desgaste em dispositivos intra-orais 62 são especialmente problemáticas por afetarem justamente a atividade que está sendo medida. Do mesmo modo, trata-se de uma maneira limitada a verificação da atividade de bruxismo por meio da inspeção visual de pontos brilhantes nas restaurações metálicas, primeiro porque, principalmente na população mais jovem - faixa etária utilizada nesta pesquisa, cada vez com menor freqüência encontram-se restaurações desse tipo. A análise da hipertrofia do masséter mostrou-se inconsistente, sendo raro ocorrer o aumento de volume em três vezes quando contraído, ao contrário do que relataram LAVIGNE; ROMPRÉ; MONTPLAISIR42. Restando assim, como parâmetro mais confiável o relato do paciente (quando este era consciente da presença do hábito) associado ao de parente, cônjuge ou amigo. Lembrando que procurou-se fazer o questionário de maneira a não induzir o paciente a relacionar o hábito com sua sintomatologia de DTM, buscando sempre realizar as perguntas de maneira objetiva. Considerou-se que a confiabilidade do exame clínico foi bastante aumentada quando o acompanhamento de bruxismo foi devolvido e pelo fato de ter sido realizado por três examinadores. Assim, devido à subjetividade inerente ao exame clínico de bruxismo, idealmente, o exame polissonográfico deveria ser realizado por um maior número de noites visando a um diagnóstico mais seguro, completo e preciso do BS. 
Como exemplo de diagnóstico clínico, MOLINA et al.58 avaliaram 276 pacientes com DTM e, por meio de questionário, determinaram a presença ou a ausência de bruxismo e o classificaram em leve, moderado ou severo. Em seguida os autores concluíram que o grau de severidade de bruxismo correlacionava-se de maneira linear com a severidade da DTM. Convém atentar para o questionário utilizado, composto por 15 perguntas, as quais incluem informação anamnésica de sensação de tensão ou rigidez muscular ao acordar e ao longo do dia; sensação de cansaço nos músculos masséteres ao acordar; dor cervical ao acordar e sensação de fadiga no corpo e/ou sensação de sono pobre ao acordar. A cada resposta sim era dado o escore de 1 ponto, sendo que de 0 a 5 o indivíduo era classificado como bruxômano leve, de 5 a 10 como bruxômano moderado e de 10 a 15 como bruxômano severo. Acredita-se que os altos índices de correlação encontrados entre severidade de bruxismo e DTM nesse estudo deve-se ao fato de o questionário que deveria abordar apenas bruxismo, abranger também a severidade de sintomatologia de DTM além de ter sido empregado apenas em uma população com DTM. Uma vez tomada apenas a população sintomática, perde-se o parâmetro do grupo controle. Esses achados vão de encontro aos da presente pesquisa, onde apesar de a maioria dos casos de bruxismo clínico e polissonográfico encontraremse no grupo experimental (com DTM), não houve associação significativa do ponto de vista estatístico. Quanto à correlação com a severidade, também não foi verificada qualquer correlação entre os índices de atividade oromotora (epi/noite, epi/hora, b/hora ou b/epi) com os índices de DTM, fosse na amostra como um todo ou apenas na amostra com DTM, mesmo quando restrita apenas ao grupo com disfunção e bruxismo-PSG. 
Fica claro neste ponto que, de modo algum, se pode considerar como válida a discussão da existência de associação, quiçá de relação de causa-e-efeito entre bruxismo e DTM com base em valores de prevalência de bruxismo em populações sintomáticas.

Ao se avaliarem os valores de sensibilidade e especificidade do exame clínico com relação ao exame polissonográfico, vêse que o maior problema está em sua baixa especificidade, a qual pode dever-se, em parte a uma superestimativa dos pacientes com bruxismo, devido à subjetividade do método e, em parte ao fato de alguns pacientes realmente bruxômanos não terem sido dianosticados pelo método polissonográfico por este ter sido realizado apenas em uma noite. LAVIGNE; ROMPRÉ; MONTPLAISIR ${ }^{42}$ testaram a sensibilidade e a especificidade de cada uma das variáveis oromotoras de corte (epi/noite, epi/hora, b/hora e b/epi) com relação a indivíduos comprovadamente bruxômanos segundo o critério da ASDA (o qual incluía relato de bruxismo por parente, amigo ou cônjuge) de sons de ranger os dentes durante o sono no mínimo 5 noites por semana nos últimos 6 meses). LAVIGNE; ROMPRÉ; MONTPLAISIR 42 obtiveram para o número de episódios por hora, a sensibilidade de $72 \%$ e a especificidade de $94 \%$ e, para 0 número de bursts por hora, a sensibilidade de $78 \%$ e a especificidade de $100 \%$. Vêse portanto, que a polissonografia é mais específica do que sensível. Ou seja, mesmo realizada em duas noites a polissonografia mais facilmente diagnostica falsos negativos do que falsos positivos. No presente estudo a variável polissonográfica mais responsável pelo diagnóstico de bruxismo foi o número de episódios por hora. Essa variável, segundo LAVIGNE; ROMPRÉ; MONTPLAISIR42 
apresenta valor preditor positivo de $92,9 \%$ e valor preditor negativo de $77,3 \%$. Tomando por base esses valores de previsibilidade, pode-se considerar que $77,3 \%$ dos indivíduos onde a PSG não diagnosticou presença de bruxismo estão corretos, ou seja, há possibilidade de que 3 ou 4 diagnósticos de ausência de bruxismo estejam incorretos, o que provavelmente ocorreu com os pacientes 7, 10 e 12 .

Para que se tenham os valores reais da sensibilidade e, principalmente da especificidade do exame clínico, em relação à PSG, seria necessário que esta última fosse realizada em um número maior de noites consecutivas. Não se contesta a objetividade do exame polissonográfico em detectar a atividade parafuncional ao longo da noite do exame, entretanto, a fim de aumentar sua confiabilidade e de proporcionar-lhe condições para que ele atue realmente como gold standard, em função da variabilidade temporal do bruxismo exige-se que o registro não esteja limitado a apenas uma noite.

\subsection{SOBRE A INTER-RELAÇÃO ATIVIDADE MUSCULAR E DOR}

Muito se tem discutido a respeito da inter-relação dor-atividade muscular, seja esta mensurada quanto à atividade postural $48,72,76,81$, de contração máxima48, 72, 81, funcional14, 19, 48, 76, 79-81 ou parafuncional4, 8-10, 12, $18,26,27,29,36,41,48,58,68,73,78,86 . \mathrm{E}$, embora muitos autores $13,16,20,39,52,57$, 68, 70, 86, 89 usualmente tenham dado crédito à descrição do "ciclo vicioso", o qual propõe um relacionamento de reforço mútuo entre a dor crônica e a hiperatividade muscular, estudos bem controlados, tanto quanto a estabelecimento de grupos experimental e controle correlacionados por sexo e idade, quanto a métodos mais 
objetivos de estímulo à dor4, 27, 67, 77-80 (estudos de dor experimental), de diagnóstico 26, 76 (estudos de dor clínica) e de verificação da atividade muscular, têm avançado na elucidação dos diversos mecanismos envolvidos nessa interrelação. Embora existente, não se trata de um relacionamento de causa e efeito simplesmente mas da combinação de diversos sistemas de modulação (inibição ou excitação) dos motoneurônios alfa (modelo de adaptação à dor48, ${ }^{81}$ ), atividade reflexa ou excitação dos motoneurônios- $\gamma^{51}$.

A causa precisa da dor muscular durante o esforço ainda não é conhecida, embora tenham sido relatadas muitas alterações morfológicas e metabólicas relacionadas à contração muscular, incluindo redução significativa no $\mathrm{pH}$ muscular e a alterações nos processos metabólicos que envolvem o fosfato total, o complexo creatina-fosfato e o fosfato inorgânico ${ }^{50}$, aumento da pressão intramuscular e isquemia local21, 52.

Observou-se na presente pesquisa que, de um modo geral não houve diferença entre os níveis de atividade oromotora entre os indivíduos com ou sem DTM e com ou sem dor matinal à palpação. Entretanto, 7 indivíduos do grupo experimental (fichas 1, 5, 8, 9, 11, 13, 14) apresentaram dor à palpação dos músculos mastigatórios e cervicais na manhã seguinte ao exame após terem apresentado maiores níveis de atividade (bruxismo-PSG). Apenas 1 indivíduo do grupo controle (ficha 24) que apresentou bruxismo-PSG, também manifestou dor matinal à palpação. Os demais indivíduos do grupo controle que apresentaram bruxismo-PSG ( $\mathrm{n}=4$-fichas 17, 19, 23, e 33) não apresentaram dor à palpação na 
manhã seguinte ao exame. Isso parece sugerir que os indivíduos com DTM estão mais sujeitos a sentir dor após a realização de atividade parafuncional do que os indivíduos do grupo controle, podendo sugerir maior suscetibilidade das fibras musculares ao microtrauma, com relação aos indivíduos bruxômanos sem dor, os quais seriam mais resistentes à fadiga e ao dano 41 , ou ainda a necessidade da preexistência de algum processo patológico para que a atividade parafuncional atue desencadeando ou agravando a sintomatologia presente 12 . Outro fato que parece reforçar essa observação é o de que os indivíduos bruxômanos (B-PSG) com dor à palpação apresentaram um número significativamente maior de burst/hora do que os indivíduos bruxômanos (B-PSG) sem dor à palpação. Sendo dentre os indivíduos com B-PSG $(n=12), 8$ apresentaram dor à palpação e 4 não apresentaram. De fato, outros estudos confirmam que apenas alguns bruxômanos apresentam dor facial18, 29. DAO; LUND; LAVIGNE encontraram que, em um grupo de indivíduos com bruxismo (cuja queixa principal não era dor), havia um subgrupo livre de dor (13 de 19), e um subgrupo com altos níveis de dor (6 de 19). Já CLARK, BEEMSTERBOERT; RUGH ${ }^{13}$, encontraram que em um grupo de 60 pacientes com sinais e sintomas de DTM e relatos de atividade de apertamento ou ranger de dentes apresentava aumento linear da intensidade de sintomatologia com relação ao aumento de atividade eletromiográfica noturna. Essa observação está parcialmente de acordo com a presente pesquisa. Há concordância no fato de que os indivíduos com DTM e bruxismo-PSG apresentaram dor à palpação. Entretanto, os achados discordam com os autores quando estes afirmam que existe uma relação 
linear, visto que no presente estudo, os demais indivíduos com DTM sem bruxismoPSG também apresentaram dor à palpação.

Encontram-se na literatura pesquisas levantando a hipótese e apresentando evidências de que a dor, em alguns pacientes, exerçe um papel modulador sobre a atividade parafuncional. Embora essa hipótese pareça paradoxal ao que foi anteriormente exposto, verificou-se neste estudo, que 4 indivíduos do grupo experimental com BC manifestaram intensa dor à palpação na manhã seguinte, sendo que em 3 deles houve dor espontânea na EAV, entretanto, os mesmos apresentaram baixos níveis de atividade durante a PSG. Isso encontra suporte nos estudos de PINHO et al.63 os quais verificaram que os pacientes com desordens na ATM apresentam uma significativa redução da capacidade de apertamento e uma inibição aparentemente paradoxal do músculo temporal anterior no lado mais afetado durante os movimentos em direção a esse lado; de GRAVEN-NIELSEN et al. ${ }^{30}$, os quais verificaram que a dor muscular experimental reduziu o torque produzido pela extensão isométrica do joelho. Concorda ainda com SVENSSON; ARENDT-NIELSEN; HOUE79 os quais verificaram que a dor provocada por injeção de salina $5 \%$ reduziu a amplitude dos movimentos durante a mastigação nos eixos vertical e lateral, reduziu a amplitude de abertura e as velocidades de fechamento da mandíbula e a atividade eletromiográfica do masseter ipsilateral durante o fechamento. SVENSSON; ARENDT-NIELSEN; HOUE80 constataram também que a dor experimental nos músculos mandibulares levou à redução de sua capacidade de trabalho contra carga, o que está de acordo com uma adaptação 
funcional à dor muscular. Provavelmente, a finalidade biológica dessa adaptação é permitir o reparo da área traumatizada.

Ainda em concordância com um possível papel da dor modulando a atividade parafuncional em alguns pacientes, no estudo de validação do exame polissonográfico realizado por LAVIGNE; ROMPRÉ; MONTPLAISIR ${ }^{42}$, os autores verificaram que 6 dentre os 18 indivíduos bruxômanos relataram dor. Quando os valores de corte das variáveis foram recalculados sem esses 6 indivíduos a sensibilidade da polissonografia aumentou de $72 \%$ para $82 \%$ para o número de episódos de bruxismo na noite e de 78\% para 91\% para o número de bursts por hora de sono, sugerindo que os indivíduos que relataram dor apresentaram um número menor de episódios e de bursts por hora. Em um outro artigo 41 , os autores publicaram o resultado da comparação da atividade oromotora desses seis indivíduos, cuja queixa principal era o bruxismo, mas que apresentavam dor nos músculos mastigatórios, com 7 indivíduos cuja queixa principal era o bruxismo e que não relatavam dor. Foi verificado que os bruxômanos com dor realizaram menos atividade oromotora, representada pelo número de epi/hora, mas não houve diferença no número de b/hora. Esses dados estão de acordo com a presente pesquisa quando foram avaliados separadamente 11 indivíduos com BC, dos quais 7 com dor à palpação apresentaram um número significativamente menor de epi/noite, epi/hora, b/hora do que aqueles sem dor à palpação(Tabela 15). Isso pode indicar que, em alguns indivíduos, quando a dor dos músculos mastigatórios é concomitante ao bruxismo do sono, este pode diminuir. Isso contradiz o paradigma do ciclo vicioso $13,16,39,68,83$ o qual prediz que músculos doloridos contrairiam 
com mais força do que aqueles sem dor. Essa observação concorda com o modelo da adaptação à dor descrito por LUND et al.48 e sustentado por PINHO et al.63, ARIMA; ARENDT-NIELSEN; SVENSSON³ e SVENSSON; GRAVEN-NIELSEN81.

Observou-se na presente pesquisa um comportamento paradoxal. Alguns indivíduos com fortes evidências de bruxismo clínico, apesar da intensa sintomatologia na manhã seguinte à PSG, não apresentaram atividade parafuncional durante a noite(Tabela 15). Entretanto, a análise estatística dos indivíduos que apresentaram bruxismo-PSG mostrou maior atividade no grupo com dor à palpação do que no grupo sem dor(Tabela 14). Pode-se considerar a possibilidade de que o mecanismo de modulação da atividade parafuncional pela dor ocorra, mas não em todos os casos. Talvez características relacionadas à cronicidade da dor 48 estejam envolvidas com o surgimento de uma atividade de modulação, enquanto indivíduos com sintomatologia de natureza não crônica poderiam não ter tido ainda tempo de desenvolvê-lo.

DAO, LUND e LAVIGNE19, mostram, surpreendentemente, que o exercício reduziu a dor em um grupo de pacientes sintomáticos. Embora tenha sido observado na presente pesquisa que, em 3 pacientes com bruxismo-PSG (fichas 8 , 11 e 13) houve melhora do quadro clínico com relação ao apresentado no primeiro exame clínico, não é possível traçar comparações diretas com esse estudo devido aos seguintes aspectos: Primeiro, DAO; LUND; LAVIGNE ${ }^{19}$ compararam medidas de dor em EAV antes e após 3 minutos de mastigação de cera. No caso da presente pesquisa, observou-se melhora clínica quanto à dor na EAV e ao índice de DTM, 
entretanto, a dor à palpação permaneceu aproximadamente semelhante à inicial, em termos de número de pontos sensíveis. Outro diferencial importante é que o pré-exame realizado não se deu imediatamente antes do registro polissonográfico, e sim alguns dias antes, no momento da triagem dos pacientes. Portanto essa melhora observada é relativa a um período relativamente distante, impedindo o estabelecimento de parâmetros objetivos de comparação com a atividade parafuncional realizada pelos indivíduos durante o exame polissonográfico.

Quando se comparam estudos com bruxismo experimental e bruxismo real, deve-se ter em mente as implicações relacionadas. A vantagem dos estudos com bruxismo experimental é o potencial de controlar certas variáveis, tais como a duração e o nível de atividade muscular, além do tipo específico de movimento. Entretanto, essa vantagem pode representar uma de suas fragilidades, uma vez que as variáveis podem não ser exatamente as mesmas das condições clínicas. A atividade natural dos músculos mastigatórios durante o sono é muito heterogênea e envolve padrões tanto rítmicos quanto sustentados com ou sem contatos dentários. Consequentemente, é difícil comparar diretamente a atividade muscular do apertamento concêntrico experimental27, 78 aos complexos padrões de atividade natural, os quais podem conter episódios intermitentes de contração excêntrica.

ARIMA; SVENSSON; ARENDT-NIELSEN4, realizaram em seu estudo com bruxismo experimental, 9 sessões de 5 minutos de ranger de dentes repetidos, a uma frequiência de meio ciclo por segundo, com 50\% da CVM, representando 2700 segundos. IKEDA et al.35 reportaram um pico médio de atividade EMG em 
bruxômanos, expressa como uma porcentagem da CVM, de 56,5 $\pm 9,7 \%$, e que a duração do ranger de dentes por noite foi de 128s : 8 horas de sono x 2 episódios de bruxismo/hora $x$ 8s de duração por evento. Vê se que o estudo com bruxismo experimental 80 utilizou um tempo superior ao que ocorre na realidade ${ }^{35}$. LAVIGNE; ROMPRÉ; MONTPAISIR 42 afirmam que a atividade de ranger os dentes, com amplitude superior a 20\% da CVM não pode ser estimada em menos do que 500 a 600 segundos de duração. Apesar de o estudo 4 com bruxismo experimental ter utilizado um tempo de atividade superior ao real, o fato de o bruxismo poder ocorrer todas as noite por muitas noites, meses ou anos, ao passo que os estudos experimentais lidam com a atividade simulada em apenas um dia, representa uma importante diferença. Apesar disso, RUGH; HARLAN68 demonstraram que períodos com dor muscular muitas vezes são precedidos por apenas 1 ou 2 noites de atividade EMG aumentada. Assim resta ser determinado se eventos repetidos de forte atividade de ranger poderiam levar a níveis mais significativos de dor, embora SVENSSON; ARENDT-NIELSEN78 tenham mostrado que eventos repetidos de atividade de apertamento com 25\% da CVM não leva a aumento progressivo da dor ou do desconforto. Já 45min de atividade padronizada de ranger de dentes, com 50\% da FOVM foi capaz de evocar mialgia pós-exercício, auto-limitante de valores significativos, porém baixos na ATM e músculos mastigatórios de indivíduos sem DTM nos dias que se seguiram ao mesmo 4 .

Deve ainda ser enfatizado que a atividade motora orofacial noturna parece ser muito distinta dos movimentos voluntários, tais como o apertamento diurno (MINAGI et al.55). Assim, futuros estudos com bruxismo experimental em 
indivíduos despertos deveriam tentar simular o padrão de movimento mandibular noturno e a duração da atividade EMG o mais fielmente possível.

Muitos estudos têm examinado os efeitos de eventos repetidos de ranger ou apertar os dentes em indivíduos saudáveis $4,8,10,12,27,78$. Pelo menos 2 pontos importantes podem ser inferidos desses estudos: 1) todos os tipos de atividade EMG sustentada causam dor imediatamente após o exercício, o que provavelmente relaciona-se à isquemia dos tecidos musculares ${ }^{53}$ e 2) apenas alguns dos estudos 4 , 12, 27, 78 têm examinados os indivíduos nos dias seguintes ao exercício, e os mesmos têm relatado níveis muito baixos de dor e desconforto nesse período. No estudo de SVENSSON78, 1996, houve uma redução da dor ao longo de 5 dias de apertamento experimental.

Alguns autores 4 , 18têm sugerido que a dor experimentada pelos bruxômanos pode ser análoga à mialgia pós exercício induzida por trabalho excessivo. O suporte para essa afirmação encontra-se no fato de que, na maioria dos casos a dor ocorre pela manhã, diminuindo gradualmente ao longo do dia. A mialgia pós exercício caracteriza-se por dano às fibras musculares e/ou aos tecidos conjuntivos, resultando em edema e conseqüente rigidez e dificuldade de movimentos. Um fator que depõe contra essa teoria é o fato de que a mialgia pós exercício não se caracteriza apenas pela sensação dolorosa após uma sessão de exercícios em músculos não acostumados, mas por um conjunto de eventos. A lesão primária da mialgia pós-exercício é a ruptura da estrutura mio-fibrilar devido à sobrecarga mecânica. A dor durante o movimento, muito provavelmente se deve à 
liberação de substâncias dos tecidos lesados durante o processo de reparo e o pico de dor da MPE ocorre de 2 a 3 dias após a realização do exercício ${ }^{53}$. Com relação a isso, ARIMA; SVENSSON; ARENDT-NIELSEN ${ }^{4}$ levantam a hipótese de que a mialgia pós-exercício (MPE) nos músculos mastigatórios possa ser diferente daquela que ocorre nos músculos dos membros, cujo pico de dor ocorre após 2 dias. Entretanto, esses autores consideram que o ranger de dentes experimental pode ser usado para induzir à MPE, mas apenas de baixo nível. De acordo com SVENSSON; ARENDTNIELSEN78, nenhum estudo tem sido capaz de reproduzir a complexidade natural dos padrões de atividade muscular dos bruxômanos e induzir à dor mantida e à sensibilidade nos músculos mastigatórios de indivíduos saudáveis.

Deve-se lembrar que o bruxismo pode levar à dor (distinta da dor miofascial), um paciente com dor mio-fascial pode apresentar bruxismo e, nesse caso, a dor mio-fascial pode ser agravada pela atividade parafuncional. Tal afirmação encontra suporte no estudo de DAO; LUND; LAVIGNE ${ }^{19}$, 1994, onde foi demonstrado que exercícios aumentam a dor na maioria dos pacientes com dor mio-fascial. Temse sugerido que a pré-existência de uma condição patológica nos músculos mastigatórios pode ser necessária para o desenvolvimento da dor muscular sustentada. ${ }^{12}$

Os pacientes com bruxismo podem ou não apresentar sintomatologia dolorosa, como manifestado em escala de análise visual e palpação, sem necessariamente, essa ser sua queixa principal ou essa dor tratar-se de dor miofascial. DAO; LUND; LAVIGNE18, confirmam esse achado. GOULET et al. ${ }^{29}$ 
encontraram que cerca de um quinto dos indivíduos conscientes dos hábitos parafuncionais experimentavam dor mandibular. A existência de subgrupos distintos de bruxômanos já havia sido evidenciada por DAO; LUND; LAVIGNE18, cujo estudo mostrou um contraste entre os níveis de dor desses subgrupos de bruxômanos (um sem dor, e outro com altos níveis de dor). Um fato pode chamar atenção na atual pesquisa, 5 indivíduos do grupo controle (fichas 18, 20, 24, 29 e 32) apresentaram sintomatologia dolorosa no segundo exame de DTM. Destes, apenas o indivíduo 24 havia apresentado bruxismo-PSG e o indivíduo 20 sentiu dor à palpação apenas na região cervical. Convém observar que os demais $(18,29$ e 32) foram diagnosticados clinicamente como bruxômanos e, apesar da ausência de atividade parafuncional durante o sono, os mesmos apresentaram sintomatologia. Deve ser explicado que os indivíduos 18 e 32 já apresentavam sintomatologia à palpação no exame inicial, na musculatura cervical para ambos e no aspecto posterior da ATM para o 18. Eles foram alocados para o grupo controle porque esses pacientes não tinham como queixa a dor, nem procurariam tratamento para ela, mesmo diante do índice de DTM 11 para o indivíduo 18. Como um dos critérios de inclusão do grupo experimental era o fato do indivíduo buscar tratamento ou apresentar como queixa principal a dor, os mesmos permaneceram no grupo controle, como indivíduos não portadores de DTM. Primeiramente, poder-se-ia questionar se os resultados dos cálculos de associação não seriam diferentes se esses indivíduos estivessem no grupo com DTM. Esse questionamento foi respondido quando realizou-se o cálculo de associação entre bruxismo clínico e/ou polissonográfico com dor à palpação no segundo exame. O que foi constatada como ausente. 
A causa dessa dicotomia (bruxômanos com e sem dor) não é clara, embora seja possível que isso possa estar relacionado com os níveis ou freqüência de atividade muscular. Os músculos podem adaptar-se muito rapidamente ao exercício e, uma vez o tendo feito, eles se tornam mais resistentes aos efeitos danosos dos eventos repetitivos do mesmo exercício. DAO; LUND; LAVIGNE18 comparam os bruxômanos livres de dor a atletas bem treinados, cuja resistência foi melhorada pelo treino. Essa hipótese encontra suporte no estudo de LAVIGNE et al. ${ }^{41}$, em que o número médio de episódios de bruxismo por hora de sono pareceram maiores em bruxômanos livres de dor.

Em situações onde a dor encontra-se instalada, permanecendo ao longo do tempo, caracterizando o quadro de dor crônica, muitos dos aspectos válidos para o entendimento de condições agudas perdem sua validade. Muitas tentativas de explicações encontram-se listadas no artigo de MENSE $^{52}$, a respeito da etiopatogenia da dor crônica. Tratando-se particularmente da dor muscular crônica, os autores explicam os principais mecanismos envolvidos: 1) mecanismos de sensitização central e periférica; 2) conceitos de convergência neuronal e dor referida e 3) ciclos viciosos envolvendo perpetuação da dor devido à isquemia local. Essa isquemia, em geral mecânica, seria induzida por congestão venosa (devido a um edema ou a uma contratura muscular). Essa seqüência tornar-se-ia cíclica, quando a própria isquemia resultante, levasse à deplessão de ATP, o que acentuaria a contratura muscular; e/ou aumentaria a liberação de substâncias vasoneuroativas (quininas e prostaglandinas), acentuando o edema. Entretanto, o mesmo autor 53 e outros estudos 48 não conseguiram comprovar a existência dessa 
relação entre dor persistente e contração muscular. Em diversas situações experimentais verificou-se um efeito contrário ao esperado, isto é, a inibição da atividade de contração máxima em músculos que envolviam uma região dolorida34 e a redução da atividade de motoneurônios- $\gamma$ após a infiltração de solução salina hipertônica no músculo52.

DROUKAS, LINDEE; CARLSSON22 relataram correlação positiva entre auto-relatos de bruxismo e dor ou fadiga na face ou maxilares, mas encontraram uma correlação negativa entre bruxismo e impedimento da função da ATM no mesmo estudo. Já no estudo de ARIMA; SVENSSON; ARENDT-NIELSEN ${ }^{4}$ os autores relatam que 1 dia após o exercício de bruxismo experimental (ranger de dentes) 7 de 12 indivíduos reportaram dor localizada na região da ATM contralateral à direção do exercício. E explicam que os sintomas podem ser originados do músculo peterigoideo lateral, os quais realizam contrações excêntricas durante a atividade de ranger ou que a ATM contralateral possa ter sido sobrecarregada pelo exercício. Tem sido recentemente sugerido 56 que, durante o carregamento da ATM em posições laterais, a articulação contralateral é mais comprimida do que a ipsilateral, devido à predominância de contatos dentários no lado de trabalho. Isso sugere que diferentes subgrupos de DTM podem estar diferentemente relacionados ao bruxismo, assim as pesquisas deveriam focalizar-se na correta identificação e medida de fatores etiológicos específicos que produzam certos subtipos de DTM. 


\subsection{RELAÇÃO DE CAUSA E EFEITO BRUXISMO E DTM}

Devido à inerente natureza inexata das ciências biomédicas, encontrase no estabelecimento de relações de causa-e-efeito, um dos maiores desafios para a compreensão da etiopatogenia das doenças em geral.

SPILKER74, 1991 explica que muitos tipos de relação podem ser observados entre duas condições. Por exemplo, quando se trata de um relacionamento de causa-e-efeito direto ou indireto, na verdade, devido à presença de subjetividade, tal relação pode não existir efetivamente, até o ponto em que pode ser possível que não exista nenhum tipo de relação entre ambas, sendo elas, portanto, completamente independentes. Logo, a fim de se estabelecer o tipo de relacionamento existente entre bruxismo do sono e DTM, dever-se-ia eliminar toda a subjetividade, o erro e as influências que possam confundir a análise. LOBBEZOO e LAVIGNE45, 1997 sugerem que tais fatores sejam diminuídos até o ponto de não serem percebidas, embora admitam a impossibilidade de sua completa eliminação (ou seja, 100\% de certeza), sugerindo que se busque a maior probabilidade de segurança possível. É necessário explicar que, excepcionalmente poder-se-á atribuir a apenas uma causa a responsabilidade por um determinado efeito quando se trata de desordens clínicas (SPILKER $\left.{ }^{74}, 1991\right)$. Em geral há várias causas envolvidas, podendo ser elas mais direta ou indiretamente relacionadas. LOBBEZOO e LAVIGNE 45 , 1997 atentam para a impossibilidade de se estudarem mais do que poucas causas diretas e indiretas em um único experimento e recomendam a utilização de grupos o mais similares possíveis, onde as diferenças tendam a restringir-se ao objeto do estudo, ou seja, as causas. 
LOBBEZZO; LAVIGNE45 descreveram os critérios que estabelecem ou fortificam a teoria de uma relação causa e efeito entre bruxismo do sono e DTM. Esses critérios são:

a) Eliminação de subjetividade, tendências ou influências de imprecisão. LOBBEZOO; LAVIGNE45 recomendam os estudos duplo-cego e randomizações clínicas como modelos preferíveis para a investigação das relações de causa e efeito, por esses eliminarem a possibilidade de que o estudo seja tendencioso em qualquer passo, incluindo a verificação final da casualidade. A presente pesquisa incluiu os casos de bruxismo nos grupos com e sem DTM de forma aleatória, visto que a seleção dos participantes, em nenhum momento, buscou por indivíduos com presença ou ausência de bruxismo. O diagnóstico de bruxismo foi realizado posteriormente à alocação do indivíduo no grupo experimental ou controle, sendo que o diagnóstico clínico final era o resultado preponderante da avaliação de 3 examinadores. Com a mesma finalidade utilizou-se o exame polissonográfico como método objetivo de registro da atividade parafuncional, sendo o diagnóstico de bruxismo definido segundo critérios já validados na literatura 42 e as eletromiografias foram lidas sem o conhecimento prévio da identidade dos pacientes.

b) Associação consistente. A probabilidade de se validar um relacionamento de causa-e-efeito seria aumentada se se coletassem dados asssociados com a condição de estudo em diferentes pontos no tempo ${ }^{45}$. Não foi possível estabelecer uma associação consistente entre o bruxismo, quer definido 
pelo critério clínico quer pelo polissonográfico, com DTM. Tanto pelos valores de qui-quadrado, 0,672 $(\mathrm{p}=0,413)$ para a PSG e 1,239 $(\mathrm{p}=0,265)$ para o clínico, quanto pela própria prevalência de bruxismo do sono nos grupos com e sem DTM.

c) Relação temporal onde a causa preceda o efeito entre bruxismo e DTM. Uma vez que é essencial que a causa preceda o efeito em um relacionamento de causa-e-efeito válido, as medidas deveriam ser feitas de forma pareada. Assim, o presente estudo avaliou o quadro clínico dos pacientes (teste de dor à palpação muscular e articular); dor na EAV e índice de DTM pré e pós exame polissonográfico. 0 fato de o exame clínico pré polissonografia não ter sido realizado imediatamente antes de sua realização leva à redução da objetividade da análise desse aspecto. Entretanto, todos os indivíduos do grupo experimental permanecerem com dor à palpação, independente da atividade parafuncional; e alguns pacientes com bruxismo-PSG apresentaram melhora geral no quadro clínico. Assim, dentro dos limites deste estudo, a relação temporal entre bruxismo do sono e DTM pode ser, no mínimo questionada. Ratificando a fraca relação temporal entre bruxismo e DTM, DAO; LUND; LAVIGNE18 verificaram em um estudo que comparava 19 indivíduos com bruxismo do sono e 61 indivíduos com dor mio-fascial, que 5 dos 6 bruxômanos com dor $(83,3 \%)$ relataram que a pior dor ocorria pela manhã e a menor à noite; apenas 1 indivíduo relatou a pior dor à noite. Resultados opostos foram encontrados para o grupo com dor mio-fascial, em que a dor da maioria $(50,8 \%)$ era pior à noite e menor pela manhã. Apenas $19,1 \%$ tinham sua pior dor pela manhã. 
d) Presença de um gradiente "dose-resposta". Significa dizer que, quanto mais forte for a causa, mais forte será o efeito ${ }^{45}$. 0 presente estudo não dispôs de ferramentas para avaliar a intensidade da sintomatologia dos indivíduos na manhã seguinte ao exame polissonográfico. Estudos posteriores poderiam investigar esse critério por meio de avaliação da alteração do limiar de dor à pressão dos indivíduos após o exame polissonográfico em comparação ao limiar inicial. Nesse modelo sugerido, o limiar de dor à pressão seria verificado imediatamente antes do exame polissonográfico (na primeira noite), na manhã seguinte; imediatamente do exame polissonográfico (na segunda noite) e na manhã seguinte do mesmo.

e) Concordância com os dados epidemiológicos. Devido ao tamanho reduzido da amostra e à restrição de faixa etária imposta como critério de inclusão, este não se trata de um estudo que englobe aspectos epidemiológicos. Não sendo possível discuti-lo.

SPILKER ${ }^{74}$ enfatiza ainda que uma única causa direta levando a um efeito é excepcionalmente encontrado na maioria das desordens clínicas. Mais comumente, múltiplas causas diretas e indiretas estão envolvidas. Infelizmente, é impossível estudar mais do que poucas causas diretas e indiretas em um único estudo. Compensando-se em parte pela comparação de grupos os mais similares possíveis, buscando-se diferenciá-los pelas causas estudadas, nesse caso, o bruxismo. O presente estudo não os diferenciou pela causa (bruxismo) e sim pelo efeito (DTM). Este modelo possibilitou uma composição mais rápida dos grupos. Do 
contrário, os exames polissonográficos deveriam ser usados para a alocação dos indivíduos em grupos com e sem bruxismo (havendo a possibilidade de falso positivo ou negativo), além da maior demanda de tempo. Sendo que a inversão realizada em nada prejudicaria a avaliação. 
CONCLUSÕES 


\section{7 - CONCLUSÕES}

1) Não houve associação entre bruxismo do sono, diagnosticado clinicamente ou pela Polissonografia e sinais e sintomas de DTM.

2) Não houve correlação entre a atividade parafuncional realizada pelo paciente na noite do exame polissonográfico e os valores da escala de análise visual (EAV) na manhã seguinte.

3) Não houve diferenças significativas entre as atividades oromotoras (ARMM) dos indivíduos com e sem sinais e sintomas de DTM.

4) Não se observou a presença de associação consistente, relação temporal nem gradiente dose-resposta entre atividade parafuncional de bruxismo do sono e sinais e sintomas de DTM, não se encontrando, portanto, suporte para a existência de uma relação de causa e efeito entre os mesmos.

5) O exame clínico de bruxismo, incorporando ao questionário, o acompanhamento de bruxismo e/ou o relato de uma terceira pessoa apresentou maior sensibilidade (75\%) do que especificidade (57\%), com relação à PSG realizada em uma noite. 
ANEXOS 


\section{Universidade de São Paulo \\ Faculdade de Odontologia de Bauru}

Al, Dr. Octávio Pinheiro Brisolla, 9-75 - Baurt-SP - CEP 17012-901 - C.P. 73 PABX (0XX14)235-8000 - FAX (0XX14)223-4679

Comitê de Élica em Pescutisa

Processo $n^{\circ} 021 / 2002$

Baun, 2 de julho de 2002

Senhor Professor,

Informamos que após o envio da documentaçāo pendente, o projeto de pesquisa encaminhado a este Comitê denominado "Associação entre bruxismo noturno e tipos especificos de disfunçäo temporo-mandibular", de autoria de Leylha Maria Oliveira Nunes, sob a sua orientaçäo, foi APROVADO.

Comunicamos que após o envio do trabalho concluido, este Comité enviará o parecer final, que será utilizado para a publicação do trabalho.

Atenciosamente,

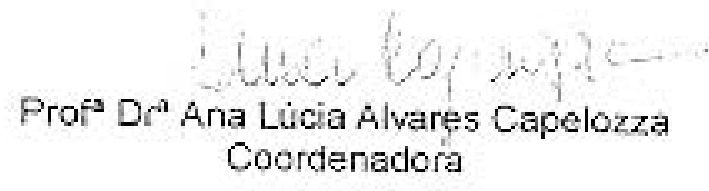

Ilmo Sr. Prof, Dr. Carlos dos Reis Pereira Araújo

DD. Docente do Departamento de Prötese 


\title{
Anexo 2
}

\author{
UNIVERSIDADE DE SÃo PAUlo \\ Faculdade de Odontologia de Bauru \\ Al. Dr. Octávio Pinheiro Brisolla, 9-75 - Bauru-SP - CEP 17012-901 - C.P. 73 \\ PABX (0XX14)235-8000 - FAX (0XX14)223-4679
}

\section{CARTA DE INFORMACÃO AO PACIENTE}

A Faculdade de Odontologia de Bauru - USP realiza esta pesquisa, com a finalidade de verificar a existência de uma relação causa-e-efeito entre o bruxismo (hábito inconsciente de ranger os dentes durante o sono) e Disfunção têmporomandibular-DTM (dor na articulação da mandíbula e/ou nos músculos da face). Para tanto, os participantes da pesquisa passarão por um exame que constará de questionário, exame clínico e radiografia panorâmica (acompanhada ou não de radiografia da ATM), a fim de diagnosticar a presença ou a ausência de sinais e sintomas de algum dos tipos de alterações na ATM. Em seguida, todos os participantes da pesquisa dormirão por duas noites consecutivas no Instituto de Medicina do Sono - Dr. Alberto Luiz Moura dos Santos, situado à rua Dr. Annis Dabus, 1-23, Bauru, SP do Sono. Durante o sono, serão realizados um eletromiograma (EMG), um eletroencefalograma (EEG) e um eletrooculograma (EOG) e (ECG), além do registro áudio visual dos episódios de bruxismo (ranger de dentes acompanhado de som). Para a realização destes exames é necessária a colocação de eletrodos (peças flexíveis adesivas) em alguns pontos do corpo do paciente: na cabeça, no queixo, na lateral da face e no peito. Esta seqüência de exames pode trazer benefícios ao paciente, tanto pelo fato de diagnosticar o tipo de alteração da articulação têmporo-mandibular que o paciente apresenta, bem como a presença ou ausência de bruxismo e outros distúrbios do sono. Uma vez diagnosticada alteração articular, o paciente será encaminhado para tratamento na clínica de Disfunção Têmporo-Mandibular da própria Faculdade bem como no Curso de Oclusão realizado nas dependências do Instituto de Ensino Odontológico (IEO). A 
privacidade dos pacientes será preservada em todos os momentos deste trabalho. Assim, esperando contar com sua colaboração, antecipadamente agradecemos. Atenciosamente,

Paciente ou responsável

Prof. Dr. Carlos dos Reis Pereira Araújo Orientador
Leylha Maria Oliveira Nunes Cirurgiã dentista, mestranda em Reabilitação Oral FOB-USP 


\title{
Anexo 3
}

\author{
UNIVERSIDADE DE SÃo PAULO \\ Faculdade de Odontologia de Bauru
}

\begin{abstract}
Al. Dr. Octávio Pinheiro Brisolla, 9-75 - Bauru-SP - CEP 17012-901 - C.P. 73
PABX (0XX14)235-8000 - FAX (0XX14)223-4679
\end{abstract}

\section{TERMO DE CONSENTIMENTO LIVRE E ESCLARECIDO}

Pelo presente instrumento que atende às exigências legais, o(a) Senhor(a)

portador(a) da cédula de identidade no expedido por . Após leitura minuciosa da CARTA DE INFORMAÇÃO AO PACIENTE, devidamente explicada em seus mínimos detalhes, ciente dos serviços e procedimentos aos quais será submetido, não restando quaisquer dúvidas a respeito do exposto, firma seu CONSENTIMENTO LIVRE E ESCLARECIDO em concordância em participar da pesquisa proposta.

Fica claro que o paciente ou seu representante legal pode a qualquer momento retirar seu CONSENTIMENTO LIVRE ESCLARECIDO e deixar de participar do estudo alvo da pesquisa e ciente que todo trabalho realizado torna-se informação confidencial guardada por força do sigilo profissional (Art. 9ํำ do Código de Ética Odontológica).

Por estarem entendidos e conformados, assinam o presente termo.

BaurutSP, de de

Paciente ou responsável

Prof. Dr. Carlos dos Reis Pereira Araújo Orientador
Leylha Maria Oliveira Nunes Cirurgiã dentista, mestranda em

Reabilitação Oral FOB-USP 
Data

Dados Pessoais

Nome

Data de Nascimento

Sexo M( ) F ( )

Endereço residencial

Bairro

Cidade

Idade

Telefone residencial

Telefone trabalho

Profissão

Celular

\section{CRITÉRIOS DE EXCLUSÃO INICIAIS}

\section{QUESTIONÁRIO}

Você apresenta alguma queixa de sono?

Sua principal queixa de sono compreende: (marque todas se achar necessário e descreva)

( ) Problemas para dormir a noite

( ) Sonolência durante o dia

( ) Comportamento indesejado durante o sono (explique abaixo)

( ) Outros

Favor descreva os seus problemas de sono:

Sofre de insônia?

Toma remédios ou álcool para dormir?

Acorda muitas vezes durante a noite?

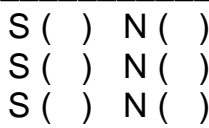

$\mathrm{S}(\mathrm{N}(\mathrm{N})$

$\mathrm{S}() \mathrm{N}()$

Por favor dê notas para você mesmo marcando de 1 a 7 para o grau ou a freqüência do que mais o aborrece em um determinado problema. É muito importante responder todos os itens.

\begin{tabular}{|c|c|c|c|c|c|c|}
\hline 1 & 2 & 3 & 4 & 5 & 6 & 7 \\
\hline $\begin{array}{c}\text { Nada ou } \\
\text { nunca }\end{array}$ & $\begin{array}{c}\text { Muito leve } \\
\text { ou raros }\end{array}$ & $\begin{array}{c}\text { Leve ou } \\
\text { às vezes }\end{array}$ & $\begin{array}{c}\text { Moderado ou } \\
\text { ocasionalmente }\end{array}$ & $\begin{array}{c}\text { Bastante ou } \\
\text { freqüente }\end{array}$ & $\begin{array}{c}\text { Muito ou muito } \\
\text { freqüente }\end{array}$ & $\begin{array}{c}\text { Excessivo } \\
\text { ou sempre }\end{array}$ \\
\hline
\end{tabular}

1 - 123456 7Quantas vezes você cai no sono durante o dia quando está parado ou sem fazer nada?

2 - 1234567 Quantas vezes a pessoa que dorme com você percebeu que você pára de respirar durante o sono?

3 - 1234567 Quantas vezes o seu sono é perturbado por outros problemas respiratórios?

Descreva:

4 - 1234567 Quão importante é o problema do ronco para você?

5 - 1234567 Quão importante é o problema de pegar no sono?

6 - 1234567 Quantas vezes você acorda durante a noite e tem dificuldade em voltar a dormir?

7 - 1234567 Quantas vezes a pessoa que dorme com você notou que suas pernas se mexem ou chutam durante o seu sono?

8 - 1234567 Quantas vezes você teve problemas com suas pernas não pararem de se mexer ou formigar a noite?

9 - 1234567 Quantas vezes você já se sentiu complemente paralisado quando acabou de pegar no sono ou de acordar?

10 - 1234567 Quantas vezes você já teve alucinações com pessoas, vozes ou sons no quarto 
quando você está para pegar no sono ou acordar?

11 - 123456 7Quantas vezes durante o dia você tem episódios de fraqueza muscular súbita quando ri, fica com raiva ou outras situações emocionais?

12 - 123456 7Quantas vezes você tem comportamento incomum durante o sono? (marque o(s) tipo(s) de comportamento: andar, gritar, comer, pesadelos, agressividade, confusão,

13 - $123456 \overline{7 Q u a n t a s ~ v e z e s ~ s e u s ~ o m b r o s ~ e ~ b r a c ̧ o s ~ t e ̂ m ~ c o n t r a c ̧ o ̃ e s ~ s e m e l h a n t e s ~ a ~ e s p a s m o s ~}$ musculares quando você dorme?

14 - 123456 7Quantas vezes você já apresenta ou já apresentou algum episódio de epilepsia?

15 - 123456 7Apresenta Mal de Parkinson?

16. - Toma alguma medicação?

Medicamento dose diária

Medicamento dose diária

Medicamento dose diária

17 - Apresenta alguma outra desordem neurológica ou psiquiátrica Qual?

18 - Apresenta problema de movimentação do corpo de movimento?

19 - Utiliza algum dispositivo intra-oral para dormir?

20 - Utiliza álcool com freqüência?

21 - Utiliza alguma droga?

Com que freqüência?

$S() N()$

Tente ser específico nas questões seguintes evitanto usar aproximações (Por exemplo, não use "8 ou 10 da noite" ou então "5 ou 6 vezes").

22 - A que horas você normalmente vai para a cama?

23 - Quanto tempo você leva normalmente par apegar no sono após decidir dormir?

24 - Quantas horas de sono total você consegue por noite: (Não contar com tempo na cama acordado)

25 - A que horas normalmente você acorda pela manhã?

AVALIAÇÃO DENTÁRIA E OCLUSAL

\begin{tabular}{|l|l|l|l|l|l|l|l|l|l|l|l|l|l|l|l|}
18 & 17 & 16 & 15 & 14 & 13 & 12 & 11 & 21 & 22 & 23 & 24 & 25 & 26 & 27 & 28 \\
\hline 48 & 47 & 46 & 45 & 44 & 43 & 42 & 41 & 31 & 32 & 33 & 34 & 35 & 36 & 37 & 38
\end{tabular}

Próteses

Trespasse vertical_ $\mathrm{mm}$

Trespasse horizontal $\mathrm{mm}$ maior que $6 \mathrm{~mm}$

Mordida aberta anterior

Mordida cruzada unilateral

Apresenta dois ou mais dentes perdidos? (exceto os terceiros molares)?

Utiliza prótese dental removível?

Interferência no arco de fechamento com $\mathrm{RC} / \mathrm{MIH}>5 \mathrm{~mm}$

$\begin{array}{ll}\mathrm{S}() & \mathrm{N}() \\ \mathrm{S}() & \mathrm{N}() \\ \mathrm{S}() & \mathrm{N}() \\ \mathrm{S}() & \mathrm{N}() \\ \mathrm{S}() & \mathrm{N}() \\ \mathrm{S}() & \mathrm{N}()\end{array}$

$\mathrm{S}(\mathrm{N}) \mathrm{N}($ )

$\mathrm{S}($ ) $\mathrm{N}($

$\mathrm{S}($ ) $\mathrm{N}($ ( )

$\mathrm{S}($ ) $\mathrm{N}()$ 


\section{Anexo 5 - QUESTIONÁRIO DE AVALIAÇÃO OBJETIVA}

Data

Dados Pessoais

Nome

Data de Nascimento

Sexo $M() \quad F()$

Idade

\section{Escala de análise visual}

Indique a média de seu nível de dor na semana que passou, marcando com uma linha vertical a escala abaixo. A extremidade esquerda indica ausência total de dor e a extremidade direita indica a pior dor imaginável.

sem dor

pior dor imaginável

\section{QUESTIONÁRIO}

1. Você sente dificuldade de abrir a boca?

2. Você sente dificuldade de movimentar sua mandíbula para os lados?

3. Você sente desconforto ou dor muscular quando mastiga?

4. Você sente dores de cabeça com freqüência?

5. Você sente dores no pescoço e/ou ombros?

6. Você sente dores de ouvido ou próximo a ele?

7. Você percebe algum ruído na ATM?

8. Você considera sua mordida "anormal"?

9. Você usa apenas um lado de sua boca para mastigar?

10. Você sente dores na face ao acordar?

NÃO PORTADOR DE DTM

PORTADOR DE DTM LEVE

PORTADOR DE DTM MODERADA

PORTADOR DE DTM SEVERA
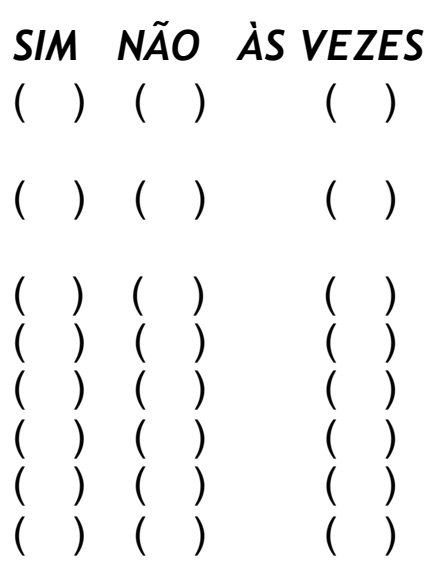

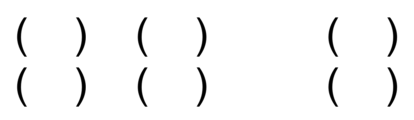

As questões 4, 6 e 7 receberão valor 3 para cada resposta "sim" se corresponderem a sintomas bilaterais ou intensos, valor 2, se corresponderem a sintomas unilaterais ou leves; receberão valor 1 para a resposta "às vezes" e valor 0 para a resposta "não".O somatório dos valores obtidos permitirá a classificação da amostra em relação ao grau de disfunção temporomandibular em:

Valores de 0 a 3: não portador de DTM

Valores de 4 a 8: portador de DTM leve

Valores de 9 a 14: portador de DTM moderada

Valores de 15 a 23: portador de DTM severa. 


\section{Anexo 6 - GRUPO EXPERIMENTAL OU GRUPO CONTROLE}

Data

Dados Pessoais

Nome

Data de Nascimento

Sexo $M() \quad F()$ Idade

\section{Questionário}

Queixa principal?

\section{Questionário para subgrupo articular ou misto}

Apresenta clicking na articulação?

$\mathrm{S}() \mathrm{N}()$

O clicking é recíproco?

$\mathrm{S}(\mathrm{)}) \mathrm{N}(\mathrm{)}$

O clicking é ou não acompanhado de dor?

$\mathrm{S}(\mathrm{)}) \mathrm{N}(\mathrm{)}$

Qual o histórico?

Apresenta alguma restrição do movimento mandibular?

Não consegue abrir a boca?

Já apresentou travamento com boca aberta?

$\mathrm{S}(\mathrm{)}) \mathrm{N}(\mathrm{)}$

$\mathrm{S}(\mathrm{)}) \mathrm{N}(\mathrm{)}$

Qual o histórico?

Apresenta dor articular quando mastiga?

$\mathrm{S}(\mathrm{N}) \mathrm{N}(\mathrm{)}$

\section{Questionário para subgrupo M ou misto}

Apresenta dor nos músculos da face?

$S() N()$

Qual a característica da dor nos músculos?

Apresenta dor no pescoço e/ou ombros?

Quando notou os sintomas pela primeira vez?

Sente dor de cabeça com freqüência?

Qual a freqüência?

Sofre de enxaqueca?

O que você acha que causou estes problemas?

O início dos problemas relaciona-se a algum acidente?

Em quanto tempo esta condição mudou desde que começou?
( ) anos
( )meses
semanas ( ) dias ( ) 1 dia ( )

Como esta condição mudou desde que começou?
( )piorou
melhorou ( )
estável ( ) 


\section{Questionário geral}

Você teve ou tem algum dos problemas abaixo?

Cardiovascular

Gastrointestinal/Fígado

Musculoesqueletal

Endócrino

Genitourinário

Hematopoiético

Neurológico

Respiratório

Alergias
$\mathrm{S}(\mathrm{)}) \mathrm{N}(\mathbf{)}$

$\mathrm{S}()^{\prime} \mathrm{N}()$

$\mathrm{S}()^{\prime} \mathrm{N}()$

$\mathrm{S}(\mathrm{)}) \mathrm{N}($ )

$\mathrm{S}(\mathrm{s}) \mathrm{N}($ )

$\mathrm{S}()^{\prime} \mathrm{N}()$

$\mathrm{S}(\mathrm{s}) \mathrm{N}($ )

$\mathrm{S}(\mathrm{s}) \mathrm{N}($ )

$\mathrm{S}(\mathrm{)}) \mathrm{N}()$

$\mathrm{S}(\mathrm{)}) \mathrm{N}()$

Você está bem de saúde?

Data da última consulta médica?

Está sendo tratado por outro problema?

Explique:

Liste qualquer acidente ou traumatismo e suas datas

\section{Exame físico de DTM}

\section{Avaliação da ATM}

Movimentação

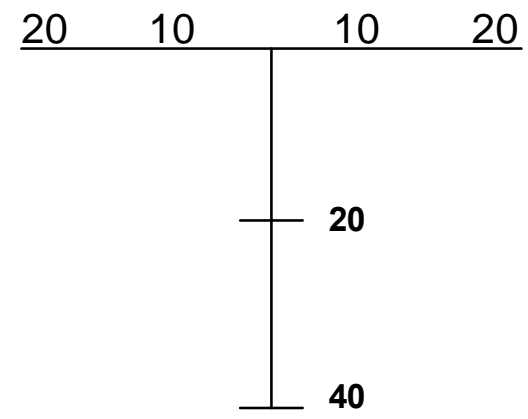

Abertura: ( ) Simétrica ( )Desvio ( )Deflexão

Ruídos Articulares

Estalido

Abertura

Fechamento

$\mathrm{S}(\mathrm{)}) \mathrm{N}()$

Crepitação

$\mathrm{S}(\mathrm{N}) \mathrm{N}()$

Abertura

$\mathrm{S}(\mathrm{f}) \mathrm{N}($ )

Fechamento

$\mathrm{S}($ ) $\mathrm{N}($ ) 
Palpação da ATM (Dor)

Aspecto lateral

Aspecto posterior

$\mathrm{S}(\mathrm{)} \mathrm{N}($ )

$\mathrm{S}($ ) $\mathrm{N}()$

D

$\begin{array}{ll}\mathrm{S}() & \mathrm{N}() \\ \mathrm{S}(\mathrm{)}) & \mathrm{N}() \\ \mathrm{S}(\mathrm{)}) & \mathrm{N}() \\ \mathrm{S}(\mathrm{l}) & \mathrm{N}(\mathrm{l})\end{array}$

E

$\mathrm{S}($ ) $\mathrm{N}($ )

$\mathrm{S}(\mathrm{)}) \mathrm{N}($ )

$\mathrm{S}($ ) $\mathrm{N}($ )

$\mathrm{S}($ ) $\mathrm{N}()$

Grupo ao qual pertence o paciente

\section{Grupo Experimental}

Subgrupo ARTICULAR

$\mathrm{S}($ ) $\mathrm{N}($ )

Subgrupo MUSCULAR

$\mathrm{S}($ ) $\mathrm{N}($ )

Subgrupo MISTO

Grupo controle

$\mathrm{S}($ ) $\mathrm{N}($ ( )

$\mathrm{S}(\mathrm{N}) \mathrm{N}()$ 


\section{Anexo 7 - Exame Clínico de Bruxismo}

Data

Dados Pessoais

Nome

Sexo M( ) F ( )

Data de Nascimento Idade

\section{QUESTIONÁRIO DE BRUXISMO}

Acorda durante apertando ou rangendo os dentes?

Sente cansaço nos músculos da face ao acordar?

Acorda pela manhã com as articulações travadas?

Sente desconforto nos dentes ao acordar?

Teve restaurações deslocadas recentemente?

$\mathrm{S}($ ) $\mathrm{N}($ ( )

$S() N()$

$\mathrm{S}(\mathrm{N}) \mathrm{N}($ )

$\mathrm{S}(\mathrm{)}) \mathrm{N}($ )

$\mathrm{S}($ ) $\mathrm{N}()$

\section{EXAME CLÍNICO DE BRUXISMO}

Apresenta facetas de desgaste coincidentes?

Apresenta restaurações metálicas com pontos brilhantes?

Apresenta hipertrofia do músculo masséter?

DIAGNÓSTICO

Paciente com bruxismo ativo 


\section{Anexo 8}

Teste de calibração da atividade oromotora com os indivíduos em vigília.

Após o preparo do paciente, e já tendo iniciado o registro, foram dadas aos participantes:

1. Encaixe os dentes e aperte com força máxima

2. Encaixe os dentes e aperte com um pouco menos de força

3. Encaixe os dentes e aperte com pouca força

4. Coloque os dentes para o lado direito e aperte

5. Coloque os dentes para o lado esquerdo e aperte

6. Coloque os dentes para frente e aperte

7. Abra e feche a boca

8. Coloque os dentes para o lado direito e volte ao centro

9. Coloque os dentes para o lado esquerdo e volte ao centro

10. Coloque os dentes para frente e volte ao centro

11. Encaixe os dentes e aperte várias vezes

12. Esfregue os dentes rangendo

13. Engula a saliva 


\section{Anexo 9}

\begin{tabular}{|c|c|c|c|c|c|c|c|c|c|}
\hline \multirow[t]{2}{*}{ FICHA } & \multirow[t]{2}{*}{ DTM } & \multicolumn{4}{|c|}{ VARIÁVEIS OROMOTORAS } & \multirow[b]{2}{*}{$\begin{array}{c}\text { BRUXISMO } \\
\text { PSG }\end{array}$} & \multirow[b]{2}{*}{$\begin{array}{c}\text { BRUXISMO } \\
\text { CLÍNICO }\end{array}$} & \multirow[b]{2}{*}{ DOR (EAV) } & \multirow[b]{2}{*}{$\begin{array}{c}\text { DOR À } \\
\text { PALPAÇÃO }\end{array}$} \\
\hline & & EPI/NOITE & EPI/HORA & B/HORA & B/EPI & & & & \\
\hline 1 & $\mathrm{~S}$ & 35 & 6,2 & 29,2 & 4,7 & $\mathrm{~S}$ & $\mathrm{~S}$ & $\mathrm{~N}$ & $\mathrm{~S}$ \\
\hline 3 & $\mathrm{~S}$ & 8 & 1,3 & 7,9 & 6,3 & $\mathrm{~N}$ & $\mathrm{~N}$ & $\mathrm{~N}$ & $\mathrm{~S}$ \\
\hline 5 & S & 29 & 5,0 & 20,6 & 4,1 & $\mathrm{~S}$ & $\mathrm{~S}$ & $\mathrm{~S}$ & $\mathrm{~S}$ \\
\hline 6 & S & 15 & 2,1 & 8,0 & 3,8 & $\mathrm{~N}$ & $\mathrm{~S}$ & $\mathrm{~S}$ & $\mathrm{~S}$ \\
\hline 7 & $\mathrm{~S}$ & 11 & 1,8 & 7,0 & 3,9 & $\mathrm{~N}$ & $\mathrm{~S}$ & $\mathrm{~S}$ & $\mathrm{~S}$ \\
\hline 8 & $\mathrm{~S}$ & 27 & 4,4 & 30,7 & 7,0 & $\mathrm{~S}$ & $\mathrm{~N}$ & $\mathrm{~S}$ & $\mathrm{~S}$ \\
\hline 9 & $S$ & 45 & 7,9 & 33,0 & 4,2 & $S$ & $S$ & $\mathrm{~N}$ & $\mathrm{~S}$ \\
\hline 10 & $\mathrm{~S}$ & 18 & 3,1 & 11,9 & 3,8 & $\mathrm{~N}$ & $\mathrm{~S}$ & $\mathrm{~S}$ & $\mathrm{~S}$ \\
\hline 11 & $\mathrm{~S}$ & 27 & 4,1 & 19,2 & 4,6 & $\mathrm{~S}$ & $S$ & $\mathrm{~N}$ & $\mathrm{~S}$ \\
\hline 12 & $S$ & 9 & 1,73 & 8,6 & 5,0 & $\mathrm{~N}$ & $S$ & $\mathrm{~N}$ & $S$ \\
\hline 13 & $\mathrm{~S}$ & 23 & 5,2 & 19,3 & 3,7 & $\mathrm{~S}$ & $S$ & $\mathrm{~S}$ & $\mathrm{~S}$ \\
\hline 14 & $\mathrm{~S}$ & 19 & 4,0 & 17,2 & 4,3 & $\mathrm{~S}$ & $S$ & $\mathrm{~S}$ & $\mathrm{~S}$ \\
\hline 15 & $\mathrm{~S}$ & 14 & 2,5 & 6,6 & 2,6 & $\mathrm{~N}$ & $\mathrm{~N}$ & $\mathrm{~N}$ & $S$ \\
\hline 34 & $\mathrm{~S}$ & 20 & 3,3 & 7,2 & 2,2 & $\mathrm{~N}$ & $S$ & $S$ & $\mathrm{~N}$ \\
\hline 17 & $\mathrm{~N}$ & 26 & 4,3 & 19,0 & 4,5 & $\mathrm{~S}$ & $\mathrm{~N}$ & $\mathrm{~N}$ & $\mathrm{~N}$ \\
\hline 18 & $\mathrm{~N}$ & 5 & 0,8 & 3,2 & 3,8 & $\mathrm{~N}$ & $\mathrm{~S}$ & $\mathrm{~N}$ & $\mathrm{~S}$ \\
\hline 19 & $\mathrm{~N}$ & 40 & 5,8 & 20,7 & 3,6 & $S$ & $S$ & $\mathrm{~N}$ & $\mathrm{~N}$ \\
\hline 23 & $\mathrm{~N}$ & 26 & 4,7 & 18,5 & 3,9 & $\mathrm{~S}$ & $\mathrm{~N}$ & $\mathrm{~N}$ & $\mathrm{~N}$ \\
\hline 29 & $\mathrm{~N}$ & 17 & 2,9 & 18,1 & 6,3 & $\mathrm{~N}$ & $S$ & $\mathrm{~N}$ & $\mathrm{~S}$ \\
\hline 30 & $\mathrm{~N}$ & 3 & 0,6 & 2,8 & 5,0 & $\mathrm{~N}$ & $\mathrm{~N}$ & $\mathrm{~N}$ & $\mathrm{~N}$ \\
\hline 31 & $\mathrm{~N}$ & 11 & 2,0 & 11,3 & 5,5 & $\mathrm{~N}$ & $\mathrm{~N}$ & $\mathrm{~N}$ & $\mathrm{~N}$ \\
\hline 33 & $\mathrm{~N}$ & 43 & 6,4 & 17,0 & 2,6 & $\mathrm{~S}$ & $S$ & $\mathrm{~N}$ & $\mathrm{~N}$ \\
\hline 20 & $\mathrm{~N}$ & 12 & 2,0 & 3,2 & 1,6 & $\mathrm{~N}$ & $\mathrm{~N}$ & $\mathrm{~N}$ & $\mathrm{~S}$ \\
\hline 24 & $\mathrm{~N}$ & 29 & 6,0 & 23,1 & 3,8 & $\mathrm{~S}$ & $\mathrm{~S}$ & $\mathrm{~S}$ & $\mathrm{~S}$ \\
\hline 32 & $\mathrm{~N}$ & 15 & 3,1 & 8,7 & 2,9 & $\mathrm{~N}$ & $\mathrm{~S}$ & $\mathrm{~N}$ & $\mathrm{~S}$ \\
\hline 36 & $\mathrm{~N}$ & 12 & 2,7 & 5,6 & 2,1 & $\mathrm{~N}$ & $\mathrm{~N}$ & $\mathrm{~N}$ & $\mathrm{~N}$ \\
\hline
\end{tabular}


Anexo 10

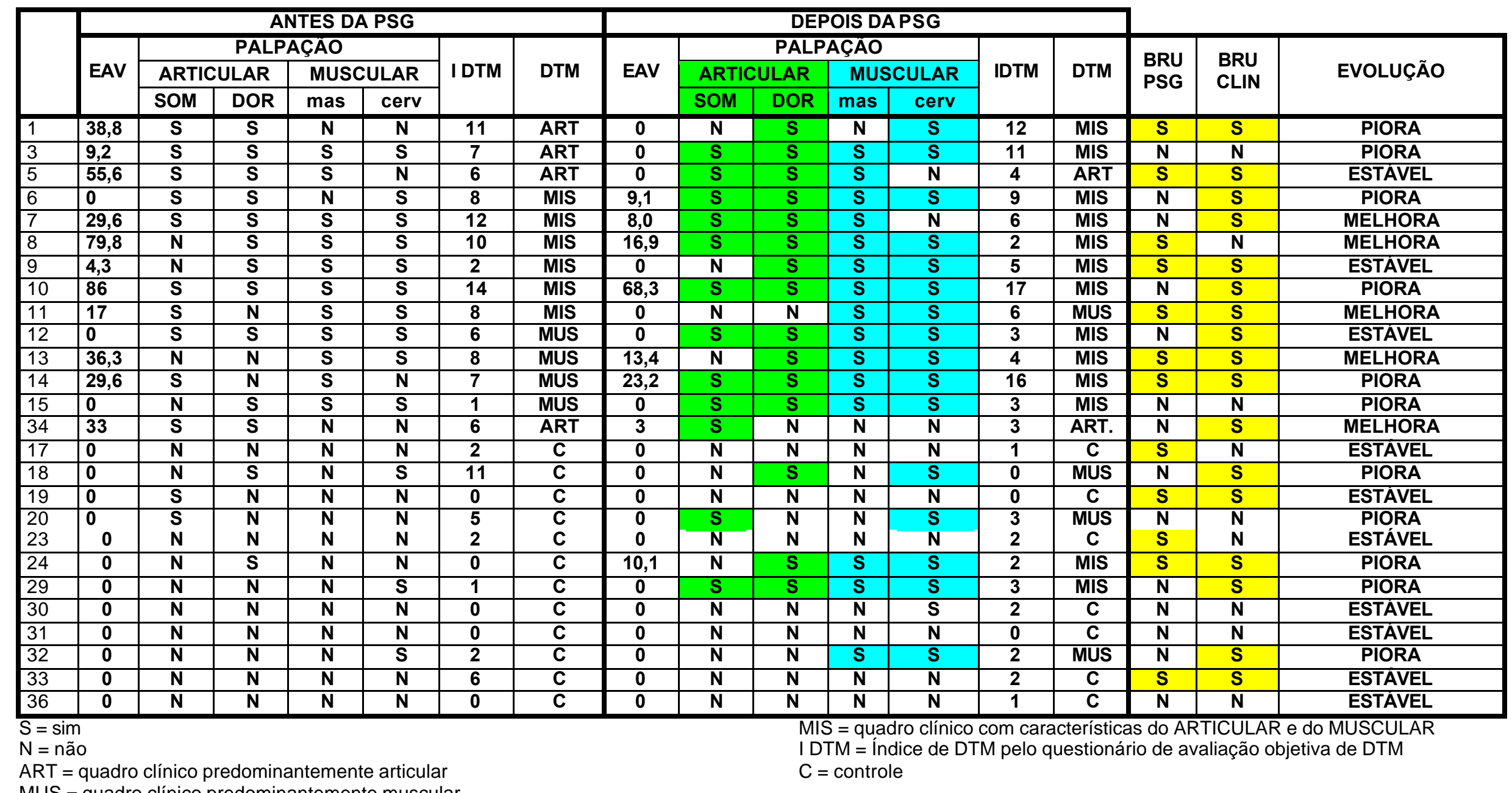

ART = quadro clínico predominantemente articular
MUS = quadro clínico predominantemente muscular

DTM = Índice de DTM pelo questionário de avaliação objetiva de DTM 


\section{Anexo 11}

\begin{tabular}{|c|c|c|c|c|c|}
\hline & ACOMPANHAMENTO ${ }^{\dagger \dagger}$ & \begin{tabular}{|c} 
Examinador \\
1
\end{tabular} & \begin{tabular}{|c} 
Examinador \\
$\mathbf{2}$
\end{tabular} & \begin{tabular}{|c} 
Examinador \\
3
\end{tabular} & $\begin{array}{c}\text { BRU. } \\
\text { CLÍNICO }\end{array}$ \\
\hline 1 & 1,5 & $\mathbf{s}$ & $\mathbf{s}$ & $\mathbf{s}$ & $\mathbf{s}$ \\
\hline 3 & - & $\mathbf{N}$ & $\mathbf{N}$ & s & $\mathbf{N}$ \\
\hline 5 & 7,0 & $\mathbf{N}$ & $\mathbf{s}$ & s & $\mathbf{s}$ \\
\hline 6 & - & s & $\mathbf{s}$ & s & $\mathbf{s}$ \\
\hline 7 & 5,0 & s & $\mathbf{s}$ & s & $\mathbf{s}$ \\
\hline 8 & - & $\mathbf{N}$ & $\mathbf{N}$ & s & $\mathbf{N}$ \\
\hline 9 & - & s & $\mathbf{s}$ & s & $\mathbf{s}$ \\
\hline 10 & 1,8 & $\mathbf{N}$ & $\mathbf{s}$ & $\mathbf{s}$ & $\mathbf{s}$ \\
\hline 11 & 2,7 & $\mathbf{s}$ & $\mathbf{s}$ & $\mathbf{s}$ & $\mathbf{s}$ \\
\hline 12 & 2,0 & $\mathbf{s}$ & $\mathbf{N}$ & $\mathbf{s}$ & $\mathbf{s}$ \\
\hline 13 & - & $\mathbf{s}$ & $\mathbf{s}$ & $\mathbf{s}$ & $\mathbf{s}$ \\
\hline 14 & 6,7 & $\mathbf{s}$ & $\mathbf{s}$ & s & $\mathbf{s}$ \\
\hline 15 & 0,0 & $\mathbf{N}$ & $\mathbf{N}$ & $\mathbf{N}$ & $\mathbf{N}$ \\
\hline 17 & 0,0 & $\mathbf{N}$ & $\mathbf{N}$ & $\mathbf{N}$ & $\mathbf{N}$ \\
\hline 18 & - & $S$ & s & s & s \\
\hline 19 & - & s & s & $s$ & s \\
\hline 20 & - & $s$ & $\mathbf{N}$ & $\mathbf{N}$ & $\mathbf{N}$ \\
\hline 23 & - & $\mathbf{N}$ & $\mathbf{N}$ & $\mathbf{N}$ & $\mathbf{N}$ \\
\hline 24 & - & s & S & 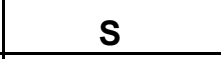 & s \\
\hline 29 & - & $s$ & $\mathbf{N}$ & $s$ & $s$ \\
\hline 30 & - & $\mathbf{N}$ & $\mathbf{N}$ & $\mathbf{N}$ & $\mathbf{N}$ \\
\hline 31 & - & $\mathbf{s}$ & $\mathbf{N}$ & $\mathbf{N}$ & $\mathbf{N}$ \\
\hline 32 & - & $s$ & $s$ & $\mathbf{N}$ & s \\
\hline 33 & - & $S$ & $\mathbf{N}$ & $\mathrm{s}$ & $\mathrm{s}$ \\
\hline 34 & - & $s$ & s & $\mathbf{s}$ & $s$ \\
\hline 36 & - & $\mathbf{N}$ & $\mathbf{N}$ & $\mathbf{N}$ & $\mathbf{N}$ \\
\hline
\end{tabular}

${ }^{\dagger \dagger}$ Acompanhamentos de bruxismo devolvidos, apresenta a freqüência de noites por semana em que o paciente e/ou companheiro de quarto percebeu a ocorrência de apertar ou ranger de dentes durante o sono. 
REFERÊNCIAS BIBLIOGRÁFICAS 


\section{REFERÊNCIAS BIBLIOGRÁFICAS \#}

1. AMERICAN ACADEMY OF OROFACIAL PAIN. Orofacial pain:. Guidelines for assessment, classification, and management. Chicago, IL, Quintessence, 1998.

2. AMERICAN ASSOCIATION OF SLEEP DISORDERS. Arousals scoring rules and examples: a preliminary report from sleep disorders atlas task force of American sleep disorders association. Sleep, v.15, n.2, p.173-84, Apr. 1992.

3. ARIMA, T.; ARENDT-NIELSEN, L.; SVENSSON, P. Effect of jaw muscle pain and soreness evoked by capsaicin before sleep on orofacial motor activity during sleep. J. orofac. Pain, v.15, n.3, p.245-56, Summer 2001.

4. ARIMA, T.; SVENSSON, P.; ARENDT-NIELSEN, L. Experimental guinding in healthy subjects: a model for post-exercise jaw muscle soreness. J. orofac. Pain, v.13, n.2, p.104-14, Spring 1999.

¥¥ Normas recomendadas para uso no âmbito da Universidade de São Paulo, com base no documento "Referências Bibliográficas: exemplos", emanado do Conselho Supervisor do Sistema Integrado de Bibliotecas da USP, em reunião de 20 de setembro de 1990. 
5. ARIMA, T.; SVENSSON, P.; ARENDT-NIELSEN, L. Capsaicin-induced muscle hyperalgesia in the exercised and non-exercised human masseter muscle. J. orofac. Pain, v.14, n.3, p.213-23, Summer 2000.

6. BADER, G.G. et al. Descriptive physiological data on a sleep bruxism population. Sleep, v.20, n.11, p.982-990, Nov. 1997.

7. BRUNETTE, D.M. Reliability, sensitivity, and specificity of dianostic tests and measurements. In: _ Critical thinking. Carol Stream, IL, Quintessence, 1996. Cap.10, p.99-112.

8. CHRISTENSEN, L.V. Influence of muscle pain tolerance on muscle pain threshold in experimental tooth clenching in man. J. oral Rehab., v.6, n.3, p.211-7, July 1979.

9. CHRISTENSEN, L.V. Jaw muscle fatigue and pains induced by experimental tooth clenching: a review. J. oral Rehab., v.8, n.1, p.27-36, Jan. 1981.

10. CHRISTENSEN, L.V.; MOHAMED, S.E.; HARRISON, J.D. Delayed onset of masseter muscle pain in experimental tooth clenching. J. prosth. Dent., v.48, n.5, p.579-84, Nov. 1982.

11. CHUNG, J.W.; KIM, C.; MCCALL, W.D. Effect of sustained contraction on motor unit action potentials and EMG power spectrum of human masticatory muscles. J. dent. Res., v.81, n.9, p.646-9, Sept. 2002. 
12. CLARK, G.T.; ADLER, R.C.; LEE, J.J. Jaw pain and tenderness levels during and after repeated sustained maximum voluntary protrusion. Pain, v.45, n.1, p.17-22, Apr. 1991.

13. CLARK, G.T.; BEEMSTERBOER, P.L.; RUGH, J.D. Nocturnal masseter muscle activity and the symptoms of masticatory dysfunction. J. oral Rehab., v.8, n.3, p.279-86, May 1981.

14. CLARK, T.T.; LYNN, P. Horizontal plane jaw movements in controls and clinic patients with temporomandibular dysfunction. J. prosth. Dent., v.55, n.6, p.730-5, June 1986.

15. CONTI, A.C.C.F. Avaliação transversal da relação entre sinais e sintomas das disfunções temporomandibulares e o tratamento ortodôntico. Bauru, 2000. 130p. Dissertação (Mestrado) - Faculdade de Odontologia de Bauru , Universidade de São Paulo.

16. COSTEN, J.B. Syndrome of ear and sinus symptoms dependent upon disturbed function of temporomandibular joint. Ann. Otol. (St. Louis), v.43, n.1, Mar. 1934.

17. DAL FABRO, C. Estudo linear de um paciente com bruxismo através da análise eletromiográfica do músculo masseter, avaliação polissonográfica e psicológica. Bauru, 1997. 184p. Dissertação (Mestrado) - Faculdade de Odontologia de Bauru, Universidade de São Paulo. 
18. DAO, T.T.T.; LUND, J.P.; LAVIGNE, G.J. Comparison of pain and quality of life in bruxers and patients with miofascial pain of the masticatory muscles. J. orofac. Pain, v.8, n.4, p.350-6, Fall 1994.

19. DAO, T.T.T.; LUND, J.P.; LAVIGNE, G.J. Pain responses of experimental chewing in myofascial pain patients. J. dent. Res., v.73, n.6, p.1163-7, June 1994.

20. DE LEEUW, J.R.J.; STEENKS, M.H.; ROS, W.J.G. Psychosocial aspects of craniomandibular dysfunction: an assessment of clinical and community findings. J. oral. Rehab., v.21, n.2, p.127-43, Mar. 1994.

21. DELCANHO, R.R.; RIM, Y.J.; CLARK, G.T. Haemodynamic changes induced by submaximal isometric contraction in painful and non-painful human masseter using near-infra-red spectroscopy. Arch. oral Biol., v.41, n.6, p.585-96, June 1996.

22. DROUKAS, B.; LINDEE, C.; CARLSSON, G. Occlusion and mandibular dysfunction: a clinical study of patients referred for functional distrubances of masticatory system. J. prosth. Dent., v.53, n.3, p.402-6, Mar. 1985.

23. DWORKIN, S.F. et al. Epidemiology of signs and symptoms in temporomandibular disorders: clinical signs in cases and controls. J. Amer. dent. Ass., v.120, p.273-81, Mar. 1990. 
24. FRICTON, J.R.; KIN, Y.J.; CLARK, G.L. Predictors of outcome for treatment of temporomandibular disorders. J. orofac. Pain, v.10, n.1, p.54-65, Winter 1996.

25. GLAROS, A. Incidence of diurnal and nocturnal bruxism. J. prosth. Dent., v.45, n.5, p.545-9, May 1981.

26. GLAROS, A.G.; GLASS, E.G. Electromyographic data from TMD patients with myofascial pain and from matched control subjects: evidence for statistical, not clinical, significance. J. orofac. Pain, v.11, n.2, p.125-9, Spring 1997.

27. GLAROS, A.G.; TABACCHI, K.N.; GLASS, E.G. Effect of parafuncional clenching on TMD pain. J. orofac. Pain, v.12, n.2, p.145-52, Spring 1998.

28. GOULET, J.P.; LAVIGNE, G.J.; LUND, J.P. Jaw pain prevalence among Frenchspeaking Canadians in Quebec and related symptoms of temporomandibular disorders. J. dent. Res., v.74, n.11, p.1738-44, Nov. 1995.

29. GOULET, J.P. et al. Daily clenching nocturnal bruxism, and stress and their association with TMD symptoms. J. orofac. Pain, v.7, p.120, Feb. 1993. /8989 /

30. GRAVEN-NIELSEN, T. et al. Inhibitory of maximal voluntary contraction force by experimental muscle pain: a centrally mediated mechanism. Muscle Nerve, v.25, n.4, p.576-84, Apr. 2002. 
31. GREENE, C.S. The etiology of temporomandibular disorders: implication for treatment. J. orofac. Pain, v.15, n.2, p.93-105, Spring 2001.

32. GREENE, C.S.; MARBACH, J.J. Epidemiological studies of mandibular dysfunction: a critical review. J. prosth. Dent., v.48, n.2, p.184-90, Aug. 1982.

33. HARTMAN, E. Bruxism. In: KRYGER, M.H.;T., T.;DEMENT, W.C. Principles and practice of sleep medicine. 2.ed. Philadelphia, WB Sanders, 1994. Cap.59, p.598-601.

34. HIGH, A.S.; MACGREGOR, A.J.; TOMLINSON, G.E. A gnathodynamometer as an objective means of pain assessment following wisdom tooth removal. J. oral Maxillofac. Surg., v.26, n.4, p.284-91, 1988.

35. IKEDA, T. et al. Criteria for the detection of sleep-associated bruxism in humans. J. orofac. Pain, v.10, n.3, p.270-82, Summer 1996.

36. JUNGE, D.; CLARK, G.T. Electromyographic turns analysis of sustained contraction in human masseter muscles at various isometric force levels. Arch. oral Biol., v.38, n.7, p.583-8, July 1993.

37. KATO, T. et al. Sleep bruxism: an oromotor activity secondary to microarousal. J. dent. Res., v.80, n.10, p.1940-4, Oct. 2001. 
38. KATO, T. et al. Bruxism and orofacial movements during sleep. Dent. Clin. N. Amer., v.45, n.4, p.657-85, Oct. 2001.

39. LASKIN, D.M. Etiology of the pain-dysfunction syndrome. J. Amer. dent. Ass., v.79, n.7, p.147-53, July 1969.

40. LAVIGNE, G.J.; MONTPLAISIR, J.Y. Restless legs syndrome and sleep bruxism: prevalence and association among Canadians. Sleep, v.17, n.8, p.739-43, Dec. 1994.

41. LAVIGNE, G.J. et al. Motor activity in sleep bruxism with concomitant jaw muscle pain: a retrospective study. Eur. J. oral Sci., v.105, n.1, p.92-5, Feb. 1997.

42. LAVIGNE, G.J.; ROMPRÉ, P.H.; MONTPLAISIR, J.Y. Sleep bruxism: validity of clinical research diagnostic criteria in a controlled polysomnographic study. J. dent. Res., v.75, n.1, p.546-52, Jan. 1996.

43. LAVIGNE, G.J. et al. Rhythmic masticatory muscle activity during sleep in humans. J. dent. Res., v.80, n.2, p.443-8, Feb. 2001.

44. LIPINSKI, D.; NELSON, R.O. The reactivity and unreliability of self recordings. J. cons. clin. Physiol, v.42, n.1, p.118-23, Feb. 1974. 
45. LOBBEZOO, F.; LAVIGNE, G.J. Do bruxism and temporomandibular disorders have a cause-and-effect relationship? J. orofac. Pain., v.11, n.1, p.15-23, Winter 1997.

46. LOBBEZOO-SCHOLTE, A.M. et al. Diagnostic subgroups of craniomandibular disorders Part I: self-report data and clinical findings. J. orofac. Pain, v.9, n.1, p.24-36, Jan. 1995.

47. LOCKER, D.; SLADE, G. Prevalence of symptoms associated with temporomandibular disorders in a Canadian population. Community dent. oral Epidem., v.16, n.5, p.310-3, May 1988.

48. LUND, J.P. et al. The pain-adaptation model: a discussion of the relationship between chronic musculoskeletal pain and motor activity. Canad. J. Physiol. Pharmacol., v.69, n.5, p.683-94, May 1991.

49. MACALUSO, G.M. et al. Sleep bruxism is a disorder related to periodic arousals during sleep. J. dent. Res., v.77, n.4, p.565-73, Apr. 1998.

50. MARCEL, T. et al. Magnetic resonance spectroscopy of the human masseter muscle in nonbruxing and bruxing subjects. J. orofac. Pain, v.9, n.2, p.116-30, 1995.

51. MATRE, D.A. et al. Experimental muscle pain increases the human stretch reflex. Pain, v.75, n.2-3, p.331-9, Apr. 1998. 
52. MENSE, S. Considerations concerning the neurobiological basis of muscle pain. Canad. J. Physiol. Pharmacol., v.69, n.5, p.610-6, May 1991.

53. MENSE, S.; SIMONS, D.G. Muscle pain:. understanding its nature diagnosis, and treatment Baltimore, Lippincott Williams \& Wilkins, 2001.

54. MIGRAINE, D. et al. Bruxism and onychophagy in children: prevalence and relative risk factors J. dent. Res., v.75, p.219, 1996. /Abstract 1610 /

55. MINAGI, S. et al. Relationship between mandibular position and the coordination of masseter muscle activity during sleep in humans. J. oral Reab., v.25, n.12, p.902-7, Dec. 1998.

56. MINAGI, S. et al. Effect of balancing-side occlusion on the ipsilateral TMJ dynamics under clenching. J. oral. Rehab., v.24, n.1, p.57-62, Jan. 1997.

57. MOLINA, O.F. et al. Oral Jaw behaviors in TMD and bruxism: a comparison study by severity of bruxism. Cranio, v.19, n.2, p.114-22, Abr. 2001.

58. MOLINA, O.F. et al. A clinical study of specific signs and symptoms of CMD in bruxers classified by the degree of severity. Cranio, v.17, n.4, p.268-79, Oct. 1999.

59. NISHIGAWA, K.; BANDO, E.; NAKANO, M. Quantitative study of bite force during sleep associated bruxism. J. oral Rehab., v.28, n.5, p.485-91, May 2001. 
60. OKESON, J.P. Nocturnal bruxing events in healthy geriatric subjects. J. oral Rehab., v.17, n.5, p.411-8, Sept. 1990.

61. PICCIONE, A. et al. Nocturnal biofeedback for nocturnal bruxism. Biofeedback self regul., v.7, n.4, p.405-19, Dec. 1982.

62. PIERCE, C.J.; GALE, E.N. Methodological considerations concerning the use of bruxcore plates to evaluate nocturnal bruxism. J. dent. Res., v.68, n.6, p.1110-4, June 1989.

63. PINHO, J.C. et al. Electromyographic activity in patients with temporomandibular disorders. J. oral Rehab., v.27, n.11, p.985-90, Nov. 2000.

64. PULLINGER, A.G.; SELIGMAN, D.A.; DORNBEIN, J.A. A multiple logistic regression analysis of the risk and relative odds of temporomandibular disorders as a function of common oclusal features. J. dent. Res., v.72, n.6, p.968-79, June 1993.

65. RECHTSCHAFFEN, A.; KALES, A. A manual of standardized terminology? techniques and scoring system for sleep stages of human subjects. Los Angeles, UCLA, Brain Information Service/Brain Research Institute, 1968.

66. REIMÃO, R. Parassônias: epidemiologia, diagnóstico, terapêutica. In: Sono:. 2.ed. São Paulo, Atheneu, 1996. Cap.34, p.347-60. 
67. RO, J.Y.; SVENSSON, P.; CAPRA, N. Effects of experimental muscle pain on electromyographic activity of masticatory muscles in the rat. Muscle Nerve, v.25, n.4, p.576-84, Apr. 2002.

68. RUGH, J.D.; HARLAN, J. Nocturnal bruxism and temporomandibular disorders. Advanc. Neurol., v.49, p.329-41, 1988.

69. RUGH, J.D.; SOLBERG, W.K. Electromyographic studies of bruxist behavior before and after treatment. J. Calif. dent. Ass., v.3, p.56-9, 1975.

70. SCHWARTZ, L. Disorders of the temporomandibular joint. Philadelphia,, WB Saunders, 1959.

71. SELIGMAN, D.A.; PULLINGER, A.G. The degree of dental attrition in modern society is a function of age and of canine contact. J. orofac. Pain, v.9, n.3, p.266-75, Summer 1995.

72. SHEIKHOLESLAM, A.; MÖLLER, E.; LOUS, I. Postural and maximal activity in elevators of mandible before and after treatment of functional disorders. Scand. J. dent. Res., v.90, n.1, Feb. 1982.

73. SHERMAN, R.A. Relationship between jaw pain and jaw muscle contraction level: underlying factors and treatment effectiveness. J. prosth. Dent., v.54, n.1, p.114-8, July 1985.

74. SPILKER, B. Guide to clinical trials. Nes York, Raven Press, 1991. 
75. STOCK, P.; CLARKE, N.G. Monitoring bruxism. Med. Biol. Eng. Comput., v.21, n.3, p.295-300, May 1983.

76. STOHLER, C.S.; ASHTON-MILLER, J.A.; CARLSON, D.S. The effects of pain from the mandibular joint and muscles on masticatory motor behavior in man. Arch. oral Biol., v.33, n.3, p.175-82, 1988.

77. STOHLER, C.S.; ZANG, X.; LUND, J.P. The effect of experimental jaw muscle pain on postural muscle activity. Pain, v.66, n.2-3, p.215-21, Aug. 1996.

78. SVENSSON, P.; ARENDT-NIELSEN, L. Effects of 5 days of repeated submaximal clenching on masticatory muscle pain and tenderness: an experimental study. J. orofac. Pain, v.10, n.4, p.330-8, Winter 1996.

79. SVENSSON, P.; ARENDT-NIELSEN, L.; HOUE, L. Sensory-motor interactions of human experimental unilateral jaw muscle pain: a quantitative analysis. Pain, v.64, n.2, p.241-9, Feb. 1996.

80. SVENSSON, P.; ARENDT-NIELSEN, L.; HOUE, L. Muscle pain modulates mastication: an experimental study in humans. J. orofac. Pain., v.12, n.4, p.343-53, July 1998.

81. SVENSSON, P.; GRAVEN-NIELSEN, T. Craniofacial muscle pain: review of mechanism and clinical manifestations. J. orofac. Pain., v.15, n.2, p.11745, Spring 2001. 
82. THORPY, M.J. International classification of sleep disorders:. diagnostic and coding manual Rochester, MN, Allen Press, 1997.

83. TRAVELL, J.; RINZLER, S.; HERMAN, M. Pain and disability of the shoulder and arm: treatment by intramuscular infiltration with procaine hydrochloride. J. Amer. dent. Ass., v.120, p.417-22, 1942.

84. VELLY-MIGUEL, A.M. et al. Bruxism and other orofacial movements during sleep. J. craniomandibular dis. fac. oral pain, v.6, n.1, p.71-81, Winter 1992.

85. WAGNER, M.T. Controlling nocturnal bruxism through the use of aversive conditioning during sleep. Amer. J. clin. biofeed., v.4, p.87-92, 1981.

86. WARE, J.C.; RUGH, J.D. Destructive bruxism: sleep stage relationship. Sleep, v.11, n.2, p.172-81, Apr. 1988

87. WILDMALM, S.E.; CHRISTIANSEN, R.L.; GUNN, S.M. Oral parafunctions as temporomandibular disorder risk factors in children. J. craniomandibular pract., v.13, n.4, p.242-6, Oct. 1995.

88. YAMAGUCHI, T. et al. Electromyographic activity of the jaw-closing muscle $\mathrm{s}$ during jaw opening in patients with masseter muscle contracture. J. craniomandibular pract., v.20, n.1, p.48-54, Jan. 2002. 
89. YEMM, R. A neurophysiological approach to the pathology and etiology of temporomandibular dysfunction. J. oral. Rehab., v.12, n.4, p.343-53, July 1985. 
ABSTRACT 


\section{ABSTRACT}

Fourteen patients with Temporomandibular Disorders (TMD) and 12 non symptomatic control subjects (sex and age matched) were evaluated for the presence of sleep bruxism (SB) by means of clinical diagnosis (performed by three examiners) and polysomnographic (PSG) recording. Clinical evaluation of TMD was carried out by clinical examination, which consisted of pain measurement by visual analog scale (VAS), TMJ and muscle palpation before and in the morning following PSG exam, in order to verify a possible association between SB and signs and symptoms of TMD. The reliability of clinical exam when compared to PSG findings was also performed. No association between SB and TMD, nor between SB and TMD or muscle tenderness to palpation were found. Clinical examination has shown $75 \%$ and $57 \%$ of specificity. Regardless of bruxism activity's presence in the previous night, all TMD patients had pain to palpation in the following morning to PSG. Bruxers diagnosed by PSG, and presenting with tenderness to palpation had more activity than those without pain. It can be concluded that the fact of some individuals with SB did not have present any pain nor discomfort and others with signs and symptoms of TMD did not have present SB strengthens the lack of association between two entities. The founds denote that not always a positive association between SB and TMD is present and the existence of two groups of bruxers, with and without pain. 